\title{
UM MODELO NÃO-LINEAR APLICADO AO ESTUDO DAS INTERACÕES DE GENÓTIPOS COM AMBIENTES
}

\author{
LÁZARO JOSÉ CHAVES
}

Orientador: ROLAND VENCOVSKY

Dissertação apresentada d Escola Superior de Agricultura "Luiz ide Queiroz", da Universidade de São Paulo, para obtenção do título de Mestre em Genética e Melhoramento de Plantas.

P I R A C I CA B A

Estado de São Paulo - Brasil

Fevereiro, 1.982 
ii.

Aos meus pais, José Augusto e Geracina,

OFERE $C_{\zeta} O$

A minha esposa Marilene e nossos filhos

Gustavo e Larissa, 


\section{AGRADECIMENTOS}

Ao Prof. Roland Vencovsky, pela orientação, es

tímulo e amizade;

aos professores e funcionārios do Departamento e Instituto de Genētica da ESALQ, pelos ensinamentos e colabo raçao;

ao Batista, Hélio, Fernando, Suely, Maurício, Mauro e demais colegas da Pós-Graduação, pelo companheirismo de todos os momentos;

aos Professores Humberto de Campos, José Branco de Miranda Filho e lsaías 0. Geraldi, pelas inúmeras suge tões;

à Senhorita Marilúcia Pessoa, pelos serviços da

t i lográficos;

ao Centro Nacional de Pesquisa de Arroz e Fe jão da EMBRAPA pela cessão dos dados de feijão;

ao Departamento de Genētica da ESALQ, pelas fä cilidades concedidas;

à Escola de Agronomia da Universidade Federal

de Goì̃s e;

a todos que de qualquer forma contribuiram para a realização deste trabalho;

os meus sinceros agradecimentos. 
LAZARo jose chaves, filho de José Augusto Chạ ves Filho e de Geracina Augusta Chaves, nasceu em Bambuí, esta do de Minas Gerais, no dia 12 de junho de 1952. Concluiu o cur so de Técnico Agrícola, em junho de 1971, pelo Colēgio Agríco la de Bambuí-MG. Em agosto de 1972 iniciou o curso de Agrono mia pela Universidade Federal de Goiàs, tendo sido diplomado em dezembro de 1976. Em março de 1977, ingressou como Auxiliar de Ensino na Escola de Agronomia e Veterināria da UFG, exercen do atualmente a função de Professor Assistente. Iniciou o cur so de Mestrado em Genētica e Melhoramento de Plantas, na ESALQ, em Piracicaba, em março de 1978. 
INDICE

Pāgina

LISTA DE TABELAS $\ldots \ldots \ldots \ldots \ldots \ldots \ldots \ldots \ldots \ldots \ldots \ldots \ldots \ldots \ldots \ldots \ldots$

RESUMO $\ldots \ldots \ldots \ldots \ldots \ldots \ldots \ldots \ldots \ldots \ldots \ldots \ldots \ldots \ldots \ldots \ldots \ldots \ldots \ldots \ldots$

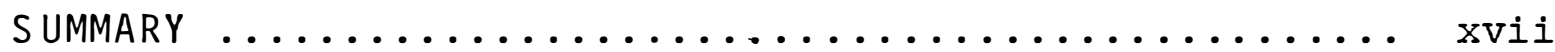

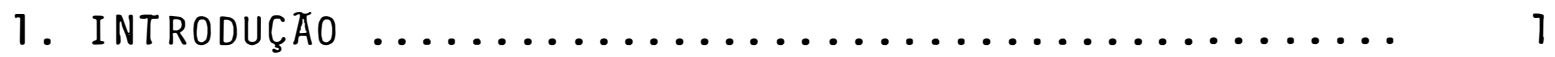

2. REVISAO DE Literatura $\ldots \ldots \ldots \ldots \ldots \ldots \ldots \ldots \ldots \ldots \ldots \ldots \ldots \ldots$

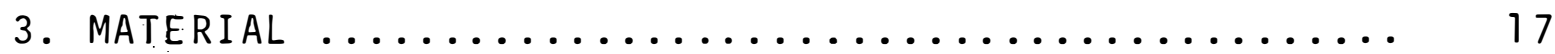

3.1. Soja $[$ Glycine $\max$ (L.) Merril] ........... 17

3.2. Trigo (Triticum aestivum L.) ............. 18

3.3. Mandioca (Manihot esculenta Cranz) .......... 18

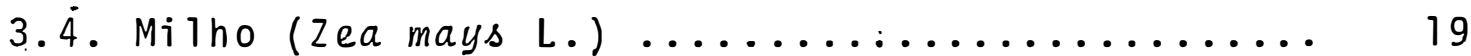

3.5. Feijão (Phaseolus vulgaris L.) ............. 20

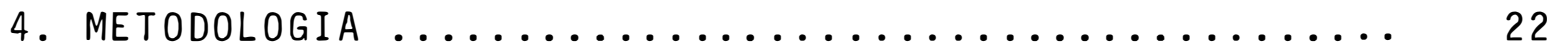

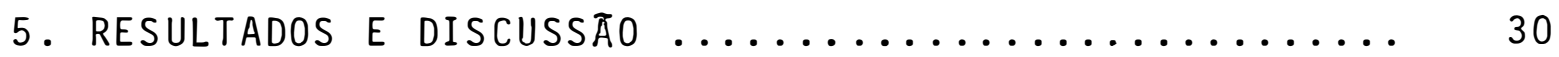

5.1 . Considerações teóricas................. 30

5.1.1. Efeito da mudança de ambientes sobre ca racteres compostos .............. 30

5.1.2. Variāncias e covariāncias de tratamentos

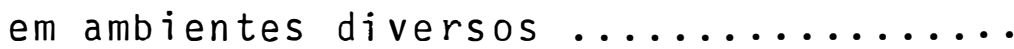

5.1.3. Modelo não-linear e parāmetros de estabi

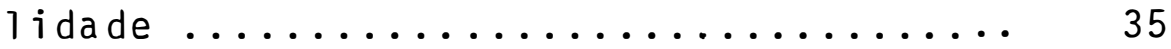

5.1.4. Detalhamento dos efeitos de locais eanos

5.1.5. Relação com modelos que envolvem trans

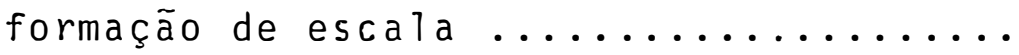


Pāgina

5.1.6. Ajuste de médias de ensaios com tratamen tos comuns ....................... 41

5.2. Anātises de dados experimentais ............ 43

$5.2 .1 . \operatorname{Soja} \ldots \ldots \ldots \ldots \ldots \ldots \ldots \ldots \ldots \ldots . \ldots \ldots$

5.2 .2 . Trigo $\ldots \ldots \ldots \ldots \ldots \ldots \ldots \ldots \ldots \ldots \ldots . \ldots \ldots$

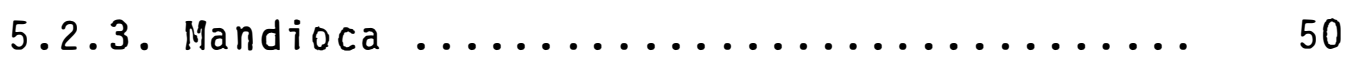

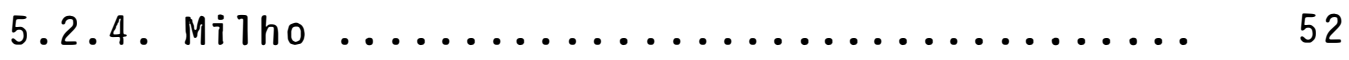

5.2 .5$. Feijão $\ldots \ldots \ldots \ldots \ldots \ldots \ldots \ldots \ldots \ldots \ldots$

5.2.6. Anāitises com pares de 1ocais .........: 62

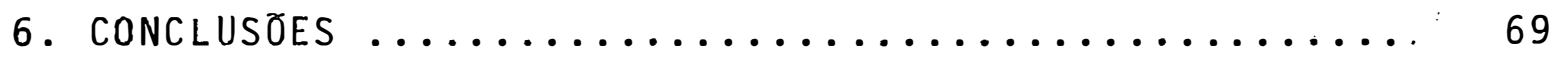

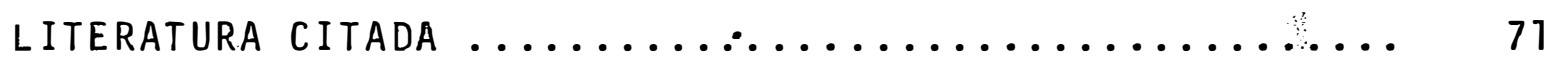

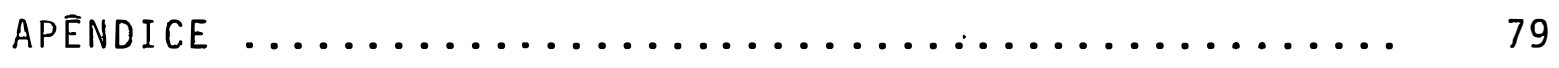


vii.

\section{LISTTA DE TABELAS}

Tabela n?

Pāgina

01

Representação dos fatores $\alpha_{i}\left(1+\beta_{j}\right)$ de $N \cdot t r a t a \underline{~}$ mentos repetidos em $M$ ambientes, segundo o mo delo de VENCOVSKY e GERALDI (1977), com efeito fixo dos ambientes e auséncia de desvios

02 Anālise da variância, baseada no modelo line ar (modelo a): para $N$ tratamentos ensaiados em

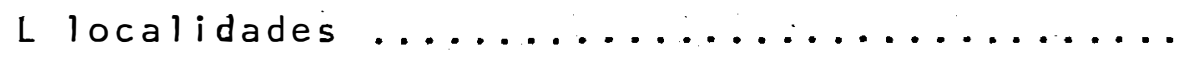

03 Valores simulados dos caracteres $X, Y, Z$ e W, para 5 genōtipos em 2 ambientes $\ldots \ldots \ldots \ldots$

04 Valores das somas de quadrados da interação do modelo linear (modelo a) e dos desvios do mo delo não-linear. (modelo b), para os dados de

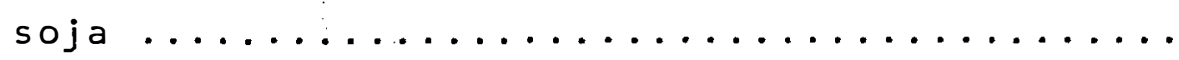

05 Valores do coeficiente de alienação $\left(1-R^{2}\right)$ dos modelos jinear (modelo a), não-linear (mo delo b) e intrinsecamente linear com transfor mação logarítmica (modelo c), para os dados de

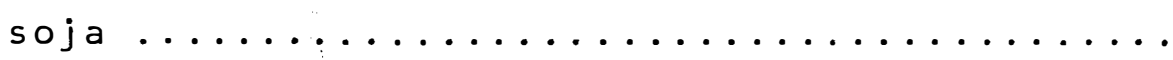


06 Valores das somas de quadrados dà interação do modelo linear (modelo a) e dos desvios do modelo não-linear (modelob), para os dados de $\operatorname{trigo} \ldots \ldots \ldots \ldots \ldots \ldots \ldots \ldots \ldots \ldots \ldots \ldots \ldots \ldots \ldots \ldots \ldots \ldots \ldots \ldots$

07 Valores do coeficiente de alienação $\left(1-R^{2}\right)$ dos modelos linear (modelo a), não-linear (mo delo b) e intrinsecamente linear com transfor mação logarítmica (modeloc), para os dados de trigo

08 Valores das somas de quadrados da interação do modelo linear (modelo a) e dos desvios do mo delo não-linear (modelo b), para os dados de

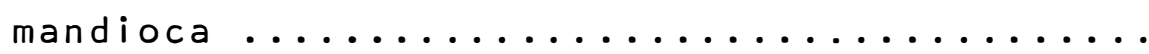

09 Valores do coeficiente de alienação $\left(1-R^{2}\right)$ dos modelos linear (modelo a), não-linear. (mo delo b) e intrinsecamente linear com transfor mação logarítmica (modeloc), para os dados

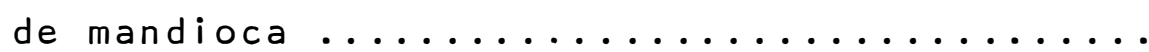

10 Valores das somas de quadrados dá interação do modelo linear (modelo a) e dos desvios do modelo não-linear (modelo b), para os dados 


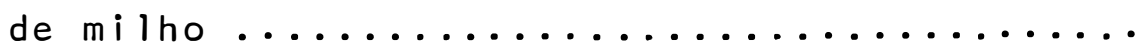

Valores do coeficiente de alienação dos modelos linear (modelo a), não-linear (mo delo b) e intrinsecamente linear com transfor mação logarítmica (modelo c), para os dados

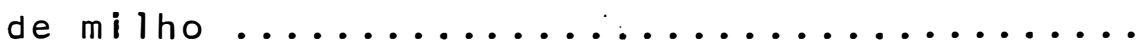

12 Valores oas somas de quadrados da interação do modelo linear (modelo a) e dos desvios do modelo não-linear (modelo b), para os dados

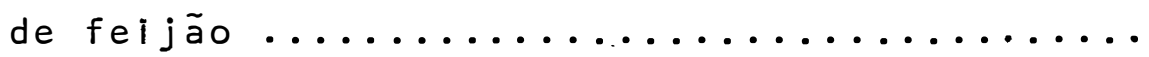

13 Valores do coefıciente de alienação dos modelos linear (modelo a), não-linear (mo delo b) e intrinsecamente linear com transfor mação logarítmica (modelo c), para os dados de feijão

14 Valores médios do coeficiente de correlação entre médias de tratamentos $\left(\bar{r}_{j j^{\prime}}\right)$, soma de quadrados dos desvios do modelo não-linear $\left(\overline{S Q}_{d}\right)$, soma de quadradós da interação de genó tipos com locais do modelo linear $\left(S_{T L}\right)$ e com ponente B, para os dados de feijão 
15 Valores mēdios do coeficiente de correlação entre médias de tratamentos $\left(\bar{r}_{j j^{\prime}}\right)$, soma de quadrados dos desvios do modelo não-linear $\left(\overline{S Q}_{d}\right)$, soma de quadrados da interação de genō tipos com locais do modelo linear $\left(\overline{S Q}_{T L}\right)$ e com ponente $B$, para os dados de milho ..........

16 Valores do coeficiente de correlação de Spear man $\left(r_{s}\right)$, entre as estimativas da soma de qua drados dos desvios do modelo não-linear, soma de quadrados da interação de genótipos com am bientes do modelo linear e componente B, para

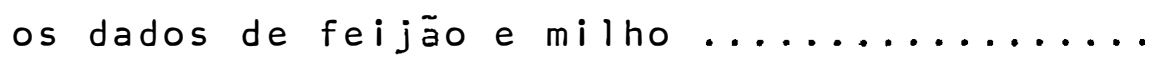

\section{TABELAS DE APENDICE}

A.l Produções médias de grãos ( $\mathrm{kg} / \mathrm{ha})$, coeficien tes de variação, e estimativas de $\alpha_{i}$ e $\left(1+\beta_{j}\right)$ de dez cultivares de soja, em onze localida. des do estado do Rio Grande do Sul, no ano

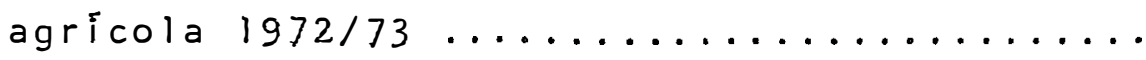

A.2 Produções médias de grãos ( $\mathrm{kg} / \mathrm{ha})$, coeficien tes de variação, e estimativas de $\alpha_{i}$ e $\left(1+\beta_{j}\right)$ de dez cultivares de soja, em onze localida 
des do estado do Rio Grande do Sul, no ano

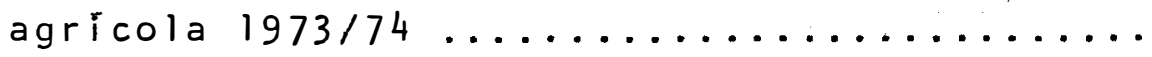

A.3 Produções mëdias de grãos ( $\mathrm{kg} / \mathrm{ha}$ ), coeficientes de variaçăo, e estimativas de $\alpha_{i}$ e $\left(1+\beta_{j}\right)$ de dez cultivares de soja, em onze localidades do estado do Rio Grande do Sul, no ano agríco

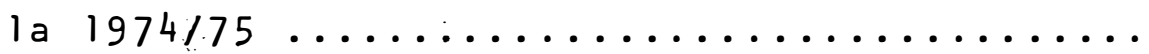

A. 4 Produções mēdias de gräos (kg/ha) e estimatí vas de $\alpha_{i}$ e $\left(1+\beta_{j}\right)$ do Ensaio Regional Pauli $\underline{s}$ ta de Variedades de Trigo, no ano de 1969....

A. 5 Produções mëdias de Grãos (kg/ha) e estimat vas de $\alpha_{i}$ e $\left(1+\beta_{j}\right)$ do Ensaio Regional Paulis ta de Variedades de Trigo, no ano de 1970...

A.6 Produções médias de grãos (kg/ha) e estịmati vas de $\alpha_{i}$ e $\left(1+\beta_{j}\right)$ do Ensaio Regional Paulis ta de variedades de trigo no ano de $1971 \ldots$.

A.7 Produção média de rama ( $t / h a)$ e estimativas de $\alpha_{i}$ e $\left(1+\beta_{j}\right)$ de ensaios de produção de cul tivares de mandioca em três locais e três anos 
A. 8 Produção média de raízes (t/ha) e estimativas de $\alpha$. e $\left(1+\beta_{j}\right)$ de ensaios de produção de cul tivares de mandioca, em três locais e três

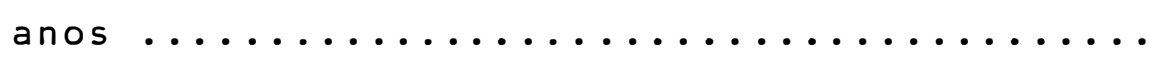

A.9 Altura média da planta (cm) e estimativas de $\alpha_{i}$ e $\left(1+\beta_{j}\right)$ do Ensaio Nacional de Milho Pre coce, no ano agrícola $1976 / 77 \ldots \ldots \ldots \ldots$

A. 10 Produção média de espigas (t/ha) e estimatí vas de $\alpha_{i} e\left(1+\beta_{j}\right)$ do Ensaio Nacional de Mi lho Planta Baixa, no ano agrícola 1977/78...

A.11 Produção média de espigas (t/ha), coeficien tes de variação, e estimativas de $\alpha_{i}$ e $\left(1+\beta_{j}\right)$ do Ensaio Nacional de Milho Opaco, no ano agrícola $1974 / 75$

A. 12 Produção média de espigas ( $t / h a)$, coeficien tes de variação, e estimativas de $\alpha_{i} e\left(1+\beta_{j}\right)$ do Ensaio Nacional de Milho Opaco, no ano agrí

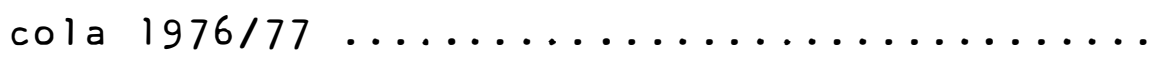

A. 13 Produção média de espigas (t/ha) coeficientes de variação, e estimativas de $\alpha_{i}$ e $\left(1+\beta_{j}\right)$ do 
Ensaio Nacional de Milho, no ano ágrícola

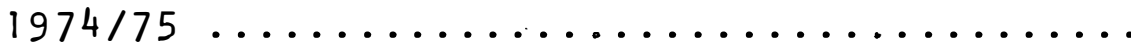

A. 14 Produção média de espigas ( $t /$ ha), coeficientes de variação, e estimativas de $\alpha_{i} e\left(I+\beta_{j}\right)$ do Ensaio Nacional de Milho, no ano agricola

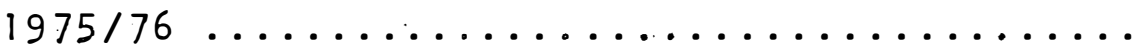

A. 15 Produçao mēdia.de espigas ( $t / h a)$, coeficientes de variação, e estimativas de $\alpha_{i} e\left(I+\beta_{j}\right)$ do Ensaio Nacional de Milho, no. ano agrícola

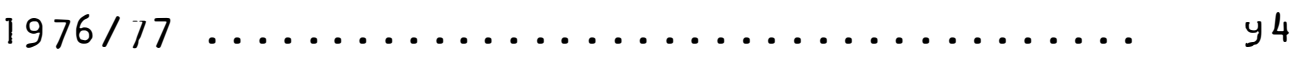

A. 16 Produção média de graos ( $t / h a)$, coeficientes de variação, e.estimativas de $\alpha_{i}$ e $\left(1+\beta_{j}\right)$ do Ensaio Nacional de Variedades de Feijão, no

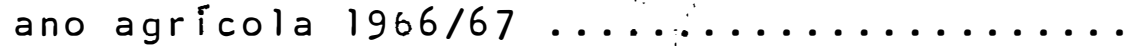

A.17, Produção media de grãos ( $\mathrm{kg} / \mathrm{ha})$, coeficientes de variação, e estimativas de $\alpha_{i}$ e $\left(1+\beta_{j}\right)$ do Ensaio Nacional de Variedades de Feijão, no

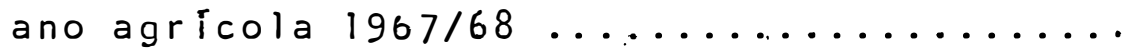

A. 8 Produção média de grãos (kg/ha), coeficientes de variação, e estimativas de $\alpha_{i}$ e $\left(1+\beta_{j}\right)$ do 
Ensaio Nacional de Variedades de Feijão, no ano Agrícola $1968 / 69 \ldots \ldots \ldots \ldots \ldots$

A.19 Produção média de grãos ( $\mathrm{kg} / \mathrm{ha}$ ), coeficientes de variação, e estimativas de $\alpha_{i} e\left(1+\beta_{j}\right)$ do Ensaio Nacional de Variedades de Feijão, no

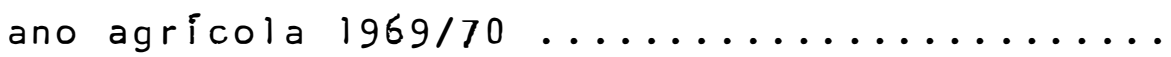

A.20 Produção média de grãos (kg/ha), coeficientes de variação, e estimativas de $\alpha_{i}$ e $\left(1+\beta_{j}\right)$ do Ensaio Nacional de variedades de Feijão, no ano agrícola, $1970 / 71 \ldots \ldots \ldots \ldots \ldots$

A.21 Produção média de grãos ( $\mathrm{kg} / \mathrm{ha}$ ), coeficientes de variaçao, e estimativas de $\alpha_{i}$ e $\left(1+\beta_{j}\right)$ do Ensaio Nacional de Variedades de Feijão, no ano agrícola $1971 / 72 \ldots \ldots \ldots \ldots \ldots \ldots \ldots$ 


\author{
Autor: Läzaro Josē Chaves \\ Orientador: Prof. Dr. Roland Vencovsky
}

R E S U M O

$\mathrm{Na}$ hipótese de que o efeito dos ambientes sobre os genōtipos na manifestação fenotípica de um carāter se dá de forma multiplicativa, um modelo não-linear que ē multiplicati vo em seus parâmetros genético e ambiental, foi estudado.

Atravēs de deduçōes matemäticas foram verifica das as possíveis. implicações da multiplicatividade dos efeitos genético e ambiental sobre alguns aspectos do melhoramento de plantas. Dados dé produtividade de ensaios de soja, trigo, man dioca, milho e feijão, foram utilizados com o fim de sé veri ficar a possível aplicabilidade do modelo multiplicativo no co nhecimento da natureza da interação de genótipos com ambientes.

Os resultados mostraram que o modelo multiplicą tivo foi similar ao modelo linear de análise, com os dados to mados em escala natural ou logarítmica, na explicação dos da dos de soja, trigo e mandioca. Para os dados de milho e feijão 
foi detectada uma certa multiplicatividade dos efeitos dos am bientes sobre os genótipos. O efeito multiplicativo dos ambien tes sobre os genótipos foi responsável por $16,9 \%$ da interação de genótipos com ambientes, na média dos ensaios de milho opạ co; por $9,8 \%$, na média dos ensaios de milho normal e por $10,1 \%$, na média dos ensaios de feijão. A transformação logarítmica não foi eficiente para remover a multiplicatividade dos efeitos dos ambientes sobre os genótipos, nestas culturas.

A possível utilização dos desvios do modelo não linear como medida da similaridade de locais para fins de zone amento ecológico, foi verificada atravēs da comparação desta estatística com a interação do modelo linear e a parte desta devida à falta de correlação das médias dos genótipos entre lo cais. Para os dados de milho e feijão analisados, os resulta dos de zoneamento são similares, quando se usam as três estä tísticas para medir a similaridade de locais. 


\title{
A NON-LINEAR MODEL APPLIED TO GENOTYPE-ENVIRONMENT
}

\section{INTERACTION ANALYSIS}

\author{
Author: Lāzaro Josē Chaves \\ Adviser: Prof. Dr. Roland Vencovsky
}

S U M MAR Y

Under the assumption that the environment acts multiplicatively on genotypes, the analysis of genotypeenvironment interaction was based on a non-linear model, which is multiplicative in genetic and environmental parameters and additive for the error term.

Matematical derivations provided the basis for the analysis of some implications of the multiplicative action of the environment on the genotypes, in relation to some plant breeding aspects. Experimental data of soybean, "wheat, manioc, maize and common bean cultivars, were analysed, in order to determine the applicability of the non-linear model to genotypeenvironment interaction studies. 
For soybean, manioc and wheat, results showed that the multiplicative model, the linear model and the intrinsically linear model with a logaritimic transformation gave a similar pattern of fitness to experimental data as indicated by the magnitude of deviations from the models. For maize and common bean data, the non-linear model fitted better in comparison to the linear model; for opaque maize, normal maize and common bean data, the non-linear model explained.16.9, $9: 8$ and $10.1 \%$ of the interaction sum of squares, respectively... The model transformed to logaritimic scale was less efficient than the others, as far as the power of fitness is concerned.

The application of the residual sum of squares of the non-linear model in measuring the similarity of locations with respect to genotype-environment interaction, was investigated. Such sum of squares was compared with that due to interaction in the linear model and also with part of the interaction sum of squares that is due to lack of correlation of the cultivar means between locations. Such comparison showed no apparent differences between the statistics for measuring the distance between locations in aglomerations studies. 
1. INTRODUÇAOO

Dentre as dificuldades encontradas por melhoris tas de plantas na identificação e recomendação de materiais ge nēticos superiores, estão aquẹlas relacionadas à resposta dife rencial destes materiais genēticos, quando submetidos a diferen tes condições ambientais. Os estudos relativos a este fenômeno, têm sido efetuados pressupondo-se que os ambientes exercem um efeito aditivo sobre os genótipos. Para tanto, modelos estatís ticos lineares têm sido adaptados e largamente uti lizados em tais situações, sendo os desvios da aditividade dos feitos prin - cipais, detectados na forma de interação de genótipos com ambi entes.

A natureza da interação de genótipos com ambien tes tem merecido a atenção de inümeros pesquisadores e uma sé rie de trabalhos tentando explicá-la pode ser encontrada na li teratura. Contudo, a possivel ação multiplicativa dos ambientes sobre os genótipos, tem sido pouco considerada pelos melhori $\underline{s}$ tas e, em caso de detecção de efeitos multiplicativos em tabe las de dupla entrada, mudanças de escala têm sido aplicadas pa 
ra contornar o problema.

Na hipótese de que os ambientes possam influir de forma multiplicativa sobre os genótipos na manifestação fenö típica, o presente trabalho teve por objetivo aferir a apli cabilidade do modeló não-linear de VENCOVSKY e GERALDI (1977), que é multiplicativo em seus parāmetros principais, em estudos sobre a natureza da interação de genótipos com ambientes. Para tanto, possíveis implicações de uma ação multiplicativa dos am bientes sobre os genōtipos foram consideradas a nível teórico, alēm da anălise de dados experimentais de soja, trigo, mandio ca, milho e feijão. 


\section{REVISÁO DE LITERATURA}

A literatura referente aos estudos das interações de genótipos com ambientes é.bastante vasta. Para o melhoramento de plantas é de grande importäncia que se conheçam as reações de diferentes materiais genéticos de espécies cultivadas, quando sub metidos a ambientes diversos. A prätica de ensaios de materiais genēticos em mais de um ambiente é assim, um procedimento roti neiro em programas de melhoramento de plantas. Os diferentes am bientes são proporcionados pela variação simples ou combinada de locais, anos, estações, épocas de plantio, etc. Conforme salien ta COMSTOCK (1955), em vista da multiplicidade de fatores que compõem o ambiente e interagem com a planta em diferentes fases do seü ciclo, a probabilidade de que dois indivíduos sejam expos tos a ambientes idénticos, deve ser não menos remota que aquela de que genōtipos idênticos sejam encontrados em dois organismos de uma população panmítica.

Com um nūmero $N$ de genótipos submetidos a $M$ dife rentes ambientes, o nūmero de tipos de interações possíveis é da do por (MN)! /M!N! - Destes apenas uns poucos são de interesse 
do melhorista e em apenas um caso, de todos os possíveis, um mes mo genōtipo é o melhor em todos os ambientes (ALLARD e BRADSHAW, $1964)$.

A ocorrēncia de interação de genōtipos com ambien tes pode ser detectada estatisticamente através da anālise con junta de experimentos repetidos em mais de um ambiente e cujos tratamentos sejam constituídos de materiais genéticos. A detecção de significância para a interação não esclarece, contudo, as im plicações que esta possa ter sobre o melhoramento (VENCOVSKY, 1978), de forma que estudos de detalhamento desta componente da variação são, em geral, necessários.

Um dos procedimentos para detalhamento do efeito da interação de genótipos com ambientes se refere ao estudo da estabilidade de cultivares. Tal procedimento consiste, basicamen te, em se analisar a variação ocorrida entre ambientes para cada material genético separadamente, permitindo a seleção daqueles com o tipo de resposta desejado.

A mais simples e tradicional metodologia para se estudar a estabilidade de cultivares, consiste em se calcular uma variância entre ambientes dentro de cada tratamentó. Tal metodo logia, apesar de fornecer uma medida da variabilidade de cada cultivar nos diferentes ambientes, não permite o conhecimento da contribuição particular de cada cultivar na interação total. Is to porque a variância assim calcul ada para cada tratamento, con siste em um desdobramento dos $N(M-1)$ graus de liberdade corres pondentes à fusão das somas de quadrados devidas aos efeitos de 
ambientes e da interação, sendo $N$ o número de cultivares e $M O$ nümero de ambientes.

A primeira metodologia para se conhecer acontribui ção relativa de cada variedade para a interação total de varieda des com ambientes foi proposta por PLAISTED e PETERSON (1959). A metodologia consiste em se realizaremanälises conjuntas da va riància para cada combinação de variedades duas a duas, computan do-se para cada caso a componente da variáncia relativa à intera ção de genótipos com ambientes. A média aritmética das estimati vas da interação, envolvendo cada cultivar é usada com uma medi da da contribuição desta cultivar no total da interação.

WRICKE (1964) propós o termo ecovalència para indi car a contribuição de cada genötipo na interação total de genóti pos com ambientes. A metodologia consiste em se calcular o efe to da interação em cada combinação de tratamentos com ambientes. A soma de quadrados destes efeitos é computada para cada trata mento através da förmula $w_{i}=\sum_{j=l}^{M}\left(x_{i j}-\frac{X_{i}}{M}-\frac{X_{. j}}{N}+\frac{X}{M N}\right)^{2}$, sen do $N$ o nümero de tratamentos e M o nümero de ambientes. Com r re petições a contribuição de cada variedade na soma de quadrados da interação total é dada por $r w_{i}$, correspondendo esta estatística à ecovalència.

Princípios de regressão linear são utilizados em diversos estudos de determinação da natureza da interação de ge nótipos com ambientes. A metodologia básica consiste em se esta belecer uma relação linear entre o desempenho de cada material genētico e um índice ambiental. A primeira aplicação da técnica 
da regressão linêar no estudo da estabilidade de cultivares foi realizada por FINLAY e WILKINSON (1963). Para cada uma das varie dades de cevada estudadas, foi determinada uma equação de regres são linear relacionarido o rendimento individual de cada varieda de em cada local e ano com a média de rendimento de todos os tra tamentos naquele ambiente. 0 coeficiente de regressão ('b)' assim determinado constitui o parâmetro medidor da estabilidade da cul tivar. No cálculo das médias e das regressões, os dados básicos de produção foram tratados em uma escala logarítíica. Este proce dimento, segundo os autores, induz um alto grau de linearidade nas regressões, além de proporcionar uma maior homogeneidade das variancias residuais dos experimentos. A metodologia de finLAY e WILKINSON (1963) permite o desdobramento da soma de quadrados da interação de genōtipos com ambientes em suas partes devidas a re gressão linear e aos desvios da regresãão. Para os dados de ceva da analjsados, $79 \%$ da componente da variáncia devida à interação pôde ser atribuída à regressão linear.

Uma tēcnica semelhante à de FINLAY e WILKINSON (1963) para estudo da estabilidade de cultivares fio i proposta por EBERHART e RUSSELL (1966). Alēm do coeficiente de regressão ( $\left.b_{i}\right)$, os autores ustilizam um segundo parâmetro de estabilidade, qual seja, a variância relativa aos desvios da regressão ( $\left.{ }^{2}{ }^{2}{ }^{\prime}\right)^{\prime}$, para representar a estabilidade do materialigenético i. Idealmente, por esta metodologia, uma variedade estável deve possuir coefici ente de regressão unitário e variância dos desvios da regressāo nula. As duas metodologias diferem ainda, quanto à forma de cál culo do indice ambiental. EBERHART e RUSSELL (1966) utilizam um 
indice ambiental que corresponde ao desvio da média de todas as cultivares em um dado ambiente, em relação à média geral dos en saios. A escala logarítmica não é empregada por estes autores.

Partindo de modelos genēticos que detalhám os efé tos aditivo e dominante dos alelos de um locoe considerando efe tos de ambientes diversos, alguns estudos indicam que o efeito da interação de genōtipos com ambientes pode ser representado co mo uma função linear do efeito ambiental principal. Através do emprego destes modelos sobre dados de altura final de plantas em Nicotiana rustica, foi mostrado que existe uma relação linear positiva entre a interação e o efeito ambiental, sejam os genóti pos constituídos de linhagens endogàmicas (BUCIO ALANIS, 1966), geração híbrida F, (BUC.10 ALANIS e HILL, 1966) ou mistura de li nhagens e cruzamentos (PERK.INS e JINKS, 1968).

Outras alterações na metodologia básica de regres são linear para detalhamento da interação de genótipos com ambi entes têm surgido. HANSON (1970). propõe uma combinação dos parâ metros de estabilidade de EBERHART e RUSSEL (1966) e:m um ünico parâmetro. TAl (1971) aplica uma forma diferente na estimação de parâmetros de estabilidade, introduzindo os parámetros $\alpha$ e $\pi$, para medir, respectivamente, os efeitos da regressão linear e dos desvios da regressão. BILBRO e RAY (1976) utilizam o coeficiente de determinação $\left(R^{2}\right)$ como parâmetro, de estabilidade em lugar da soma de quadrados dos desvios da regressão. 0 coeficiente de de terminação tem a vantagem de ser uma medida de natureza relativa do ajustamento dos pontos à linha de regressão.

OLIVEIRA (1976) realizou uma comparação entre os 
principais métodos de estudo da estabilidade de cultivares, com aplicação a dados de ensaios de produção de milho. Segundo este autor, os métodos que melhor se prestaram à determinação da es tabilidade foram os métodos de FINLAY e WILKINSON (1963) e de EBERHART e RUSSELL (1966). Ambos estão baseados nos princípios da regressão linear e definem estabilidade de uma forma dinâmica, levando em conta, não somente estabilidade absoluta, mas tambëm estabilidade média.

Inümeras críticas tēm surgido, aos métodos mais usuais de estudo da estabilidade de oultivares. A maioria se re fere à maneira pela qual é determinado o índice ambiental e a va lidade estatística dos testes. e estimações efetuados.

HANSON (1970) considera que a estimativa do coefi ciente de regressão pelo método de EBERHART e RUSSELL (1966) so reflete uma medida realista da estabilidade fenotípica, quando os genótipos possuem regressoes diferentes.

FREEMAN e PERKINS (1971) ressaltam que a regressao linear do valor fenotípico dos vārios genótipos sobre a média des tes em cada ambiente, leva a regressöes estatísticas invälidas, nas quais a soma de quadrados para a regressao conjunta e a mes ma da soma de quadrados total entre ambientes, e não parte dela. Estes autores propõem, uma medida do indice ambiental que seja in dependente dos dados ém estudo. Entre as alternativas apresenta das para se dispor de tal índice, a primeira consiste em se divi dir as repetições dos" experimentos em dois grupos, servindo um para o estudo das interaçōes de genōtipos com ambientes e outro 
para fornecer uma medida do ambiente. Outra possibilidade seria usar um ou mais genōtipos como padrão para medir o ambiente.

A constatação de que um üñico ?genótipo :pode forne cer uma medida extremamente boa do ambiente foi feita por FRIPP e CATEN (1971), que estudaram "dicarions" do fungo Schizophyllum commune em diferentes ambientes. O genótipo parental dos "dica rions" em estudo foi o padrão utilizado para medida do índice am biental. Notaram estes autores, no entanto, que os resultados ob tidos tomando-se uma medida independente do ambiante, diferiram muito pouco daqueles estudos prévios em que indices ambientais não-independentes foram utilizados. Em um estudo posterior, uti lizando o mesmo organismo, FRIPP (1972) comparou alguns métodos de medida do ambiente para estudos de regressão. A anālise de re gressão utilizando os diversos métodos foi marcadamente similar, com uma ligeira tendência de decréscimo da linearidade da regres são, quando o material genētico usado como medida do ambiente se tornava distanciado daqueles em estudo e quando medidas físicas do ambiente eram tomadas. O autor considera que quando o número de genótipos e de ambièntes è grande, a utilização de medidas não-independentes do ambiente pode ser feita, sem que haja a in trodução de erro considerável na anălise.

HARDWICK e WOOD (1972) mostram que existe uma ten denciosidade na estimativa do coeficiente de regressão linear quando a regressão e tomada sobre os efeitos ambientais.. Esta ten denciosidade tende a ser diminuída se o nūmero de ambientes é ele vado e também quando a razão entre as variâncias ambiental e re sidual é alta. Os autores propõem a utilização de um indice amb 
ental calculado por uma regressão mültipla sobre um conjunto de vāriáveis do ambiente. A aplicação deste método é ilustrado por WOOD (1976).

A amostragem aleatória de genōtipos e àpontada por MIEZAN et alii (1979) como um requisito essencial para que o coe ficiente de regressão dos valores fenotípicos sobre índices ambi entais não-independentes seja uma medida fiel daestabilidade dos genōtipos.

Um enfoque alternativo que pode ser dado à contro le dos efeitos indesejāveis da interação de genōtipos com ambi entes, é aquele que diz respeito ao agrupamento de localidades em sub-āreas, dentro das quais a interação é minimirzada. Estä téc nica, conhecida como zoneamento ecológico, foi primeiro utilizada por HORNER e FREY (1957), no zoneamento do estado de lowa-EUA, Pa ra a cultura de aveia.

o procedimento básico para se realizar o zoneamen tó ecolōgico, consiste em se fazer anālises conjuntas da. var.iān cia envolvendo os locais, dois a dois, os pares de locais para os quais a componente da variância devida à interação for baixa, são agrupados formando sub-regiões, dentro das qua.is se admite uma maior similáridade dos fatores ecológicos que afetam a cultu ra. A recomendação de cultivares deve ser feita para cada sub-di visão, elimando tse assim, o efeito da interação de cultivares com sub-regiões, parte normalmente considerável da interação total. VENCOVSKY (1978) ressalta a necessidade de se confrontar o mapea mento ecológico de uma região pelo processo de minimização das. 
interações, com mapas que envolvam fatores físicos do meio, como clima, solo, etc:

Um importante aspecto da natureza da interação de genótipos com ambientes, foi abordado por ROBERTSON (1959). Ele mostrou que a componente dà varíância devida à interação podeser desdobrada em duas partes aträēs da fórmula:

$\sigma_{\text {ga }}^{2}(1,2)-\frac{1}{2}\left(\sigma_{g i}-r_{12}\right)$, sendo:

$\sigma^{2} g a(1,2) \quad$ componente da variância relativa a interação de ge nōtipos com os ambientes 1 e 2;

$\sigma_{g 1}^{2}$ e $\sigma^{2} g_{2}$ : componentes da variância relativas aos efeitos dos genótipos dentro dos locais. 1 e 2, respectivamente; coeficiente de correlação genētica das mēdias dos genōtipos nos ambientes 1 e 2 .

Pode-se observar por esta fórmula, que a interação de genótipos com ambientes pode ser atribuída a duas causas distintas. Parte da interação, dada por $\frac{1}{2}\left(\begin{array}{lll}\sigma_{g 1} & \sigma_{g}{ }^{2}\end{array}{ }^{2}\right.$, se devè à diferença das variâncias genéticas entre os materiais nos locais 1 e 2 . A ou tra parcela, dada por $\sigma_{g l} \sigma_{g 2}\left(1-r_{12}\right)$, pode ser atribuida à falta dé correlação dos vaḷöés geńotípicos dos tratamentos de um para outro local. Conforme salienta VENCOVSKY (1978), apenas a segunda parte da interação é problemātica ao melhoramento, vi $\underline{s}$ to que uma pequena correlação dos valorès dos genótipos nos ambi entes indica que os melhorés tratamentosem um ambiente poderão não o ser em outro.

A fórmula de ROBERTSON (1959) pode ser estendida 
para mais de dois ambientes fazendo:

$\sigma_{g a}^{2}=\sum_{j<j^{\prime}}\left[\left(\sigma_{g j}-\sigma_{g j^{\prime}}\right)^{2}+2 \sigma_{g j} \sigma_{g j^{\prime}}\left(1-r_{j j^{\prime}}\right)\right] / M(M-1)$. para M ambientes (COCKERHAM, 1963).

o detalhamento da interação de genōtipos com amb entes pela fórmula de ROBERTSON (1959) tem uma importante aplica ção no zoneamento ecológico. Sendo a parcela devida á falta :lde correlação dos valores dos genōtipos de um para outro local, a parte problemätica da interação, o zoneamento pode ser fẹito atra vēs da minimização desta parcela da interação dentro de sub-re giōes, ao invēs de se trabalhar com a interação totál. Apesar desta utilidade, a decomposição da interação de genōtipos com am bientes não tem sido usada süficientemente pelos pesquisadores (ROSITO, 1974).

ABOU-EL-FITTOUH et alii (1969), analisando dados de produção de fibra de algodão em diversos lociais, mostraram que um coeficiente de distância entre locais, calculado pela fórmula $\left.d_{j j^{\prime}}=i_{i} \sum_{i}^{n}\left[(\hat{g l})_{i j}-(\hat{g l})_{i j}\right]^{2} / N\right\}^{1 / 2}$, funciona como uma boa medida da similaridade de locais para fins de estudos da in teração de genōtipos com ambientes. Na fōrmula, djj'. : correspon de ao coeficiente de distância entre os locais je j'; (g7) ije (g) j j' correspondem às estimativas dos efeitos da interação do genōtipo i com os locais $j$ e j', respectivamente e $N$ se refere ao nümero de genōtipos.

Apesar da diversidade dos modelos estatísticos co mumente empregados na anālise da interação de genótipos com am bientes, todos têm em comum o fato de partirem da pressuposição 
da existência de aditividade dos efeitos do modelo. Consequente mente, tais modelos são lineares em seus párámetros:

o modelo mais geral para descrever o comportamento de materiais genéticos submetidos a diferentes ambientes pode ser escrito como $\bar{Y}_{\mathbf{i j} .}=m+g_{\mathbf{i}}+a_{\mathbf{j}}+(g a)_{\mathbf{i}} \mathbf{j}+\bar{e}_{\mathbf{i} \mathbf{j}} \cdot \mathbf{j}$ sendo

$\bar{Y}_{i j .} \quad$ : valor fenotipico médio do caráter $Y$, medido no material genētico i, no ambiente $\mathbf{j}$;

m : média geral dos dados em estudo;

$g_{\text {i }} \quad$ : efeito do genōtipo i;

$a_{j} \quad$ : efeito do ambiente $j$;

(ga) $i j:$ efeito da interação do genótipo i com o ambiente j; $\bar{e}_{i j .} \quad$ : erro médio associado à observação $\bar{Y}_{i j .}$, na suposição de que estevalor resulte da média de mais de uma repeti ção. Tal modelo, amplamențe utilizádo na anälise conjun ta da variância de experimentos repetidos em mais de $\because$ um ambien te, parte do princípio de que os efeitos dos genótipos edos am bientes são aditivos à média. os desvios da aditividade são cap tados na interação de genōtipos com ambientes. A existência de qualquer relação não-aditiva entre os efeitos principais, vai. contribuir, portanto, para um aumento do efeito da interăção.

TUKEY (1949) apresenta uma metodologia para se de tectar a existência de não-aditividade em tabelas de dupla entra da e indica mudanças adequadas de escala para aumentar a aditivi dade dos efeitos. O procedimento consiste em se isolar da soma de quadrados do resíduo, ou da interação, a parte rreferente à 
não-aditividade, com um grau de liberdade. Caso haja significān cia para o quadrado"mēdio da não-aditividade, por um testé f con tra ó resíduo, transformăções apropriadas dos dados são recomen dadas.

A transformação de escala ē um procedimento comum em estatística. MATHER (1971) considera que em genētica, deve ser muito raro o fato de a escala usada para medir caracteres ser ba seada em considerações biológicas. As escalas usadas, são toma das porque são familiares ou óbvias, não existindo, portanto, ne nhuma razão pela qual os dados não possam ser mudados para uma escala diferente. KNIGHT (1970), por outro lado, ressalta que o modelo matemātico básico relacionando o comportament:o de um genō tipo em diversos ambientes, é diferente se se aplica uma mudança de escala e conclusões biológicas diferentes podem ser tiradas.

-E raro o emprego de transformações de escala na anā ise das interaçōes de genótipos com ambientes. De todos os méto dos mais comumente utidizados no detalhamento da ințerą̧ão, ape nas o de FINLAY e WILKINSON (1963) envolve uma transformação, ana lisando os dados em uma escala logarítmica. Esta transformação tem, segundo os autores, a finalidade de induzir uma maior linea ridade nas regressões dos valores dos genótipos sobré os índices ambientais. De acordo com KNIGHT (1970) uma maior linearidade da regressão só ē induzida se as diferenças entre os genótipos nos ambientes ótimos forem maiores que nos ambientes inferiores. As sim sendo, a seleção de genótipos com base nos valorés de regres são calculados em uma escala logaritmica, enfatiza as di fẹenças 
nos altos rendimentos para a discriminação entre tratamentos.

A utilização de um modelo linear de anälịse da varị ância em uma escala logarítmica, pressupōe a multị̂lícatívidade dos efeitos do modelo na escala original. o efeito multiplicati vo dos ambientes sobre os genōtipos, como fonte de interação, tem sido pouco considerado pelos melhoristas. De fato, alguns fe nômenos como a maior diferença entre genōtipos em ambientes favo räveis (BUCIO ALANIS e HILL, 1966; KNIGHT, 1970), correlação po sitiva entre mëdias e coeficientes de regressão dos cultivares (EBERHART e RUSSELL, 1966; PERKINS e JINKS, 1968; KNIGHT, 1970; KALTSIKES e LARTER, 1970; FRIPP e CATEN, 1971; WESTERMAN, 1971; FRIPP e CATEN, 1973) e assoclação entre mëdias e variàncias, po dem indicar um certo grau de multiplicatividade dos efeitos dos ambientes sobre os genōtipos.

VENCOVSKY e GERALDI (1977) utilizaram o modelo:

$Y_{i j}=\alpha_{i}\left(l+\beta_{j}\right)+\bar{\varepsilon}_{\mathbf{i} j}$, que é multiplicativo nos parāmetros ge nëtico $\left(\alpha_{i}\right)$ e ambiental ( $\left.\beta_{j}\right)$, para explicar o comportamento do genōtipo i no ambiente $j$. sendo $\bar{\varepsilon}_{i j}$ um desvio aleatōrio associa do à média $Y_{i j}$. Um modelo desse tipo é adequado para explicar o efeito de fatores não-independentes sobre uma obsèrvação e sua estrutura simples torna os parámetros facilmentes interpretáveis, em comparação com parâmetros de modelos que envolvem transforma ção de dados (OSBORN, 1975). Atravēs da aplicação do modelo à anālise de trinta pares de ensaios de milho,. VENCOVSKY e GERALDI (1977) determinaram que na mëdia de todas as anälises efetuadas, $18,4 \%$ da interação detectada com o modelo linear de anālise foi 
devida à ação multiplicativa dos efeitos dos ambientes sobre os efeitos genotípicos.

O fato da existência de multiplicatividade nos,efei

tos genético e ambiental, tem uma série de implicações sobre o melhoramento de plantas, tanto no que diz respeito à interpreta ção de resultados, quanto no procedimento que se deva ter na con dução e anālise de ensaios de materiais genéticos em differentes ambientes. A se confirmar, para uma maior amostra de ambientes e em culturas diversas, a ocorrência de ação multiplicativa dos ambientes sobre os valores dos genótipos, vários aspectos relati vos à interação de genótipos com ambientes poderão ser esclarecí dos, com real proveito para o melhoramento genético das plantas. 


\section{MAJERIAL}

Os dados experimentais utilizados no presente trabalho, englobam ensaios de cultivares realizados em diferen tés ambientes, nas eulturas désoja, trigo, mandioca, milho e feijão. Estes dados constam, basicamente, das médias de cultiva res obtidas em ensaios com repetições, instalados em diferen tes locais e anos. Em sua maioria, os dados foram obtidos de trabalhos cientificos e outras publicações de pesquisadores ou instituições de pesquisa.

\subsection{Soja [Glycine $\max$ (L.) Merrill]}

Foram analisados dados "de produtividäde de dez cultivares de soja plantadas em onze locais do Rio Grande do Sul, duránte os anos agrícolas de 1972/73, 1973/74 e 1974/ 75, em um total de trinta e três experimentos. Os ensaios fo ram conduzidos pela Secretaria da Agricultura daquele estado e pelo Instituto de Pesquisas Agropecuārias do Sul, sendo que os dados foram retirados do trabalho de BONATO (1978). As cultiva res utilizadas, os locais dos ensaios, os coeficientes de varia 
ção dos ensaios, bem como as médias das cultivares em cada lo cal, estão transcritas nas Tabelas A.l, A.2 e A.3 (apêndice), com algumas simplificações.

\subsection{Trigo (Triticum aestivum L.)}

Foram utilizados, para a cultura do trigo, da dos de médias de produtividade de grãos derivados dos Ensaios Regionais de Trigo, conduzidos pelo Instituto Agronómico do Es tado de São Paulo, em diferentes localidades deste estado, nos anos agrícolas de 1969, 1970 e 1971 em um total de vinte e um ensaios. Os dados foram tomados do trabalho de CAMARGO

e estão transcritos nas Tabelas A.4, A.5 e A.6, bem como as cul tivares empregadas, as localidades em que os ensaios foram con duzidos e os coeficientes de variação dos ensaios.

\subsection{Mandioca (Manihot esculenta Cranz)}

Dados de produtividade de ramas e de raízes de mandioca, de ensaios conduzidos, em três localidades no estado do Pará e território do Amapá, por seis anos, foram utilizados no presente estudo. Tais dados foram retirados do trabalho de BARRIGA (1980) e resultam de ensaios conduzidos pelo Céntro de Pesquisa Agropecuária do Trópico Omido da EMBRAPA, sendo que do ze cultivares são comuns aos nove ambientes, conforme mostram as Tabelas A.7 e A.8. : 


\subsection{Mitho (Zea mays L.)}

Todos os dados relativos à cultura do milho uti lizados para análise neste trabalho, constam de resultados de Ensaios Nacionais publicados pelo Centro Nacional de Pesquisa de Milho e Sorgo da EMBRAPA.

Do Ensaio Nacional de Milho Precoce do ano agrí cola de 1976/77, foram aproveitados dados de altura de plantas de quinze cultivares comuns a quatro localidades, para análise deste caráter. A Tabela A.9 discrimina os tratamentos e locali dades dos ensaios, com os respectivos dados médios do caráter (BRASIL, 1977a).

Na Tabela A.lo estão os dados de produtividade de espigas de doze materiais em nove localidades de diferentes estados, originārios do Ensaio Nacional de Milho Planta Baixa, no ano agrícola de 1977/78, alēm dos coeficientes de variação dos ensaios (BRASIL, 1978).

Foram analisados ainda, dados de produtividade de espigas dos Ensaios Nacionais de Milho Opaco, conduzidos nos anos agrícolas de! $1974 / 75$ e 1976/77, constantes das Tabelas A.11 e A.12 (BRASIL, 1975a; BRASIL, 1977b). Os dados do ano de $1974 /$ 75 resultam de ensaios conduzidos em onze localidades com oito tratamentos comuns, enquanto que no ano de $1976 / 77$, os dados são resultantes de experimentos instalados em nove locais, tendo es tes doze tratamentos comuns.

Além destes, foram analisados dados de produt $\underline{\mathbf{i}}$ 
vidade de espigas dos Ensaios Nacionais do Milho dos anos agrí colas de 1974/75, com trinta tratamentos em quatorze localida des; 1975/76, com trinta tramentos em nove localidades e $1976 /$ 77, com trinta e seis tratamentos em doze localidades. Nas Tabe las A.13, A.14 e A. 15, estão transcritos tais dados com discri minação dos tratamentos, locais dos ensaios e coeficientes de variação destes (BRASIL, 1975b; BRASIL, 1976; BRASIL, 1977c).

Ao todo foram analisados dados de produtividade de espigas de sessenta ensaios de milho e de quatro para altura de plantas.

\subsection{Feijão (Phaseolus vulgaris L.)}

Os dados de produtividade de grãos de cultiva res de feijão, analisados neste trabalho foram cedidos pelo Cen tro Nacional de Pesquisa de Arroz, Feijão, da EMBRAPA. Derivam dos Ensaios Nacionais de Variedades de Feijão conduzidos pelo antigo Departamento Nacional de Pesquisa Agropecuāria do Minis tërio da Agricultura, em diversos estados brasileiros, nos anos agrícolas de 1966/67 a 1971/72. Os números de cultivares e loca lidades dos ensaios variaram de ano para ano, tendo sido" apro veitados apenas os tratamentos comuns aos diversos ensaios, den tro de cada ano, resultando nos seguintes números por ano agrí cola: 1966/67, dez cultivares em oito localidades; 1967/68, dez cultivares em nove localidades; 1968/69, doze cultivares em do ze localidades; 1969/70, nove cultivares em dez localidades;

$1970 / 71$, nove cultivares ém nove loçalidades e 1971/72, doze cul 
tivares em quinze localidades.

A discriminação das variedades e localjidades dos ensaios em cada ano agrícola, bem como os coeficientes de variação dos ensaios encontram-se nas Tabelas de A.16 a A.21, com as respectivas produtividades médias de grãos de cada expe rimento. 
Na suposição de que em ensaios de materiais ge néticos repetidos em diversos ambientes, o ambiente possa ter efeito multiplicativo sobre ${ }^{s}$ genötipos, o modelo $y_{i j}=\alpha_{i}\left(1+\beta_{j}\right)$ $+\varepsilon_{i j}$ proposto por VENCOVSKY e GERALD! (1977) foi estudado do ponto de vista teórico e aplicado, procurando-se determinar as implicações de tal comportamento em programas de melhoramento de plantas. Neste modelo, Yij representa a mëdia de observações fenotípicas tomadas em vārias repetições, do material genético i no ambiente $\mathbf{j} ; \alpha_{\mathbf{i}}$ representa o efeito'do tratamento $\mathbf{i}$; $\beta_{\mathbf{j}}$ cor responde ao efeito do ambiente $\mathbf{j}$ e $\varepsilon_{\mathbf{i}} \mathbf{j}$. corresponde a um erro aleatório associado à observação $Y_{i j}$. Se se considera um conjun to de $N$ materiais genēticos, ensaiados em $M$ diferéntes ambien tes e, considerando ainda um efeito totalmente multiplicativo dos ambientes sobre os genótipos, de tal modo que $\varepsilon_{\mathbf{i}}=0$ para qualquer i,j; temos uma Tabela de dupla entrada em que os dados podem ser representados como na Tabela 1 , sendo considerado $f \mathbf{i}$ xo.. o. efeito ambièntal.

Alguma fórmulas normalmente utilizadas em melho 
ramento, foram desenvolvidas assumindo-se o modelo de VENCOVSKY e GERALDI (1977). Assim, atravēs de derivaçōès matemātiças obti veram-se," em termos de parámetros deste modelo, : estatísticas tais como, a covariància de genōtipos entre ambientes diversos, - progresso esperado na seleção e parâmetros de estabilidade de EBERHART e RUSSEL (1966).

Tábela 1. Representação dos fatores $\alpha_{i}\left(1+\beta_{j}\right)$ de $N$ tratamentos repetidos em $M$ ambientes, segundo 0 modelo de VENCOVSKY e GERALDI (1977), com efeito fixo dos amb $\underline{i}$ entes e ausēncia de desvios.

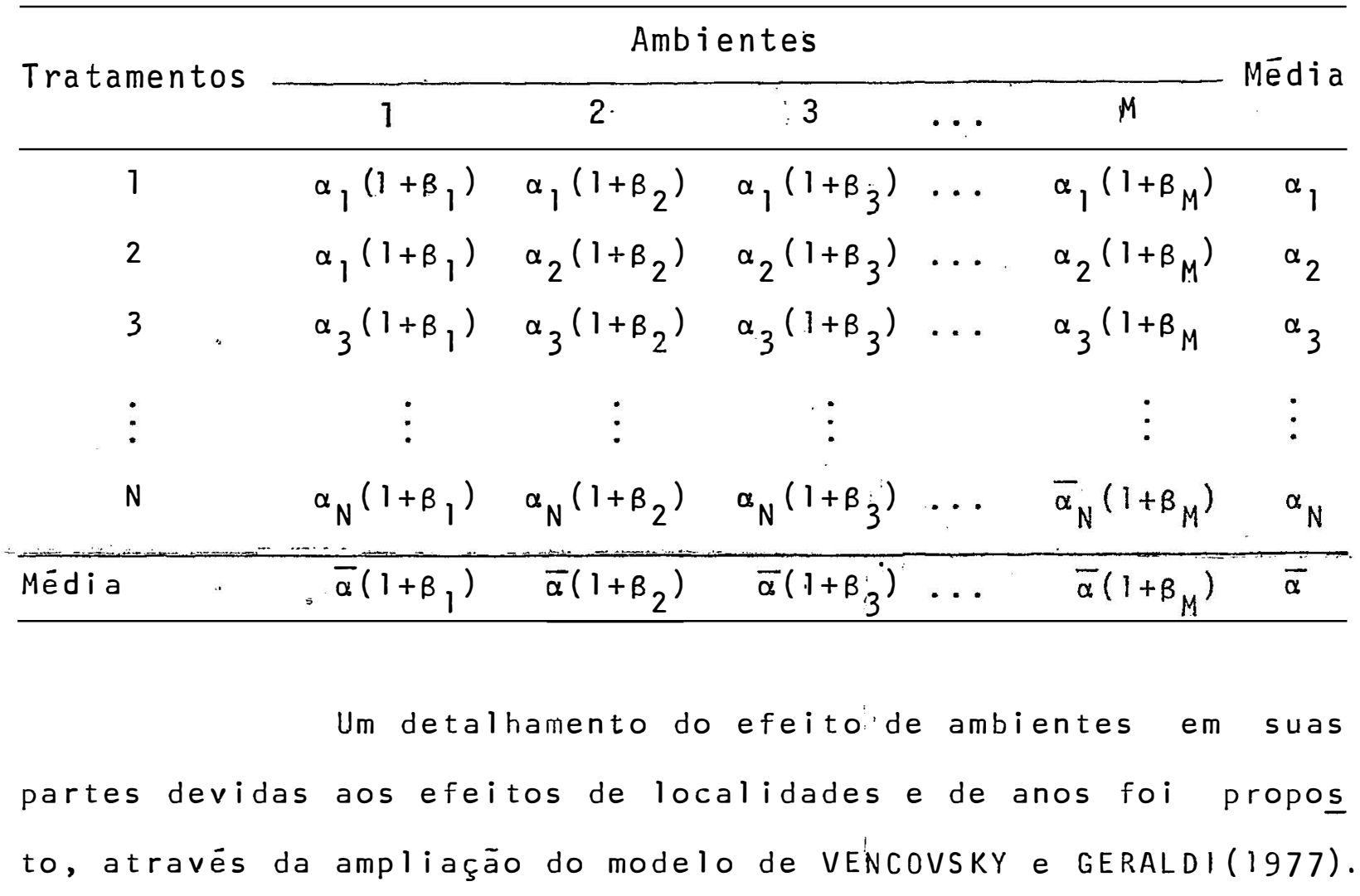


Deste modo admitiu-se o modelo $\gamma_{i j k}=\alpha_{i}\left(1+\beta_{j}\right)\left(1+\gamma_{k}\right)+\varepsilon_{i j k}$, sendo:

$Y_{i j k}$ : Média do carāter fenotípico Y, tomada do material genēt co i, no local je no ano $k$;

$a_{i}:$ efeito do tratamento i;

$\beta_{j}$ : efeito da localidade j;

$\gamma_{k}$ : efeito do ano $k$ e

$\varepsilon_{i j k}$ : desvio aleatório associado à média Y $i j k$.

Através do método dos quadrados mínimos, foram obtidas förmulas para estimação dos parâmetros do modelo, bem como das somas de quadrados devidas aos efeitos principais e aos desvios do modelo. Foi verificado ainda, o conteūdo das so mas de quadrados das interações duplas e tripla do modelo line ar convencional (pägina 33), assumindo-se multiplicatividade dos efeitos de locais e anos sobre os genótipos. Isto foi féto, através da superposição das fórmulas usuais com o modelo não-l near ampliado.

A comparação do modelo não-linear de VEncovsky e GERALDI (1977) (modelo b), com o modelo linear convencional de anälise conjunta da variáncia, (modelo a) foi fejta basica mente através dos valores da soma de quadrados dos desvios do modelo não-linear e da soma de quadrados da interação de genótị pos com localidades de dados provenientes de ensaios de milho, feijão, soja, trígo e mandioca.

Para cada conjunto de materiais genéticos ensaia dos em diversos locais dentro de cada ano, foi realizada uma 


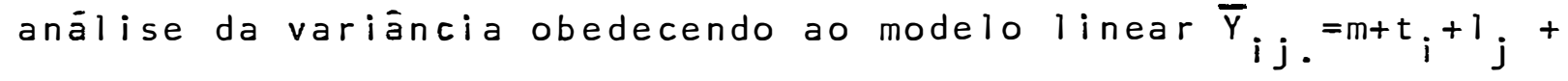
$(t)_{i j}+e_{i j}$ onde:

$\bar{Y}_{i j}$. média observada do carāter fenotíp'ico Y, rio tràtamen to i e no local j;

m : média geral de todos os ensaios;

$t_{i} \quad:$ efeito fixo do tratamento i;

Ij: efeito aleatório do local j;

(tl) ij : efeito da interação do material genético i com o lo cal j.

$\bar{e}_{i j .} \quad$ : erromédio associado à média $\bar{Y}_{i j}$.

Obteve se assim um quadro de análise da, variància como na Tabe 1 a 2 .

Tabela 2. Anālise da variāneia, baseada no modelo linear (mode 10 a) para $N$ tratamentos ensaiados em L Tocalidades.

F.V.

Tratamentos

Localidades

Interação
G.L.

$N-1$

$L-1$

$(N-1)(L-1)$
S.Q.

$S_{1}$
$S_{2}$
$S_{3}$
se as somas de quadrados de parámetros e desvios do modelo, atra ves das förmulas:

$$
S Q_{P}=\sum_{i=1}^{N} \hat{\alpha}_{i}^{2} \sum_{j=1}^{L}\left(1+\hat{B}_{j}\right)^{2} \quad e
$$




$$
S Q_{d}=\sum_{i j} \quad Y^{2} j-S Q_{p} \text { sendo } S Q_{p} \text { e } S Q_{d} \text {, as so }
$$

mas de quadrados devidas aos parâmetros e aos desvios, respec tivamente. As estimativas de $\alpha_{i}$ e $\left(1+\beta_{j}\right)$ foram obtidos por um processo iterativo de estimação, a partir das förmulas:

$$
\begin{aligned}
& \hat{\alpha}_{i}=\frac{\sum_{j=1}^{L} Y_{i j}\left(1+\hat{\beta}_{j}\right)}{\sum_{j=1}^{L}\left(1+\hat{B}_{j}\right)^{2}} \text { e } \\
& \left(1+\hat{B}_{j}\right)=\frac{\sum_{i=1}^{N} Y_{i j} \hat{\alpha}_{i}}{\sum_{i=1}^{N} \hat{\alpha}_{i}^{2}}, \text { a primeira:estimativa de }
\end{aligned}
$$

$\alpha_{i}$ pode ser obtidá pela média do tratamento i em todos os lo cais, isto é, $\bar{Y}_{i}$. (VENCOVSKY e GERALDI, 1977).

Umá comparação suplementar foi feita realizandọ se uma anālise da variância, com base no modelo linear, com os dados $\left(Y_{i j}\right)$ tomados em-escala logaritmica (modelo c). Tal pro cedimento equivale a analisar os dados na escala natural util zando-se um modelo que seja multiplicativo em todos os efeitos, inclusive os desvios. Um modelo deste tipo, que pode ser trans formado em um modelo linear atravēs de uma mudança de escala é chamado modelo intrinsecamente linear (DRAPER e SMITH, 1966). A utilização de um modelo intrinsecamente linear, quando ade quado, tem a vantagem de favorecer o uso de técnicas estatísti cas mais simples, desenvolvidas para modelos lineares.

A comparação entre modelos foi feita através dos coeficientes de alienação ou de não-determinação $\left(1-R^{2}\right)$ de 
cada um, estimados pelo quociente entre as somas de quadrados dos desvios ou da interação, conforme o caso e as somas de qua drádos totais, exclúíndo-se em ambas os casos, o efeito da dia geral.

Para cada conjunto de anälises semelhantes, foi determinado ainda, um coeficiente de alienação conjunto ou me dio. Tal valor foi calculado através da transformação dos valo res de $R$ para $Z$, pela förmula $Z=1,15129 \log \frac{1}{1} \pm \frac{R}{R}$, fazendo se a média ponderada dos valores transformados $Z_{i}$, através da fórmúla $\bar{Z} .=\frac{\sum\left(n_{i}-3\right) Z_{i}}{\sum\left(n_{i}-3\right)}$, sendo $n_{i}$. número de dados da ana $\because=$ lise i. Com o valor $\bar{z}$, calculou-se o $\left(1=R^{2}\right)$ correspondente fazendo-se $R^{2}=\left[\left(e^{2 Z}-1\right) /\left(e^{2 z} \cdot+1\right)\right]^{2}$, sendo $e$ a base dos logaritmös neperianos (STEEL e TORRIE, 1960).

Alēm das análíses considerando-se todos os . 10 cais com tratamentos comuns, dentro de cada ano, foram realiza das anälises mais detalhadas tomando-se todas as combinações

Milho e Ensaios Nacionais de Variedades de Feijão. Tal anāli se foi feita com a finalidade de se verificar a possível apli cabilidade do frodelo não-linear a estudos de aglomeração....de locaiś em regiões homogêneas, no que diz respeito à interação de genótipos com ambientes. Para cada combinação de locais fo ramideterminadas as somas de quadrados devidas aos desvios. do modelo não-linear e da iñteraçãọ de genótipos com locais do modelo linear. Esta ôltima foi dividida ainda, em suas partes devidas à diferença de variância dos materiajs genēti cos ....en 
tre os dois locais e a falta de correlação do:comportamento dos träamentos, de um para outro local. Esta partição foi feita através da fórmula apresentada por ROBERTSON (1959), devidamen te adaptada para somas de quadrados, como a seguir:

$$
\sqrt{ } S Q_{T, j} \cdot S Q_{T j}\left(1-r_{j j !}\right) \cdot \ldots N \text { Nes }
$$

ta fórmula, $S Q_{T . j}$ e $S Q_{T} j^{1}$, representam, respectivamente so mas de quadrados de tratamentos nos locais $j e j^{\prime} e r_{j} j^{\prime} \quad$ re presénta a coorrelação genētica existente entre as mēdias ... dos tratamentos entre os locais j e j': Simplificadamente esta fór mula pode ser expressa como $S_{T L}=A+B, \operatorname{com} A$ e B correspon do membro da equaçao.

A possível utilização da soma de quadrados dos desvios do modelo não-linear como parâmetro medidor da simila ridade de locais para fins de zoneamento ecológico foi verifi cada, comparando-se esta estatística com a soma de quadrados da interação do modelo linear " e sua componente devida à falta de correlação entre as médias de tratamentos nos locais, isto e, a componente B da fórmula de ROBERTSON (1959). Esta compara ção foi feita atravēs do coefici ęnte de correlação de Spearman, calculado por $r=1-(n-1) n(n+1)$ ' testävel contra zero por $t=r_{s} /(n-2) /\left(1-r_{s}^{2}\right), \operatorname{com}(n-2)$ graus de 1 iberdade (STEEL e TORRIE, 1960).

As análises estatísticas dos dados com diferen tes modelos, foram feitas em computador IBM - 1130, do Departa mento de Matemática e Estatística da Escola Superior de Agri 
29.

cultura Luiz de Queiroz da USP. 


\section{RESULTADOS E DISCUSSAOO}

\subsection{Considerações teōricàs}

\subsubsection{Efeito da mudança de ambientes sobre caracteres compostos}

A ação não-aditiva dos efeitos ambientais sobre os valores genotipicos pode ocorrer de diferentes formas. Em primeiro lugar, a mudança de um ou mais fatores do ambiente po de afetar de forma não-aditiva, o gene em sua ação bāsica, ou seja a sintese de proteinas. Assim por exemplo, uma variação na temperatura ambiental, poderia afetar a velocidade de uma rea ção enzimática ou a quantidade de produto formada, diferencial mente para diferentes genótipos no loco formador da enzima em questão. Em se tratandọ de caracteres com expressão final, tal qual a maioria dos caracteres de importáncia para o melhoramen to de plantas, a ação ñão-aditiva dos efeitos ambientais sobre os genótipos, pode acontecer devido a outros fatores, além da ação primāria sobre o produto gênico. Seria, por exemplo, o ca 
so de interações gênicas não-alēlicas diferenciais para ambien tes diversos.

Muitos dos caracteres de importância econômica, em plantas, entre os quais a produção de grãos, podem em geral, ser decompostos em componentes, que se multiplicam para formar - caráter final. Dados simulados, considerando caracteres com dois e três componentes, mostram que, mesmo se cada componente se comportar de forma idealmente aditiva em dois ambientes, a anālise do caráter composto mostra a existência de uma intera ção de genōtipos com ambientes e que parte considerável desta interação pode ser removida atravēs da análise com o modelo de VENCOVSKY e GERALDI (1977), que considera multiplicativo o efe i to dos ambientes sobre os genótipos. A Tabela 3 mostra dados si mulados de 5 genōtipos repetidos em 2 ambientes para os caracte res $X, Y, Z$ e $W$, sendo $W=X Y Z$. A análise da variância, atravēs do modelo linear usual, - mostrapara os caracteres $X, Y$ e $Z$, uma soma de quadrados nula para a interação de genótipos com ambi entes. Para o caráter composto $W$, pode ser detectada uma soma de quadrados para a interação de genōtipos com ambientes de 325,2. 0 tratamento deste mesmo carāter com o modelo não-linear de VENCOVSKY e GERALDI (1977) mostra uma soma de quadrados para os desvios do modelo de 33,6 , o que corresponde a apenas da interação calculado:com o modeló linear de añàise. 
Tabela 3. Valores simulados dos caracteres $X, Y, Z$ e W, para 5 genōtipos em 2 ambientes

\begin{tabular}{|c|c|c|c|c|c|c|c|c|}
\hline \multirow{3}{*}{ Genōtipos } & \multicolumn{8}{|c|}{ Ambientes } \\
\hline & \multicolumn{4}{|c|}{1} & \multicolumn{4}{|c|}{2} \\
\hline & $x$ & $Y$ & Z & $W$ & $x$ & $Y$ & Z & $W$ \\
\hline 1 & 15 & 6 & 0,8 & 72,0 & 19 & 8 & 0,9 & 136,8 \\
\hline 2 & 13 & 5 & 0,5 & 32,5 & 17 & 7 & 0,6 & 71,4 \\
\hline 3 & 18 & 6 & 0,7 & 75,6 & 22 & 8 & 0,8 & 140,8 \\
\hline 4 & 14 & 8 & 0,6 & 67,2 & 18 & 10 & 0,7 & 126,0 \\
\hline 5 & 16 & 7 & 0,8 & 89,6 & 20 & 9 & 0,9 & 162,0 \\
\hline$S Q_{G A}(W)=$ & 25,2 & & line & & & & & \\
\hline$S Q_{d}(W)=$ & 33,6 & de & näo- & ear) & & & & \\
\hline
\end{tabular}

5.1.2. Variāncias e covariāncia de tratamentos em ambi entes diversos

Um aspecto de fundamental importância quando se pratica seleção para fins de melhoramento é a resposta ou ganho de seleção verificado em vārios ambientes de uma população, ten do sido a seleção praticada em ambientes particulares. A repe titividade do desempenho de materiais genéticos em diferentes ambientes pode seŕ medida pela covariância dos valores fenotí picos de um determinado caräter entre os ambiéntes considerados. Se se considera um conjunto de $N$ genótipos $(i=1,2, \ldots$, 
ensaiados nos ambientes $j$ e $j^{\prime}$, assumindo-se total aditividade dos efeitos dos ambientes sobre os genótipos, isto e, na ausen cia de interação; as variâncias dos valores de um determinado carater Y dentro de cada ambiente são iguais entre si e a cova riância destes mesmos valores entre ambientes, ou seja, $\hat{\sigma}_{Y}^{2}(j)=\dot{\sigma}^{2}{ }_{Y\left(j^{\prime}\right)}=\operatorname{cov}_{Y\left(j ; j^{\prime}\right)}$.

As variancias e covariâncias de valores fenotípicos nos ambien tes, foram consideradas utilizando-se o modelo de anälise de VENCOVSKY e GERALDI (1977), ou seja assumindo-se multiplicativí dade dos efeitos do ambiente sobre os genótipos. Desprezando-se os desvios do modelo, foram determinadas as expressoes:

$$
\begin{aligned}
& \operatorname{cov}_{Y\left(j ; j^{\prime}\right)}=\left(1+\beta_{j}\right) \quad\left(1+\beta_{j^{\prime}}\right) \ddot{\sigma}^{2}(\alpha)(1) \text {, } \\
& 2 \\
& \text { (j) }=(1+\beta .)^{2} \sigma^{2} \cdot(\alpha) \\
& \left(j^{\prime}\right)=\left(1+\beta_{j \prime}\right)^{2} \dot{\sigma}^{2}(\alpha)
\end{aligned}
$$

$\operatorname{cov}_{Y}\left(j ; j^{\prime}\right)$ covariância dos valores do caráter $Y$ nos $N$ genót pos, entre os ambientes $j$ e j';

$\begin{aligned} \sigma^{2} Y(j) \text { e } \sigma^{2}{ }^{2} Y\left(j^{\prime}\right) \quad & \text { variancias de } Y \text { dentro dos ambientes } j \text { e } j^{\prime} \\ & \text { respectivamente: }\end{aligned}$ $\alpha$ e $\beta$ efeitos genético e ambiental do modelo, respectivamen te.

Pode-se observar por estas expressaes que a cova riância entre locais, com total multiplicatividade dos efeitos dos ambientes sobre os genötipos, é igual a média geométrica das variâncias dentro de cada local. Isto equivale dizer que a correlação dos valores fenotípicos entre locais é positiva e 
igual a 1,0. Pelas fórmulas (2) e (3) pode-se observar que ocor rerá maior variância entre médias de tratamentos, nos melhores locais, isto é, quando o valor de $\beta$ for positivo. Esta e uma pos sível explicação para o fato destacado por ; BUClO ALANIS e HILL (1966) de que os melhoristas e geneticistas consideram que, em geral, quanto melhor o ambiente, maiores são as diferentes en tre genótipos. Um outro ëfeitoda ação multiplicativa dos ambi entes pode ser a correlação, muitas vezes observada, entre me dias e variâncias de tratamentos em diferente ambientes.

$$
\text { Relacionando-se as expressoes (2) e (3) pode ser }
$$

demonstrado que:

$\left.\sigma_{Y\left(j^{\prime}\right)}^{2}=\left(\frac{1+\beta}{1+\beta}\right)^{\prime}\right)^{2} \sigma^{2}(j)$

Verifica-se por esta expressao que a variância entre tratamen tos em um ambiente j' qualquer pode ser predita se se conhecem a variancia entre tratamentos, em um dado ambiente j e os efe tos ambientais $\beta_{j}$ e $\beta_{j}{ }^{\prime}$.

Em caso de ocorrência de aditividade completa dos efeitos ambientais sobre os genótipos, o ganho de seleção é - mesmo, em valor absoluto para todos os ambientes considera dos. Deste modo, em termos percentuais, o ganho de seleção será maior nos piores ambientes. Se os ambientes modificarem os valo res dos genótipos de forma multiplicativa, será constante entre ambientes o ganho de seleçãol expresso em termos percentuais. Em valor absoluto o ganho será maior, portanto, nos ambientes mais favorāveis. Se a ūltima suposição for verdadeira, a prática da 
seleção em ambientes ótimos poderá ajudar na discriminação en tre materiais, se bem que, o ganho por seleção em עm coutro am biente não seja afetado pela qualidade do ambiente sob zo qual a seleção se deu.

5:1.3. Modelo não-linear e parāmetros de estabilidade

Das metodologias disponíveis para se estudar a estabilixdade fenotípica de cultivares, as de FINLAY e WIL KINSON (1963) e EBERHART e RUSSEL (1966) são as mais comumente empregadas. Ambas se baseiam na técnica da regressão linear e

de.

VENCOVSKY e GERALDI (1977) mostraram que em ca so -de ocorrencia de multiplicatividade completa dos efeitos am biental e genético, isto é, utilizando-se o modelo não-line ar, sem desvios, o coeficiente b de EBERHART e RUSSEL

passa a ser: $b_{i}=\frac{\alpha}{\alpha}-\frac{1}{\alpha}$, estimável por $b_{i}=\frac{Y}{\bar{y}} \frac{1}{y}$. Verifica-se ai que haverá uma correlação positiva, de natureza não-genética entre as estimativas dos coeficientes de regressão $\left(b_{i}\right)$ e as médias dos genótipos $\left(\bar{\gamma}_{i}\right)$, em caso de multiplicatividade dos efeitos genéticos e ambiental. De fato, em diversos: trabalhos tem sido verificada uma correlação positiva entre taís estatís ticas (EBERHART e RUSSEL; 1966; PERKINS e JINKS; 1968; KNIGHT, 1970; KALTSIKES e LARTER, 1970; FRIPP e CATEN, 1971 ; WESTERMAN, 1971; FRIPP E CATEN, 1973).

o coeficiente de regressao calculado segundo a 
metodologia de FINLAY e WILKINSON (1963) difere daquele de EBERHART e RUSSEL (1966) apenas pọr tomar as médias de trata mentos por énsaio; em uma escala logarítimica. Em caso de uma, total multiplicatividade dos efeitos genéticos e ambiental na escala original, os dados transformados se comportarão de acor do com.um modelo li hear sem interação. Neste caso. o: coeficien, te de: regressão de FINLAY e WILKINSON (1963) será: $b_{i}=1,0$, pä ra qualquer i. A utilização da escala logarítmica é justifica da por estes autores como tendo a finalidade, exatamente, de, provocar uma maior linearidade dos efeitos principais, além de aumentar a homogeneidade das variáncias residuais.

de

EBERHART e RUSSEL (1966), que corresponde à variância dos des vios da regressão, é calculado a partir da diferença entre me dias observada e esperađa do modelo de regressãó linear, isto $\bar{e}, d_{i j}=Y_{i j}-Y_{i j}$, sendo $Y_{i j}=\bar{X}_{i}+b_{i} I_{j}$. Considerando-seo mo delo de VENCOVSKY e GERALDI (1977), desprezando-se os désvios., tem-se que: $\bar{x}_{i}=\alpha_{i} ; b_{i}=\frac{\alpha_{i}}{\alpha}$ e $I_{j}=\alpha \beta_{j}$, sendo $x_{i}$ e $b_{i}$, res pectivamente, a média do genótipo i e o coeficiente de regres são dós valores do genōtipo i em cada ambiente, sobre o índice ambiéntal l $j$, do modéló dé EBERHART e RUSSEL (1966). Déstè mo do, $Y_{i j}=\alpha_{i}\left(1+B_{j}\right)$ e $\hat{d}_{i j}=0$, para qualquer $i j$, com multipli catividade total dos efeitos do ambiente sobre os genótipos, resultando que $s^{2} \mathrm{di}=0$. Assim, todos os genōtipos são conside rados completamente estáveis quanto a este parâmetro, se os da dos se adaptarem perfeitamente ao modelo multiplicativo. 


\subsubsection{Detalhamento dos efeitos de locais e anos}

A avaliação de materiais genéticos em fase final de melhoramento, isto é, na fase de recomendação de cultivares, é feita, via de regra, através do estudo de diversos materiais em ensaios repetidos em vários locais e anos. As implicações da possível ação multiplicativa destes componentes do ambiente so bre os genōtipos nas anālises com modelos lineares comumente usados, foram determinadas através de uma ampliação do modelo de VENCOVSKY e GERALDI (1977) (Página 24).

Através do método dos quadrados mínimos foram de terminadas fórmulas de estimativas dos parâmetros do modelo, a saber:

$$
\begin{aligned}
& \hat{\alpha}_{i}=\frac{\sum_{j, k}\left[Y_{i j k}\left(1+\hat{\beta}_{j}\right)\left(1+\hat{\gamma}_{k}\right)\right]}{\sum_{j, k}\left(1+\hat{\beta}_{j}\right)^{2}\left(1+\bar{\gamma}_{k}\right)^{2}} \\
& \left(1+\widehat{B}_{j}\right)=\frac{\sum_{i, k} \gamma_{i j k} \hat{\alpha}_{i}\left(1+\hat{\gamma}_{k}\right)}{i, j \hat{\alpha}_{i}^{2}\left(1+\hat{\gamma}_{k}\right)^{2}} \\
& \left(1+\hat{\gamma}_{k}\right)=\frac{\sum_{i, j} Y_{i j k} \hat{\alpha}_{i}\left(1+\hat{\beta}_{j}\right)}{i, j \hat{\alpha}_{i}^{2}\left(1+\bar{\beta}_{j}\right)^{2}}
\end{aligned}
$$

A estimação destes parâmetros é feita ,por processo iterativo, i.sto é, de aproximações sucessivas, em' que cada aproximação ob tiida é lançada nas fórmulas dos demais parâmetros até que os va lores convirjam. As primeiras estimativas dos parâmetros podem ser obtidas por: $\hat{\alpha}_{i}=\bar{\gamma}_{i} \ldots,\left(1+\hat{\beta}_{j}\right)=\frac{\bar{Y} \cdot j \cdot{ }^{\bar{Y}} \ldots}{\text { e }}\left(1+\hat{\gamma}_{k}\right)=\frac{\bar{Y}}{\bar{Y} \ldots k}$. 
Obtiveram-se, ainda, as förmulas para obtenção das somas de quadrados devidas aos parâmetros principais e aos desvios do modelo, quais sejam:

$$
\begin{aligned}
& S Q_{\alpha, \beta, \gamma}=\sum_{i} \hat{\alpha}_{i}^{2} \sum_{j}\left(1+\hat{\beta}_{j}\right)^{2} \sum_{k}\left(1+\hat{\gamma}_{k}\right)^{2} \quad(8) \text { e, } \\
& S Q_{d}=\sum_{i, j, k} Y_{i j k}^{2}-\sum_{i}^{\sum} \hat{\alpha}_{i}^{2} \sum_{j}\left(1+\hat{\beta}_{j}\right)^{2} \sum_{k}\left(1+\hat{\gamma}_{k}\right)^{2}
\end{aligned}
$$

VENCOVSKY e GERALDI (1977) determinaram que, em caso de ser válido o modelo multiplicativo, a soma de quadra dos da interação detectada com o modelo linear de anālise, é diretamente proporcional às somas de quadrados devidas aos efei

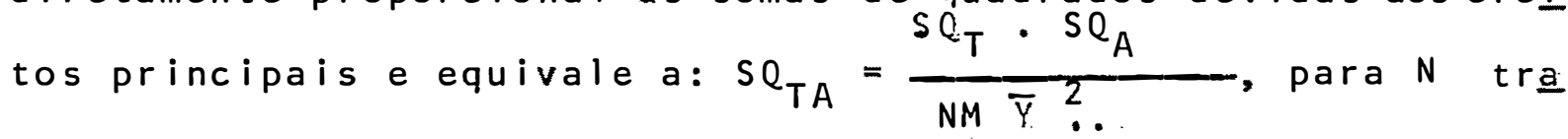
tamentos, ensaiados em $M$ ambientes. Conśsiderándo-se a análise com detalhamento dos efeitos de locais e anos, obtiveram-se as seguintes expressões para as somas de quadrados das interações duplas e tripla:

$$
S Q_{T L}=\frac{S Q \cdot S Q}{N L A \bar{Y} \cdot \ldots}
$$$$
S Q_{T A}=\frac{S_{T} \cdot S Q_{A}}{N L A \bar{Y} \ldots ?}
$$$$
S Q_{L A}=\frac{S O \cdot S Q}{N L A \bar{Y} \ldots}
$$$$
S Q_{T L A}=\frac{S O \cdot S_{L} \cdot S Q}{(N L A \bar{Y} \ldots)^{2}}
$$

(13). As expressões para qua drados mëdios são equivalentes a $(10),(11),(12)$ e (13). N, $L$ e A correspondem respectivamente aos nümeros de genötipos, lo 
cais e anos. Verifica-se por estas expressões, que em caso de ocorrência de ação multiplicativa dos efeitos de locais e ranos

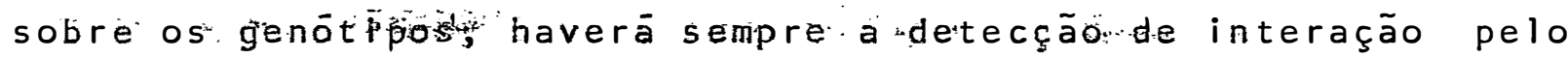
modelo linear de anälise, a menos que seja nula a soma de qua drados para o efeito principal de, pelo menos um dos fatores

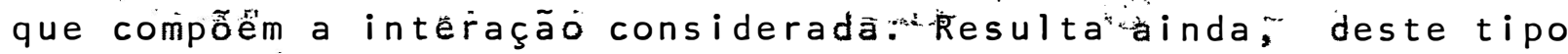
de ação, uma correlação positiva entre os efeitos da interação e os efeitos principais, isto $\bar{e}$, quanto maiores forem as dife renças entre tratamentos, locais e anos, maiores serão as so mas de quadrados detectadas para as interações entre estes fato res.

5.1.5. Relação com modelos que envolvem transformação de escala

Segundo-DRAPER e SMITH (1966), um modelo de anā lise é linear quando for do tipo $Y=\beta_{0}+\beta_{1} Z_{1}+\beta_{2} Z_{2}+\ldots$ + ${ }^{B} Z_{p}+\varepsilon$, onde $\beta_{i}$ representam parâmetros do modelo e $Z_{i}$ represen tam quaisquer funções das variáveis básicas $x_{1}, x_{2}, \ldots, x_{k}$. Qualquer modelo que não é desta forma pode ser chamado de mode lo não-linear.

Segundo aqueles autores, quando se utilizam mode lo não-lineares para explicar dados observados, surgem algumas dificuldades na anälife destes dados, principalmente no que se refere à estimação dé parâmetros e à validade de testes de hípó teses aplicados, Assim é que, na maioria dos casos, quando a varią̧ão dos dados não se adâpta satisfatoriamente a um mo 
delo do tipo linèr, sao aplicadas transformações de escala que permitam a utilização de um tal modelo.-Os modelos não- li neares podem ser classificados em dois tipos (DRAPER e SMITH, 1966). No primeiro típo estão aqueles que podem ser transforma dos em modelos lineares através de uma mudança de escala e são chamados intrinsecamente lineares. 0 segundo tipo engloba aque les modelos impośsíveis de serem transformados em outros linea res. Um modelo deste tipo é chamado intrinsecamente não-linear. No primeiro caso, a análise dos dados não apresenta maiores di ficuldades. Basta áplicar sobre os mesmos a transformação apro priada de escala e proceder à análise segundo o modelo linear resultante. E rellevante, porēm, considerar que conclusões bio lögicas diferentes podem ser tiradas se os dados são analisa dos em uma escala original ou transformada (KNIGHT, 1970), de vendo a interpretação dos resultados esta-tísticos ser feita. à luz deste fato.

Em estudosireferentes à interação de genōtipos com ambientes, em plantas, é raro o tratamento dos dados em uma escala transformada. Em caso de ocorrência de multiplicativida de dos efeitos principais, a.:transformação logarítmica é, ge ralmente, indicada (TUKEY, 1949; STEEL e TORRIE, 1960). O tra tamento estatistico dos dados em uma escala logarítmica, atra vēs do modelo linear usual, pressupõe uma multiplicatividade de todos os efeitos do modelo básico, inclusive do erro experi mental:ou interação, conforme o caso. Este fato pode ilevar a: al gumas dificuldades de interpretação dos resultados, devido à 
provāvel não-normalidade da distribuição do erro na escala ori ginal. Nisto difere o modelo de VENCOVSKY e GERALDI (1977), que é multiplicativo nos parámetros principais, considerando aditi vo o erro associado à observação. Apesar de algumas dificulda des teōricas encontradas na aplicação deste modelo, sua estr. tura simples pode tornar os parámetros mais facilmente inter pretáveis em comparação com modelos envolvendo transformação. Um modelo não-linear semelhante ao de VENCOVSKY e GERALDI (1977), isto é, multiplicativo nos parâmetros e aditivo quanto ao er ro, foi empregado por CARMER (1970) em estudos de densidades de plantio emımi..lho. De acordo com simulaģãa effetuada.por este au tor, há umá razoável aprox̉imáção da normalıidade, das dist.ribui çoes das estimativas dos parâmetros do modelo.

-. istr A principal. limitação quanto à utilização de mo delos não-lineares é, 'talvez, a impossibilidade de aplicação de testes usuais de hipótese. Apesar do conhecimento de esta

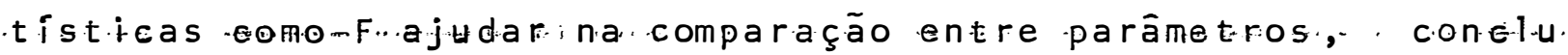
sões nao podem ser tiradas em nenhum nível de probabilidade de terminado (DRAPER e SMITH, 1966).

5.1.6. Ajuste de médias de ensaios com tratamentos co muns

E comum, quando se pretende avaliar um grande numero de materiais genétićos em ensaios de campo, a divisão dos tratamentos em mais de um ensaio, usando-se tratamentos co muns. A posterior comparação entre tratamentos não repetidos, 
é feita através de um ajuste da média dos tratamentos nos ensa ios através dos dados observados dos tratamentos padröes. A ma neira usulal decsésetuar tal ajuste é considerar um modejo a. ditivo, istoé, onde os efeitos do ambiente se somam àqueles dos genōtipos. Se, porém, a interação dos genōtipos com os am bientes onde estiverem os ensaios; for de uma grandeza signi ficativa, erros importantes podem ser incluídos com o ajuste de mēdias. Em tais casos, uma observação mais detalhada do ti po de ação que os ambientes exercem sobre os genótipos se faz necessária. Neste áspecto, nos casos onde o modelo e VEnCOVSKY e GERALDI (1977) se mostrar mais eficiente para explicar a va riação dos dados experimentais, o ajuste deverá ser feito de forma multiplicativa.

Se se consideram dois ensaios nos ambientes'j e j', com t tratamentos comuns, as médias dos demáis tratamentos do ambiente j poderão ser ajustadas através da multiplicação $t$
$\Sigma$

pelo indice $\frac{i=i \quad i j^{\prime}}{t}$, que corresponde ao quociente entre as $\sum_{i=1}^{i} i j$

médias de todos os tratamentos comuns dos ensaios $j^{\prime}$ e j, res pectivamente.

Um ajuste deste tipo, sendo feito de maneira não aditiva, influi tambēm, hos valores das variáncias, Assim, pa ra os ensaios cujos dados sofrerem ajuste, os quadrados médios da anālise da vảriancia deverão ser corrigidos multiplicando se cada valor pelo quadrado do índice util izado. Este tipo de... ajuste foi empregado por CARVALHO (1980), em estudo de predi 
ção de médias de compostos, em milho e mantém constante o coef í ciente de variação do ensaio, antes e após a correção. Quando o ajuste é feito de forma aditiva, há uma alteração no coeficien te de variação do ensaio, uma vez que se modificam os vatores das médias, mantendo-se constante o erro residual.

\subsection{Anālises de dados experimentais}

As anālises de dados experimentais foram realiza das com a finalidade de se verificar quanto da variação do com portamento de cultivares repetidas em diferentes ambientes, po de ser explicada pelo modelo que considera multiplicativa a ação dos ambientes sobre os genótipos. Assim, não se procurou avali ar cultivares ou ambientes pelo novo modelo. Foram utilizados dados experimentais envolvendo cultivares de cinco espécies cul tivadas, em diferentes locais e anos, em um total de cento e no venta e quatro ensaios.

\section{2 .1 . Soja}

Foram utilizados dados de produção de grãos de dez cultivares de soja, ensaiadas em onze localidades, por um periodo de três anos, totalizando trinta e três ensaios: As es timativas dos parâmetros genético $\left(\alpha_{i}\right)$ e ambiental $\left(1+\beta_{j}\right)$ do mo delo de VENCOVSKY e GERALDI (1977), encontram-se nas Tabelas A.1, A. 2 e A.3.

A pequena variação verificada nos valores de $\alpha_{i}$ das cultivares nos três anos, resulta da similaridade das culti 
vares para produção de grãos. De fato, todas as cultivares são ou foram recomendadas pela pesquisa para plantio pelos produto res (BONATO, 1978). Verifica-se ainda, uma razoāvel concordān cia das estimativas de $\alpha_{i}$ com a mëdia de rendimento das cultiva res em todas as localidades, isto $\bar{e}, \bar{Y}_{i}$. Com total multiplica tividade dos efeitos genētico e ambiental, estes valores deve riam ser exatamente os mesmos, ou seja, $\bar{\alpha}_{i}=\bar{y}_{i}$, conforme de monstrado por VENCOVSKY e GERALDI (1977).

os valores de $\left(l+\widehat{B}_{j}\right)$ mostraram uma variação rela tivamente maior, em comparação com a variação entre cultivares, nos três anos. No ano agrícola 1972/73, houve uma variação de 0,5370 a 1,3805 nos valores de $\left(1+\widehat{B}_{j}\right)$. Em 1973/74, a variação foi de 0,6647 a 1,2727 , menor portanto, que aquela do ano ante rior. Em 1974/75, as estimativas de $\left(1+\beta_{j}\right)$ variaram de 0,4133 a 1,2624, havendo portanto, uma maior variação percentual, em comparação com os anos anteriores.

A interpretação dos valores estimados de $\left(1+\beta_{j}\right)$ permite uma visualização bastante clara dos valores relativos dos ambientes sob estudo. Em um modelo multiplicativo, sem des vios, os efeitos ambientais podem ser estimados por $\left(1+\hat{B}_{j}\right)=$ $\bar{Y}_{\mathbf{j}_{j}} / \bar{Y}_{\ldots}$. . Tal estimativa corresponde, portanto, ao valor per centual do ambiente considerado em relação à mëdia geral. Por exemplo, uma variação nos valores de $\left(1+\widehat{B}_{j}\right)$ de 0,4133 a 1,2224 , significa que os valores ambientais variaram de 41,33 a $122,24 \%$ em relação à mëdia de todos os ambientes.

os dados comparativos das somas de quadrados dos 
desvios do modelo não-linear e das somas de quadrados da intera ção do modelo linear, encontram-se na Tabela 4. Para os dados do ano de $1972 / 73$ a soma de quadrados dos desvios do modelo não linear foi $4,7 \%$ superior à soma de quadrados da interação do mo delo usual. Nos anos posteriores, a soma de quadrados dos desvi os do primeiro modelo foi inferior àquela do segundo, sendo es ta diferença de $2,8 \%$ em $1973 / 74$ e $2,9 \%$ em 1974/75. Na média dos três anos agrícolas não houve qualquer diferença entre os dois modelos.

A. comparação numérica entre somas de quadrados só é exata quando o número de graus de liberdade das fontes de variação forem iguais. No caso de modelos não-lineares a deter minação do nümero de graus de liberdade de uma determinada fon te de variação pode apresentar certas dificuldades. Deste modo, a comparação efetuada pode não ser exata. Contudo a natureza se melhante entre os desvios do modelo não-linear em questão e a interação do modelo linear, leva a crer em uma razoável concor dância do nümero de graus de liberdade de ambos.

Uma comparação suplementar entre modelos foi efe tuada através dos valores do coeficiente de alienação $\left(1-R^{2}\right)$ de cada modelo, que corresponde à razão entre as somas de quadra dos dos desvios ou interação de cada modelo e a soma de quadra dos total. Neste caso, compararam-se àinda, os modelos linear (mo delo a) e não-linear (modelo b) com o modelo intrinsecamente li near envolvendo transformação logarítmica (modelo c). 
Tabela 4. Valores das somas de quadrados da interação do mode 10 linear (modelo a) e dos desvios do modelo não-li near (modelo b), para os dados de soja

\begin{tabular}{|c|c|c|c|c|c|}
\hline $\begin{array}{c}\text { ano } \\
\text { agrî́cola }\end{array}$ & $\begin{array}{l}\text { no de cul } \\
\text { tivares }\end{array}$ & $\begin{array}{l}\text { no de } 10 \\
\text { calj dades }\end{array}$ & $\begin{array}{l}{ }_{T L}{ }^{S} \\
\text { modelo a }\end{array}$ & $\begin{array}{l}\mathrm{SQ}_{\mathrm{d}} \\
\text { modelo b }\end{array}$ & $\mathrm{SQ}_{\mathrm{d}} / \mathrm{SO}_{\mathrm{TL}}$ \\
\hline 1972/73 & 10 & 11 & 12.955 .990 & 13.559 .919 & 1,0466 \\
\hline $1973 / 74$ & 10 & 11 & 9.824 .057 & 9.552 .708 & 0,9724 \\
\hline $1974 / 75$ & 10 & 11 & 11.646 .061 & 304.516.316 & 0,7907 \\
\hline
\end{tabular}

Tabela 5. Valores do coeficiente de alienação $\left(1-R^{2}\right)$ dos mo delos linear (modelo a), não-linear (modelo b) e in

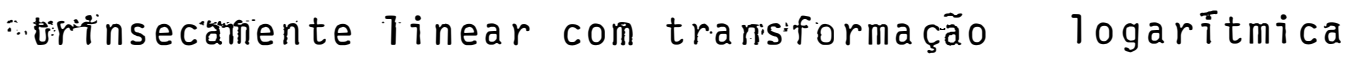
(modelo c), pará os dados de soja

\begin{tabular}{|c|c|c|c|c|c|}
\hline \multirow{2}{*}{$\begin{array}{c}\text { ano } \\
\text { agrícola }\end{array}$} & \multirow{2}{*}{$\begin{array}{l}\text { no de cul } \\
\text { tivares }\end{array}$} & \multirow{2}{*}{$\begin{array}{l}\text { no de lo } \\
\text { calidades }\end{array}$} & \multicolumn{3}{|c|}{$1-R^{2}$} \\
\hline & & & modelo a & modelo b & modelo $\mathrm{C}$ \\
\hline $1972 / 73$ & 10 & $\cdots \cdot$ & 0,1621 & 0,1696 & 0,1717 \\
\hline $1973 / 74$ & 10 & 11 & $0,2145^{\circ}$ & 0,2086 & 0,1981 \\
\hline $1974 / 75$ & 10 & 11 & 0,1335 & 0,1296 & 0,0864 \\
\hline média & & & 0,1671 & 0,1664 & 0,1440 \\
\hline$\%$ a $/$ & & & 100,0 & 99,6 & 86,2 \\
\hline
\end{tabular}

a f Valor percentual do coeficiente de alienação conjunto em re lação ao modelo linear (modelo a) 
os valores de $\left(1-R^{2}\right)$ para os diferentes mode ¿ los encontram-se na Tabela 5 .

Pode-se verificar uma grande semelhança entre os coeficientes de alienação para os diferentes modelos, dentro de cada ano. Na média dós três ános, o coeficiente de alienação pá ra o modelo näo-linear foi apenas $0,4 \%$ inferior àquele do mode lo linear, enquanto que o modelo com transformação logarítmica mostrou um coeficiente de alienação $13,8 \%$ inferior àquele do mo delo linear. A escolha entre as escalas natural e logarítmica em estúdos da interação de genōtipos com ambientes em soja, vai depender portanto, de cada sjtuação particular. Deve-se cons derar ainda, que os resultados aqui obtidos são relativos a um nümero relativamente baixo de cultivares e em uma ärea restri ta, qual seja, o estado do Rio Grande do Sul.

\subsubsection{Trigo}

Foram analisados dados de vinte e um ensaios de variedades de trigo, envolvendo vários locais em trēs anos. As estimativas dos parâmetros geriētico $\left(\alpha_{i}\right)$ e ambiental $\left(1+\beta_{j}\right)$ do modelo de VENCOVSKY e GERALDI (1977), encontram-se nas T:abelas A.4, A.5 e A.6. Verifica-se uma considerável variação nos valo res de $\left(1+\widehat{B}_{j}\right)$ nos anos de 1969 e 1970 , sendo menor esta varia ção no ano de 1971. Em alguns casos, ocorreu uma razoável dis crepáncia entre o valor de $\tilde{\alpha}$ e a média de uma mesma cultivar, mostrando um certo desajuste dos dados em relação ao modelo 
multiplicativo.

Tabela 6. Valores das somas de quadrados da interação do mode lo linear (modelo a) e dos desvios do modelo não-li near (modelo b), para os dados de trigo.

\begin{tabular}{|c|c|c|c|c|c|}
\hline ano & $\begin{array}{l}\text { no de Cul } \\
\text { tivares }\end{array}$ & $\begin{array}{l}\text { no de lo } \\
\text { cal idades }\end{array}$ & $\begin{array}{l}\mathrm{SQ}_{\mathrm{TL}} \\
\text { modelo a }\end{array}$ & $\begin{array}{l}\mathrm{SQ}_{\mathrm{d}} \\
\text { modelo b }\end{array}$ & $\mathrm{SQ}_{\mathrm{d}^{\cdot}} / \mathrm{SQ}_{\mathrm{TL}}$ \\
\hline 1969 & 16 & 7 & 5.166 .710 & 4.950 .461 & 0,9581 \\
\hline 1970 & 16 & 6 & 3.015 .632 & 2.729 .176 & 0,9050 \\
\hline $1977^{-2 x}$ & 9 & 8 & $.4 .278: 472$ & 4.451 .457 & 1,0552 \\
\hline
\end{tabular}

Na Tabela 6 encontram-se os valores das somas de quadrados dos desvios do modelo nạo-linear e das somas de quadrados da interação de genótipos com ambientes do modelo li near. o quociente entre tais valores mostra que nos anos de 1969 e 1970, o modelo não-linear explicou melhor a relação exís tente entre os efeitos genético e ambiental, nas proporções de 4,19 e 9,50\%, respectivamente. No ano de 1971 , o modelo linear foi $5,52 \%$ superior ao modelo não-linear.

$\mathrm{Na}$ comparação entre modelos através dos coefici entes de alienação, , foi envolvido a inda, -além dos modelos line ar (modelo a) e não-linear (modelo, b), o modelo intrinsecamen te linear com transformação logarítmica (modelo:c). Os valores dos - coeficientes de alienação dos três modelos encontram-se na 
Tabela 7 .

Tabela 7. Valores do coeficiente de alienação $\left(1-R^{2}\right)$ dos mode los linear (modelo a), não-linear (modelo b) e intrin secamente linear com transformação logarítmica (mode 10 c), para os dados de trigo

\begin{tabular}{lccccc}
\hline ano & $\begin{array}{c}\text { nọ de cul } \\
\text { tivares }\end{array}$ & & $\begin{array}{c}\text { no de lo } \\
\text { calidades }\end{array}$ & \multicolumn{3}{c}{$1-\mathrm{R}^{2}$} \\
\cline { 4 - 6 } & 16 & 7 & 0,1865 & 0,1787 & 0,1865 \\
1969 & 16 & 6 & 0,1060 & 0,0960 & 0,1519 \\
1970 & 9 & 8 & 0,3389 & 0,3577 & 0,3539 \\
\hline média & & 0,1810 & 0,1750 & 0,2063 \\
\hline$\%$ a. & & 100,0 & 96,7 & 114,0 \\
\hline
\end{tabular}

a/ Valor percentual do coeficiente de alienação conjunto em re lação ao modelo linear (modelo a)

No ano de 1969 os valores de $\left(1-R^{2}\right)$ foram relá tivamente baixos e muito homogêneos, mostrándo um comportamento semelhante dos modelos para explicar os dados. Em 1970, os valo res de $\left(1-R^{2}\right)$ foram, também, baixos. Houve, no entanto, uma certa inferioridade do modelo c, em relação aos modelos a e b. No ano de 1971, os valores de $\left(1-R^{2}\right)$ mostraram-se novamente homogêneos, porēm com valores maiores que nos anos anteriores. Pôde-se notar uma diferença na explicatividade dos modelos en 
tre os anos. Esta variação pode ter ocorrido devido a um efeito diferencial dos anos nos valores dos genōtipos, nos diferentes locais, ou ainda, pelo fato de o conjunto de cultivares e loca lidades não ter se mantido constante nos três anos. No conjunto dos três anos, o modelo não-linear (modelo b) foi o que apresen tou menor coeficiente de alienação, $3,3 \%$ inferior àquele do mo delo linear. Por outro lado, o modelo c apresentou um coeficien te de alienação $14,0 \%$ superior ao do modelo a.

\subsubsection{Mandioca}

Foram analisados dados de produção de ramas e de raízes de doze cultivares de mandioca ensaiadas em nove ambien tes, formados pela combinação de três localidades e três anos, por local. Os valores das estimativas dos parâmetros do modelo de VENCOVSKY e GERALDI (1977), estão apresentados nas Tabelas A. 7 e A. 8 .

Para produção de rama os valores de $\left(1+\widehat{\beta}_{j}\right)$ varia ram de 0,5625 a 1,4797, mostrando uma considerāvel diferença en tre ambientes. Para produção de raízes, a variação foi semelhan te, ou seja, de 0,4940 a 1,3735 , sendo estes valores extremos correspondentes aos mesmos ambientes que forneceram valores ex tremos de $\left(1+\hat{\beta}_{j}\right)$ para produção de rama. Também para os valores de $\bar{\alpha}_{i}$, verificou-se uma considerāvel variação entre cúltivares, tanto para produção de rama como para produção de raízes. Em am bos os casos, os valores de $\bar{\alpha}_{i}$ estão muito prōximos da média de cada cultivar nos diversos ambientes $\left(\bar{Y}_{i}\right.$, , indicando uma boa 
adaptação do modelo multiplicativo àos dados, neste aspecto.

Tabela 8. Valores das somas de quadrados da interação do modelo linear (modelo a) e dos desvios do modelo não-linear (modelo b), para os dados de mandioca

\begin{tabular}{|c|c|c|c|c|c|}
\hline carāter & $\begin{array}{l}\text { nọ de cul } \\
\text { tjuares }\end{array}$ & $\begin{array}{l}\text { no de am } \\
\text { bientes }\end{array}$ & 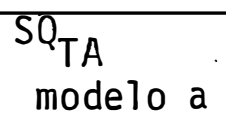 & $\begin{array}{l}\text { SQd } \\
\text { modelo b }\end{array}$ & ${ }^{S Q_{d}} / \mathrm{SQ}_{T A}$ \\
\hline produção & & & & & \\
\hline $\begin{array}{l}\text { de rama } \\
\text { produção }\end{array}$ & 12 & 9 & 1.35423 & $1.218,12$ & 0,8995 \\
\hline de raĩzes & 12 & 9 & $3.573,67$ & $3.233,30$ & 0,9048 \\
\hline
\end{tabular}

A Eabela 8 mostra os valores das somas de qua drados da interação de genótipos com ambientes do modélo linear e dos desvios do modelo não-linear. Para produção de rama, o mo delo não-linear foi $10,5 \%$ mais eficiente que o modelo linear. Pa ra produção de raízes a differença foi da ordem de $9,52 \%$, com van tagem para o modelo não-linear.

Os valores do coeficiente de alienação $\left(l-R^{2}\right)$ para os três modelos estudados encontram-se na Tabela 9. Para os dois caracteres estudados, houve grande semelhança entre mode los. Para produção de rama os valores de $\left(1-R^{2}\right)$ foram consis tentemente inferiores, comparados com os valores de $\left(1-R^{2}\right)$ pa ra produção de raízes. 
Tabela 9. Valores do coeficiente de alienação $\left(1-R^{2}\right)$ dos mode los linear (modelo a), não-linear (modelo b). e intrin secamente linear com transformação logarîtmica (mode 10 c), para os dados de mandioca

\begin{tabular}{|c|c|c|c|c|c|}
\hline \multirow{2}{*}{ carāter } & \multirow{2}{*}{$\begin{array}{l}\text { nọ de cul } \\
\text { tivares }\end{array}$} & \multirow{2}{*}{$\begin{array}{l}\text { nọ de am } \\
\text { bientes }\end{array}$} & \multicolumn{3}{|c|}{$1-R^{2}$} \\
\hline & & & $\therefore$ modelo a & modelo $b$ & modelo $\mathrm{C}$ \\
\hline \multicolumn{6}{|l|}{ Produção } \\
\hline de rama & 12 & 9 & 0,2028 & 0,1824 & 0,1870 \\
\hline Produção & & & & • & \\
\hline de raĩzes & 12 & 9 & 0,3383 & 0,3061 & 0,2829 \\
\hline
\end{tabular}

\subsubsection{Milho}

Os dados de milho analisados no presente traba lhosão originärios de várias séries de ensaios conduzidos pela Empresa Brasileira de Pesquisa Agropecuária EMBRAPA, em dife rentes locais e anos. Foram analisados, ao todo, sete conjuntos de ensaios, seis dos quais para produtividade, num total de sessenta e quatro ensaios.

A Tabela A.9 mostra os valores das estimativas de $\alpha_{i}$ e $\left(1+\beta_{j}\right)$, para altura de plantas, tomada do Ensaio Nacio nal de Milho Precoce, no ano agrícola 1976/77. Verifica-se, pe los valores pouco variáveis de $\left(\boldsymbol{i}+\hat{\beta}_{j}\right)$ que os ambientes pouco influiram na altura da planta do conjunto de cultivares. Também 
os valores de $\bar{\alpha}_{i}$ nao apresentaram grande variação e ficaram bas tante próxjmos da média de càda cultivar nos vários ambientes.

Na Tabela A.10, estão representadas as estima tivas de: $\alpha_{i}$ e $\left(1+\beta_{j}\right)$, dos dados de produção de espigas do En saio Nacional de Milho Planta Baixa, no ano agrícola 1977/78, envolvendo ensaios em nove localidades dos estados de Minas Ge rais, São Paulo, Paranā e Rio Grande do Sul. O efeito das loca 1 idades sobre os genótipos, medido pelas estimativas de $\left(1+\beta_{j}\right)$ variou de 0,6337 a 1,550.8. Entre genōtipos, foi verificada uma variação relativamente menor, como mostrado pelos "valores de $\hat{\alpha}_{i}$ e $\bar{Y}_{i .} \cdot$

As estimativas de $\alpha_{i}$ e $\left(1+\beta_{j}\right)$ para sos dádos de produção de espigas do Ensaio Nacional de Milho Opaco, nos anos agrícolas de 1974/75 e 1976/77, encontram-se :nas Tabelas A. 11 e A.12, respectivamente. No ano agrícola $1974 / 75$ os valo res de $\left(1+\hat{\beta}_{j}\right)$ variaram de 0,6023 a 1,3524 , variação esta con sideravelmente inferior àquela do ano agrícola 1976/77, ou seja, de 0,4429 a 1,6359. Com os valores de $\bar{\alpha}_{i}$ ocorreu o inverso, is to é, no ano agrícola 1974/75 a variação foi de 2,880 a 5,395 e em 1976/77 de 3,299 a 4,415. Nos dois anos, houve uma boa con cordância entre os valores de $\bar{\alpha}_{i}$ e $\bar{Y}_{i}$.

As Tabelas A.13, A.14 e A.15 mostram os valores das estimativas de $\alpha_{i}$ e $\left(1+B_{j}\right)$, para dados de produção de es pigas em milho normal, resultantes do Ensaio Nacional de Milho, nos anos agrícolas de $1974 / 7,5$ a $1976 / 77$. A variação rios valores de $\left(1+\widehat{B}_{j}\right)$ foi semelhante nos três anos, sendo de 0.5693 a 
1,5126 em 1974/75, de 0,5275 a 1,5985 em $1975 / 76$ e de 0,5743 a 1,7884 em 1976/77. Os valores de $\hat{\alpha}_{i}$ variaram pouco relativamen te, nos trēs anos, mostrando uma certa semelhança nos valores. genotípicos dos diferentes materiais genéticos. Em todos os ca sos, houve uma razoável concordáncia entre os valores de $\hat{\alpha}_{i} e a$ produção média das cultivares.

os valores das somas de quadrados da interação de genótipos com locais do modelo linear (modelo a) e dos des vios do modelo não-linear (modelo b), bem como o quociente en tre estes valores, encontram-se na Tabela lo. os valores da so ma de quadrados dos desvios do modelo não-linear foram oconsis tentemente menores que aqueles da interação do modelo linear,em todos os conjuntos de ensaios analisados. Esta diferença vari ou desde $1,33 \%$ para os dados de milho opaco de $1976 / 77$ atē $32,76 \%$ para os dados do mesmo tipo de milho no ano de $1974 / 75$.

A Tabela ll mostra os valores dos coeficientes de alienação $\left(1-R^{2}\right)$ dos modelos linear (modelo a), não-linear (modelo b) e intrinsecamente linear com transformação logarítmi ca (modeloc), para os conjuntos de ensaios de milho estudados. Para os dados de altura de planta do Ensaio Nacional de Milho Precoce de $1976 / 77$, os valores de $\left(1-R^{2}\right)$ foram semelhantes Pá ra os três modelos, mostrando o modelo não-linear o menor coef ciente. Para os dados de produção de espigas do Ensaio Nacional de Milho Planta Baixa de 1977/78, os valores de $\left(1-R^{2}\right)$ variá ram de 0,0818 para o modelob, até 0,1238 para o modelo c, fi cando o modelo a em posição intermediāria. Os dados, do . Ensaio 
Nacional de Milho Dpaco de $1974 / 75$ provocaram uma variação wnos valores de $\left(1-R^{2}\right)$ entre modelos, de 0,0788 para o mödelo b até 0,1254 para o modelo c. No ano de $1976 / 77$, houve uma menor variação nos valores de $\left(l-R^{2}\right)$, de forma que no conjunto dos dois anos, o modelo não-linear mostrou uma eficiéncia na expli cação da variação dos dados $16,9 \%$ superior ao modelo linear, sen do este ültimo $14,5 \%$ superior ao modelo que envolve transforma ção logarítmica. Tais resultados indicam que, para os dados de milho opaco analisados, $16,9 \%$ da interação captada com o modelo linear de análise pode sèr explicada pela ação multiplicativa dos efeitos dos locais sobre os genótipos e que tal multiplica tividade não é removida pelá transformação logarítmica. os dife rentes modelos, aplicados aos dados de produção de espigas do Ensaio Nacional de Milho, em trēs anos, mostraram valores dos co eficientes de alienação $\left(l-R^{2}\right)$ semelhantes aos dos ensajos com outros tipos de milho, tanto nos valores individuais, quan to na diferença absoluta entre valores de modelos diferentes. No conjunto dos très anos o modelo não-linear mostrou ser $9,8 \%$ superior ao modelo linear para explicar a variação de produção das cultivares-nos locais, indicando que $9,8 \%$ da interação de cultivares com locais detectada com o modelo linear de anälise pode ser explicada pela ação multiplicativa dos efeitos dos lo cais sobre os materiais genéticos. 0 modelo envolvendo transfor mação logarítmica mostrou um coeficiente de alienação conjunto $29,8 \%$ maior que o modelo linear, mostrando que a multiplicati vidade verificada não é remóvida com a transformação. logarítmi ca. 
Tabela 10. Valores das somas de quadrados da interação do mode 10 linear (modelo a) e dós desvios do modelo não-li near (modelo b), para os dados de milho.

\begin{tabular}{llllll}
\hline Tipo/ano & $\begin{array}{l}\text { nọ de cul } \\
\text { tivares }\end{array}$ & $\begin{array}{l}\text { no de lo } \\
\text { calidades }\end{array}$ & $\begin{array}{l}\mathrm{SQ}_{\mathrm{TL}} \\
\text { modelo a }\end{array}$ & $\begin{array}{l}\mathrm{SQ}_{\mathrm{d}} \\
\text { modelo b }\end{array}$ & $\mathrm{SQ}_{\mathrm{d}} / \mathrm{SQ}_{\mathrm{TL}}$ \\
\hline
\end{tabular}

Milho precoce $\underline{\text { al }}$

$\begin{array}{llllll}1976 / 77 & 15 & 4 & 4.349,70 & 4.114,37 & 0,9459\end{array}$

Milho planta

bàixa

$\begin{array}{llllll}1977 / 78 & 12 & 9 & 41,3353 & 36,2775 & 0,8776\end{array}$

Milho opaco

$\begin{array}{rrrrrr}1974 / 75 & 8 & 11 & 21,8203 & 14,6718 & 0,6724 \\ 1976 / 77 & 12 & 9 & 22,4571 & 22,1586 & 0,9867\end{array}$

Mi Tho normal

$\begin{array}{rrrrrr}1974 / 75 & 30 & 14 & 155,1707 & 133,9300 & 0,8631 \\ 1975 / 76 & 30 & 9 & 60,8449 & 51,1517 & 0,8407 \\ 1976 / 77 & 36 & 12 & 106,0337 & 104,0772 & 0,9815\end{array}$

a/ Dados de altura da planta em $\mathrm{cm}$. 
Tabela 11. Valores do coeficiente de alienação $\left(1-R^{2}\right)$ dos mo delos linear (modelo a), não-linear (modelo b) e in trinsecamente linear com transformação logarítmica (modelo c), para os dados de milho

Tipo/ano

nọ de cul nọ de 10

$1-R$

tivares calidades modelo a modelo b modelo $\mathrm{C}$

Milho precoce a/

1976/77

15

4

0,0730

0,0690

0,0760

Mi Tho planta

baixa

1977/78

12

9

0,0932

0,0818

0,1238

Milho opaco

\begin{tabular}{lrrrrr}
$\begin{array}{l}1974 / 75 \\
1976 / 77\end{array}$ & 8 & 11 & 0,1172 & 0,0788 & 0,1254 \\
\hline média & 12 & 9 & 0,0794 & 0,0784 & 0,0962 \\
\hline$\%$ b/ & & 0,0946 & 0,0786 & 0,1083 \\
\hline
\end{tabular}

Milho normal

\begin{tabular}{llllll}
$\begin{array}{l}1974 / 75 \\
1975 / 76\end{array}$ & 30 & 14 & 0,0942 & 0,0813 & 0,1012 \\
$1976 / 77$ & 36 & 9 & 0,0781 & 0,0656 & 0,1058 \\
\hline média & 12 & 0,1069 & 0,1049 & 0,1616 \\
\hline b b/ & & 0,0946 & 0,0853 & 0,1228 \\
\hline a/ Dados de al tura da planta em cm & 100,0 & 90,2 & 129,8 \\
b/ Valor percentual em relação ao mode lo linear (modelo a) &
\end{tabular}


Ainda com respeito aos resultados da Tabela 11 , merece destaque o fato de que, na totalidade dos conjuntos de ensaios de milho analisados, o modelo não-linear (modelo b) mos trou valores do coeficiente de alienação menores que aqueles do modelo linear (modelo a) e este por sua vez, mostrou valores me nores que aqueles do modelo envolvendo transformação logaŕftmi ca (modelo c). Tais resultados indicam que o efeito multiplica tivo dos locais sobre os genótipos parece ser um fenômero gene ralizado em milho, embora uma porção relativamente pequena da interação de genótipos com locais possa ser atribuída a tal mul tiplicatividade. Por outro lado, os resultados mostram que a transformação logarítmica não foi eficaz, em nenhum caso, para remover a multiplicatividade entre os efeitos dos genótipos edas localidades.

Os resultados das análises com os dados de milho confirmam resultados obtidos por. VENCOVSKY e GERALDI (1977). Em seu trabalho foram analisados trinta pares de ensaios de milho normal, em diferentes localidades, tendo sido determinado que, em média, $18,4 \%$ da interação observada com o modelo linear foi consequência da ação multiplicativa dos ambientes sobre os genó tipos.

\subsubsection{Feijão}

Foram analisados dados de ensaios de variedades de feijão, envolvendo grande nümero de localidades, em diferen tes estados, em um período de seis anos. As estimativas dos pa 
rāmetros genético $\left(\alpha_{i}\right)$ e ambiental $\left(1+\beta_{j}\right)$ para os diversos con juntos de ensaios estäo apresentadas nas Tiabelas A.16 a A.2.1.

Mais que nas: demais culturas estudadas, os valo res de $\left(1+\hat{\beta}_{j}\right)$ variaram de forma bastante acentuada, na maio ria dos anos, mostrando uma grande influência do ambiente sobre a produção de feijão. As estimativas de $\left(1+\beta_{j}\right)$ variaram de 0,4464 a 1,4103, em 1966/67; de 0,2912 a 2,4791, em 1967/68; de 0,4633 a 1,7919, em 1968/69; de 0,4219 a 1,8704, em 1969/70; de 0,0840 a 2,2537, em 1970/71 e de 0,4466 a 1,5779, em 1971/72.Tam bém os valores de $\hat{\alpha}_{\mathbf{i}}$ mostraram uma variação acentuada, se compa rados com outras culturas; mostrando uma maior variabilidade en tre cultivares para a cultura de feijão, fruto possivelmente, do menor grau de melhoramento atingido por esta cultura. Houve ain da, uma variação considerāvel entre os valores de $\bar{\alpha}_{i}$ nos anos es tudados; o que mostra um efeito igualmente importante dos anos sobre as variedades.

A Tabela 12 mostra os valores das somas de qua drados da interação do modelo linear (modelo a) e dos desvios do modelo não-linear (modelob); além do quociente entre estes valo res. Apenas no ano de 1969/70, a soma de quadrados dos desvios do modelo não-linear foi superior à soma de quadrados da intera ção do modelo linear, sendo a diferença de $1,99 \%$. Nos outros cin co anos o modelo não-linear mostrou desvios menores que a inte ração do modelo linear, cheǵando a diferença a $39,84 \%$ no ano agrí cola $1967 / 68$. 
60.

Tabela 12. Valores das somas de quadrados da interação do mode 10 linear (modelo a) e dos desvios do modelo não-li near (modelo b), para os dados de feijão

\begin{tabular}{lcclcc}
\hline $\begin{array}{c}\text { ano } \\
\text { agrî́cola }\end{array}$ & $\begin{array}{l}\text { no de cul } \\
\text { tivares }\end{array}$ & $\begin{array}{l}\mathrm{n} \text {. de } \underline{10} \\
\text { calidades }\end{array}$ & $\begin{array}{l}\mathrm{SQ}_{\mathrm{TL}} \\
\text { modelo a }\end{array}$ & $\begin{array}{c}\mathrm{SQ}_{\mathrm{d}} \\
\text { modelo.b }\end{array}$ & $\mathrm{SQ}_{\mathrm{d}} / \mathrm{SQ}_{\mathrm{TL}}$ \\
\hline $1966 / 67$ & 10 & 8 & 1.763 .283 & 1.660 .209 & 0,9421 \\
$1967 / 68$ & 10 & 9 & 6.811 .675 & 4.098 .044 & 0,6016 \\
$1968 / 69$ & 12 & 12 & 4.321 .639 & 4.086 .592 & 0,9456 \\
$1969 / 70$ & 9 & 10 & 2.301 .505 & 2.347 .374 & 1,0199 \\
$1970 / 71$ & 9 & 9 & 3.502 .161 & 3.386 .033 & 0,9668 \\
$1971 / 72$ & 12 & 15 & 8.649 .313 & 8.078 .927 & 0,9341 \\
\hline
\end{tabular}

Na Tabela 13 estão os valores do coeficiente de alienação $\left(1-R^{2}\right.$ ) para os modelos comparados. A eficiēncia re lativa dos modelos para se adaptar aos dados sob anälise, vari ou entre os anos agrícolas considerados, não havendo, portanto, um modelo que tenha apresentado valores menores de $\left(l-R^{2}\right)$ em todos os anos. Verificou-se ainda, uma variação relativamente elevada dos valores de $\left(1-R^{2}\right)$ de um mesmo modelo entre os anos. No conjunto dos seis anos, o modelo não-linear (modelo b) mos trou um coeficiente de alienação $10,1 \%$ menor que aquele do mode lo linear (modelo a). o modelo intrinsecamente linear com trans formação logarítmica (modelo c) foi, no conjunto dos anos, 6,6\% inferior ao modelo linear. 
Tabela 13. Valores do coeficienté de alienação $\left(1-R^{2}\right)$ dos mo delos linear (modelo a), não-linear (modelo b) e in trinsecamente linear com transformação : logarítmica (modelo c), para os dados de fejjão

\begin{tabular}{|c|c|c|c|c|c|}
\hline \multirow{2}{*}{$\begin{array}{c}\text { ano } \\
\text { ag̣rī̃cola }\end{array}$} & \multirow{2}{*}{$\begin{array}{l}\text { nọ de cuI } \\
\text { tivares }\end{array}$} & \multirow{2}{*}{$\begin{array}{l}\text { nọ de } 10- \\
\text { cal idades }\end{array}$} & \multicolumn{3}{|c|}{$1-R^{2}$} \\
\hline & & & modelo a & modelo b & modelo c \\
\hline $1966 / 67$ & 10 & 8 & 0,3160 & 0,2975 & 0,2681 \\
\hline $1967 / 68$ & 10 & 9 & 0,1129 & 0,0679 & 0,0866 \\
\hline $1968 / 69$ & 12 & 12 & 0,1466 & 0,1386 & 0,1548 \\
\hline $1969 / 70$ & 9 & 10. & 0,1011 & 0,1031 & 0,1335 \\
\hline $1970 / 71$ & 9 & 9 & 0,0852 & 0,0823 & 0,1130 \\
\hline $1971 / 72$ & 12 & 15 & 0,2417 & 0,2258 & 0,2756 \\
\hline média & & & 0,1600 & 0,1438 & 0,1705 \\
\hline$\%$ a & & & 100,0 & 89,9 & 106,6 \\
\hline
\end{tabular}

a/ Valor percentual em relação ao modelo linear (modelo a)

Os resultados da Tabela 13 mostram que para os dados analisados de feijão, $10,1 \%$ da interação observada com o modelo linear de análise pode serexplicada pela ação multipli cativa dos efeitos das localidades sobre os efeitos dos genóti pos. Na média dos anos, a transformação logarítmica não foi efi ciente para remover a multiplicatividade observada. 


\subsubsection{Anālises com pares de locais}

Uma das formas de detalhaeento da interação de genótipos com ambientes é dividir a interação total de um con junto de genótipos e ambientes em suas partes devidas à contrí buição de pares de locais. Esta técnica é usada em estudos de zoneamento ecológico e foi primeiro empregado por HORNER e FREY (1957): Com a finalidade de se verificar a possivel aplicabili daee do modelo não-linear de VENCOVKSY e GERALDI (1977) a este tipo de estudo, análises envolvendo todas as combinações de lo cais dois a dois, dentro de cada ano, foram analizadas para os dados de produção de espigas do Ensaio Nacional de Milho, de três anos e dos Ensaios de Väriedades de Feijão, de seis anos.Pa ra cada par de locais foram calculados o coeficiente de correla ção das médias de tratamentos entre locais, a soma de quadrados dos desvios do modelo não-linear e a soma de quadrados da inte ração do modelo linear, além da porção desta devida à falta de correlação entre os tratamentos nos locais, isto é, a componen te B da fórmula de ROBERTSON (1959). Os valores médios destas estatísticas, dentro de cada ano, estão apresentados na Tabela 14 , para os dados de feijão e Tabela 15, para os dados de milho.

Na Tabela 14, os valores médiós do coeficiente de correlação entre médias dos tratamentos para o conjunto de pares de locais, em cada ano, mostram uma variação de 0,0942 a 0,3508 , indicando uma pequena concordância das médias dos mate riais genéticos, em locais distintos. Esta falta de concordan cia, que reflete uma boa parte da interação, como sendo do tipo 
complexa, é atestada também, pelos valores relativamente altos da componente B da förmula de ROBERTSON (1959), em comparação com a interação total. Em apenas um ano agrícola (1967/68), a componente B foi, em média, inferior a $50 \%$ da interação total. Ainda com relação aos dados de feijão, pode-se verificar que em todos os anos as médias de somas de quadrados dos desvios do modelo não-linear foram inferiores às médias das somas de qua drados da interação do modelo linear. Pode-se notar ainda, que nos anos onde a componente $B$ mostrou um menor valor relativo, - modelo não-linear fol mais eficiente para explicar a variação dos dados. Este fato se justifica pela capacidade do modelo mul tiplicativo de remover parte da interação do tipo simples,ou se ja, causada por diferenças entre variâncias devidas aos trata mentos nos diferentes locais. Asșim sendo, tanto a componente $B$ da fórmula de ROBERTSON (1959), como os desvios do modelo mul tiplicativo, são indicadores de interação do tipo complexa.

Os resultados das análisés com dados de milho es tão apresentados na Tábela 15. Quanto ą correlação média dos tra tamentos entre locais, os valores obtidos com milho mostraram tendência a serem.superiores àqueles de feijão. Mesmo as sim, há indicativo de uma baixa concordancia entre médias dos tratamen tos em locais distintos. Da interação média de tratamentos com locais, a maior parte foi devida a esta falta de correlação, o que é mostrado pelos valores percentuais da componente B, quais sejam, $80,63 \%$ em 1974/75; $90,07 \%$ em $1975 / 76$ e, $93,42 \%$ em 1976/ 77. Resultado semelhante foi obtido por Rosito (1974), jestudan 
do a interação de genōtipos com ambientes, em trigo, no Rio Gran de do Sul.

Tabela 14. Valores médios do coeficiente de correlação entre me dias de tratamentos $\left(\bar{r}_{j j^{\prime}}\right)$, soma de quadrados dos des vios do modelo não-linear $\left(S Q_{d}\right)$, soma de quadrados da interação de genōtipos com locais dómodelo line $\operatorname{ar}\left(\overline{S Q}_{T L}\right)$ e componente $B$, para os dados de feijão

\begin{tabular}{|c|c|c|c|c|c|c|}
\hline \multirow{2}{*}{$\begin{array}{c}\text { ano } \\
\text { agrīcola }\end{array}$} & \multirow{2}{*}{$\begin{array}{l}\text { nọ de pares } \\
\text { de locais } \\
\text { a/ }\end{array}$} & \multirow{2}{*}{$r_{j j^{\prime}}$} & & \multirow{2}{*}{${ }^{\mathrm{SQ}} \mathrm{TL}$} & \multicolumn{2}{|c|}{ Componente: $\quad \bar{B}-$ l } \\
\hline & & & & & valor & $\%$ \\
\hline $1966 / 67$ & 28 & 0,2923 & 196.191 & 251.998 & 182.804 & 72,57 \\
\hline $1967 / 68$ & 36 & 0,2631 & 339.051 & 851.459 & 422.648 & 49,64 \\
\hline $1968 / 69$ & 66 & 0,2705 & 316.103 & 392.876 & 130.565 & 79,05 \\
\hline $1969 / 70$ & 45 & 0,3508 & 212.579 & 255.723 & 320.494 & 86,22 \\
\hline $1970 / 71$ & 36 & 0,0942 & 307.675 & 437.770 & 271.770 & 59,80 \\
\hline $1971 / 72$ & 105 & 0,3191 & 529.968 & 617.808 & 458.422 & 74,20 \\
\hline
\end{tabular}

a/Formados pela combinação dos L locais dois a dois

b/ Obtida àtravés da förmula $B=S_{T_{j}} \cdot S Q_{T_{j}}\left(1-r_{j j^{\prime}}\right)$, em cada par de locais, sendo $\bar{B}$ a média de todos os pares de 10 cais. 
Tabela 15. Valores mēdios do coeficiente de correlação entre mé dias de tratamentos $\left(\bar{r}_{j j^{\prime}}\right)$, soma de quadrados dos des vios do modelo não-linear $\left(\overline{S Q_{d}}\right)$, soma de quadrados da interação de genōtipos com locais do modelo linear $\left(\overline{S Q}_{T L}\right)$ e componente $B$, para os dados de milho

\begin{tabular}{|c|c|c|c|c|c|c|}
\hline \multirow{2}{*}{$\begin{array}{c}\text { ano } \\
\text { agrícola }\end{array}$} & \multirow{2}{*}{$\begin{array}{l}\text { no de pa } \\
\text { res des } \\
\text { locais }\end{array}$} & \multirow{2}{*}{$\bar{r}_{j j^{\prime}}$} & \multirow{2}{*}{$\overline{S Q_{d}}$} & \multirow{2}{*}{$\overline{\mathrm{SQ}}_{\mathrm{TL}}$} & \multicolumn{2}{|c|}{ Componentes $\bar{B} \underline{b}$} \\
\hline & & & & & valor & $\%$ \\
\hline 1974/75 & 91 & 0,5384 & 10,3399 & 11,9364 & 9,6239 & 80,63 \\
\hline $1975 / 76$ & 36 & 0,4454 & 6,6760 & 7,6057 & 6,8505 & 90,07 \\
\hline $1976 / 77$ & 66 & 0,2802 & 9,3544 & 9,6395 & 9,0054 & 93,42 \\
\hline
\end{tabular}

a/ Formados pela combinação dos L locais dois a dois

b/ Obtida pela fórmula $B=S_{T_{j}} \cdot S_{T_{j^{\prime}}}\left(1-r_{j j^{\prime}}\right)$, em cada par de locais, sendo $\bar{B}$ a média de todos os pares de locais.

Nos três anos agrícolas considerados, as médias das somas de quadrados dos desvios do modelo não-linear foram, em termos absolutos, inferiores às somas dé quadrados da intera ção do modelo linear, confirmando que uma parte da interação de tratamentos com locais é devida à ação mulțiplicativa dos efe tos dos locais sobre os genótipos.

Tanto para os dados de feijão, quanto de milho, pode-se observar que, em alguns anos, quais sejam, 1967/6.8 e 1969/70, Tabela 14 e 1975/76, Tabela 15, as médiàs das somas de quadrados dos desvios do modelo não-linear foram inferiores nu 
mericamente, à componente B da fórmula de ROBERTSON (1959). Tal fato indica que a componente da interação devida à falta de cor relação entre médias dos tratamentos nos locais pode : não...ser equivalente, totalmente, à interação do tipo complexa, viisto que a multiplicatividade removida com o modelo não-linear é capaz de provocar uma interação apenas do tipo simples.

Foi realizada uma comparação complementar entre os parâmetros soma de quadrados dos desvios do modelo não-line ar, soma de quadrados da interação de genótipos com ambientes do modelo linear e componente B desta ültima, para fins de estu dos de zoneamento ecológico. Tal comparação foi feita atraves. dos coeficientes de correlaçäo de posição de sp̈earman, conside rando-se os valores individuais de cada par de locais analisa dos, dentro de cada ano agrícola.

os valores do coeficiente de correlação, de posi ção envolvendo as três grandezas consideradas, encontram-se na Tabela 16. Todos os valores de $r_{s}$ encontrados foram significat vos ao níver de $1 \%$ de probabilidade.

0s valores altamente significativos e relativa mente altos do coeficiente de correlação de posição, mostram que resultados semelhantes de ag̣lomeração de locais devem ser ob tidos se se usam as três estatísticas comparadas. Para os dados de feijão, a maior concordáncia foi encontrada entre os valores das somas de quadrados dos desvios do modelo não-linear e da componente B da fórmula de ROBERTSON (1959). A menor concordān cia se verificou entre as somas de quadrados dos desvios do mo 
delo não-linear e as somas de quadrados da interação do modelo linear, *na maioria dos anos.

Tabela 16. Valores do coeficiente de correlação de $\operatorname{Spearman}\left(r_{\mathbf{s}}\right)$, entre as estimativas da soma de quadrados dos desvi os do modelo não-linear, soma de quadrados da, intera ção de genōtipos com ambientes do modelo linear e com ponente B, para os dados de feijão e milho

cultura/ano $\frac{r}{S Q_{d} ; S Q_{T L} \ldots} \quad{S Q_{d} ; B}^{n}$

Feijão

$\begin{array}{llll}1966 / 67 & 0,7822 & 0,9475 & 0,8752 \\ 1967 / 68 & 0,6615 & 0,8875 & 0,8219 \\ 1968 / 69 & 0,7635 & 0,8688 & 0,8841 \\ 1969 / 70 & 0,7628 & 0,9057 & 0,9062 \\ 1970 / 71 & 0,6227 & 0,9024 & 0,8026 \\ 1971 / 72 & 0,8114 & 0,9311 & 0,8099\end{array}$

Milho

$\begin{array}{llll}1974 / 75 & 0,7769 & 0,8401 & 0,9205 \\ 1975 / 76 & 0,8991 & 0,9331 & 0,9822 \\ 1976 / 77 & 0,9250 & 0,9449 & 0,9770\end{array}$

Para os dados de milho, os coeficientes de corre lação de posição obtidos, foram. de um modo geral, superiores nu 
mericamente àqueles encontrados para os dados de feijão. Nos très anos analisados, a maior concordāncia se deu entre os valo res das somas de quadrados da interação do modelo linear e sua componente B. A menor concordancia verificada foi entre os valo res das somas de quadrados dos desvios do modelo não-linear e as somas de quadrados da interação do modelo linear.

As estimativas de $r_{s}$ da Tabela 16 , mostram que, apesar de uma possível utilidade do modelo não-linear, em análi ses de aglomeração de locais, os resultados não devem levar a diferenças consideráveis se comparados com os estudos de zonea mento, usualmente efetuados. 0 uso da componente da interação devida à falta de correlação entre os tratamentos nos locais, apesar de melhor considerar a parte problemática da interação (ROSITO, 1974), não deve tambēm, levar a conclusões discrepan tes, no caso das culturas de milho e feijão.

De qualquer forma, ganhos mesmo pequenos em pre cisão, em estudosos envolvendo a interação de genótipos com ambi entes, podem representar às vezes, uma importante maneira de se conseguir ganhos adicionais em programas de melhoramento e.ma iorsegurança quanto à recomendação de cultivares. isto pode jus tificar o uso de técnicas estatísticas mais elaboradas, mesmo que sejam mais trabalhosas, principalmente com o acentuado de senvolvimento, hoje verificado, dos meios de tabulação e análí se disponíveis. 
Os resultados obtidos no presente trabalho supor tam as seguintes conclusões:

a) a multiplicatividade de componentes para for maçao de uma caráter final pode induzir um efeito multiplicati vo dos. ambientes sobre. os genótipos;

b) no caso de ocorrência de total multiplicativi dade entre os efeitos genético e ambiental, os ambientes com mé dia mais elevadaipossibilititam uma:maior discriminaçãa entre ge nōtipos; em comparação com ambientes de mais baixa média;

c) a multiplicatividade dos efeitos de localida dés e anos sobre os "genótipos próvoca uma correlação positiva entre as interações duplas e tripla detectadas com o modelo li near de análise e os efeitos principais envolvidos em cada in teração;

d) o ajuste de médias de ensaios com tratamentos comuns deve ser feita de forma multiplicativa se ombiente ti ver efeito predominantemente multiplicativo sobre os gerítipos; 
e) o modelo linear de análise, o modelo não-li near de VENCOVSKY e GERALDI (1977) e o modelo envolvendo trans formação logarítmica foram similares para explicar os dados de soja, trigo e mandioca;

f) o modelo não-linear de VEncovsky :e GERALDI (1977) mostrou uma tendencia a ser superior aos modelos linear e com transformação logarítmica, na explicação dos dados de ami lho e feijão, indicando a existência de efeitos multiplicativos dos ambientes sobre os genótipos, nestas culturas;

g) a falta de correlação entre médias de trata mentos em diferentes locais mostrou ser o fator mais importante na determinação da magnitude da interação de genótipos com 10 cais, para os dados de milho e feijão;

h) a porção da interação de genótipos com locais devida à multiplicatividade dos efeitos principais tendeu a ser maior nos conjuntos de locais com maior diferença entre varian cias de tratamentos de um para outro local;

i) a aglomeração de locais em regiões, se mos trou semelhante quer se use como medida da similaridade de lo cais a interação total de genótipos com ambientes, a parte des ta devida à falta de correlação entre médias de tratamentos nos locais, ou os desvios do modelo não-linear de VEnCOVSKY e GERAL DI (1977), para os dados de milho e feijão. 
ABOU-EL:FITTOUH, H. A. ; J. O. RAULINGS e P. A. MILLER, 1969. Clas sification of Environment Interactions with an Aplication to Cotton. Crop Science. Madison, 9: $135-140$.

ALLARD, R. W. e A. D. BRADSHAW, 1964. Implications of Genotype Envirommental Interactions in Applied Plant Breeding.

Science. Madison, 4:503-508.

BILBRO, J. D. e L. L. RAY, 1976. Environmental Stability and Adaptation of Several Cottón Cultivars. Crop Science.Madison, 16: $821-824$.

BARRIGA, R. H. M. P., 1980. Caracterização de Cultivares de Man dioca (Manithot esculenta, Crantz) com Relação a Produção e Estabilidade. Piracicaba, ESALQ/USP, 128 p. (Dissertação de Mestrado) 
BONATO, E. R., 1978. Estabilidade Fenotípica da Próduç̧ão de Grãos de Dez Cultivares de Soja [Glycine max (L.) Merril] nas Condições do Rio Grande do Sul. Piracicaba, ESALQ/USP, 75 P. (Dissertação de Mestrado).

BRASIL. Empresa Brasileira de Pesquisa Agropecuária, 1975a. En saio Nacional de Milho Opaco, Resultados do Ano 1974/75. Se te Lagoas, 17 P. (Mimeografado).

BRASIL. Empresa Brasileira de Pesquisa Agropecuāria. 1975b. En saio Nacjonal de Milho, Resultados do Ano Agrícola $1974 / 75$. Sete Lagoas, 42 P. (Mimeo̊grafado).

BRASIL. Empresa Brasileira de Pesquisa Agropecuária, 1976. En saio Nacional de Milho, Resultados Preliminares do Ano Agrí cola 1975/76. Sete Lagoas, $16 \mathrm{p}$. (Mimeografado).

BRASIL. Empresa Brasileira de Pesquisa Agropecuāria, 1977a. En saio Nacional de Milho Precoce, Resultados do Ano Agrícola 76/77. Sete Lagoas, 13 p. (Mimeografado).

BRASIL. Empresa Brasileira de Pesquisa Agropecuária, 1977b. En saio Nacional de Milho Opaco, Resultados do Ano Agrícola 76/ 77. Sete Lagoas, 16 p. (Mimeografado).

BRASIL. Empresa Brasileira de Pesquisa Agropecuària, 1977c. En saio Nacional de Milho, Resultados do Ano Agricola $1976 / 77$. 
Sete Lagoas, 50 p. (Mimeografado).

BRASIL:Empresa Brasileira de Pesquisa Agropecuária, 1978. Ensa io Nacional de Milho Planta Baixa, Resultados Preliminares do do Ano Agricola 1977/.78. Sete Lagoas, 9 p. (Mimeografado).

BUCIO ALANIS, L., 1966. Environmental and Genotype-Environmental Components of Variability. I. Inbreed Lines. Heredity. Edin burgh, $21: 387-397$.

BUCIO ALANIS, L. e J. HILL, 1966. Environmental an Genotype-E E vi ronmental Components of Variability. Il. Heterozygotes. He redity. Edinburgh, 21:399-405.

CAMARGO, C. E. 0., 1972. Estudo de Variedades de Trigo para. o Estado de São Paulo. Piracicaba, ESALQ/USP, 102 p. (Tese de Doutoramento).

CARMER, S. G., 1970. Number of Replications for Precise Estima tion of Optimum Plant Density and Maximum Corn Yield. Agro nomy Journal. Madison, 62:357-359.

CARVAlho, H. W. L., 1980. Predição de Mēdias de Compostos de Mi Iho (Zea mays. L.) para a Microrregião Homogénea 131 do Esta do da Bahia. Piracicaba, ESALQ/USP, 112 P. (Dissertação de Mestrado). 
COCKERHAM, C. C., 1963. Estimation of Genetic Variances. In:HAN SON, W. D. e H. F. ROBINSON, Coord. Statistical Genetics and Plant Breeding. Washington, National Academy of Science, $p$. $53-94$

COMSTOCK, R. E. 1955. Theory of Quantitative Genetics: Synthesis. Cold Spring Harbor Symposia on Quantitative Biology. New York, $\underline{20}: 93-102$.

DRAPER, N. R. e H. SMITH, 1966. Applied Regression Analysis. New York, John Wiley \& Sons, Inc. $407 \mathrm{p}$.

EBERHART, S. A. e W. A. RUSSEL, 1966. Stability Parameters for

FINLAY, K. W. e G. N. WILKINSON, 1963. The Analysis of Adapta tion. in a Plant Breeding Programme. Australian Journal of Agricultural Research. Victoria, 14:742-754.

FREEMAN, G. H. e J. M. PERKINS, 1971. Environmental and Genoty pe-Environmental Components of Variability. VIII. Relations between Genotypes Grown in Different Environments and Measu res of These Environments. Heredity. Edinburgh, 27:15-23,

FRIPP, Y. J. 1972. Genotype-Environmental Interactions in Schi zophyllum commune. 11 . Assessing the Environment. Heredity. Edinburgh, $28: 223-238$. 
FRIPP, Y. J. e C. E. CATEN, 1971. Genotype-Environmental Intera ctions in Schizophyllum commune. I. Analysis and Character. Heredity. Edinburgh, 27:393-407.

FRIPP, Y. J. e C. E. CATEN, 1973. Genotype-Environmental Intera ctions in Schizophyllum commune. III. The Relationship between Mean Expression and Sensitivity to Change in Envi ronment. Heredity. Edinburgh, $30: 34.1-3.49$.

HANSON, W. D., 1970. Genotypic Stability. Theoretical and Applied Genetics. Berlin, $\underline{40}: 226-231$.

HARDWICK, R. C. e J. T. W00D, 1972. Regression Methods "for:Study ing Genotype-Envi ronmental. Interactions. Heredity. Edinburgh, $28: 209-222$.

HORNER, T. W..e K. J. FREY, 1957. Methods for Determining Natu. ral Areas for 0at Variétal Recommendations. Agronomy Journal. Madison, $49: 313-315$

KALTSIKES, P. J. e E. N. LARTER, 1970. The Interaction of Geno type and Environment in Durum Wheat. Euphytica. Wageningen, $19: 236-242$.

KNIGHT, R., 1970. The Measurement and Interpretation of Genotype Environment Interactions. Euphytica. Wageningen, 19:225-235. 
MATHER, K., 1971. On Biometrical Genetics. Heredity. Edinburgh, $\underline{26}: 349-364$.

MIEZAN, K.; G. A. MILLIKEN e G. H. LIANG, 1979. Using Regression Coeficient as a Stability Parameter in Plant Breeding Pro grams. Theoretical and Applied Genetics. Berlin, 54:7-9.

OLIVEIRA, A. C., 1976. Comparação de Alguns Métodos de Determi nação da Estabilidade em Plantas Cultivadas. Brasilia, UNB, 64 p. (Dissertação de Mestrado).

OSBORN, J., 1975. A Multiplicative Model for the Analysis of Vi tal Statistics Rates. Applied Statistics. 24 : 75-84.

PERKINS, J. M. e J. L. JINKS, 1968. Environmental and Genotype Environmental Components of Variability. Ill. Multiple Lines and Crosses. Heredity. Edinburgh, 23:339-356.

PLAISTED, R. L. e L. C. PETERSON, 1959. Technique for Evaluating the Ability of Selections to Yield Consistently in Different Locations or Seasons. American Potato Journal. New Brunswick, $\underline{36}: 381-385$.

ROBERTSON, A., 1959. The Sampling Variance of the Genetic Corre lation Coefficient. Biometrics. Rẹleigh, 15:469-485.

RnsıTo, C., 1974. Interação Genótipos por Locais em Trigọ (Tri 
ticum aestivum L.) no Rio Grande do Sul. Piracicaba, ESALQ/ USP, 55 P. (Dissertação de Mestrado).

STEEL, G. D. R. e J. H. TORRIE, 1960. Principles and Procedures of.Statistics. New York, McGraw-Hill Book Co., Inc. 481 p.

TAI, G. C. C., 1971. Genotypic Stability Analysis and Its Appli cations to Potato Regionals Trials. Crop Science. Madison, $11: 184-190$.

TUKEY, J.:W., 1949. One Degree of Freedom for Non-additivity. Biometrics. Raleigh, $5: 232^{\circ-242 .}$

VENCOVSKY, R., 1978. Herança Quantitativa. In: PATERNIANI, E., Coord. Melhoramento e Produção do Milho no Brasil. Piracica ba, Marprint, p. 122-201.

VENCOVSKY, R. e I. 0. GERALDI, 1977. Um Modelo Multiplicativo Aplićado à Análise de Produção de Grãos. Relatōrio Científi co do Departamento de Genética e Instituto de Genética, 11 : $157-165$

WESTERMAN, J.M., 1971. Genotype-Envirinment Interaction and De velopmental Regulation in Arabidopsis thaliana. II. Inbreed Lines; Analysis. Heredity. Edinburgh, 26:93-106.

WOOD, J. T., 1976. The Use of Environmental Variables in the 
Interpretation of Genotype-Environment Interaction. Heredity. Edinburgh, 37:1-7.

WRICKE, G., 1964. Zur Berechnung der Ökovalenz bei Sommerweizen und Hafer. Z. Pflanzenzüchtung. 52:127-138. 
APENDICE 


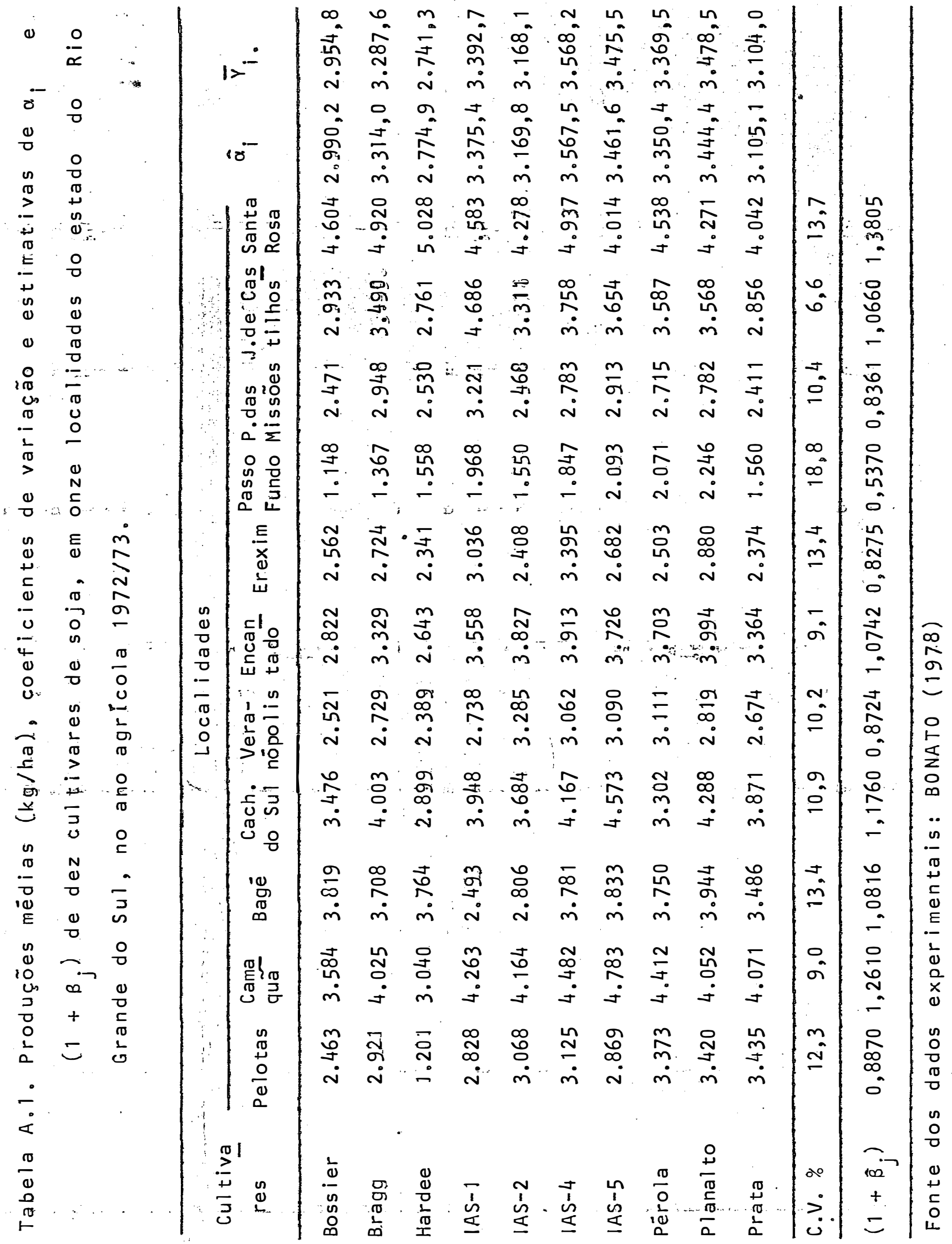




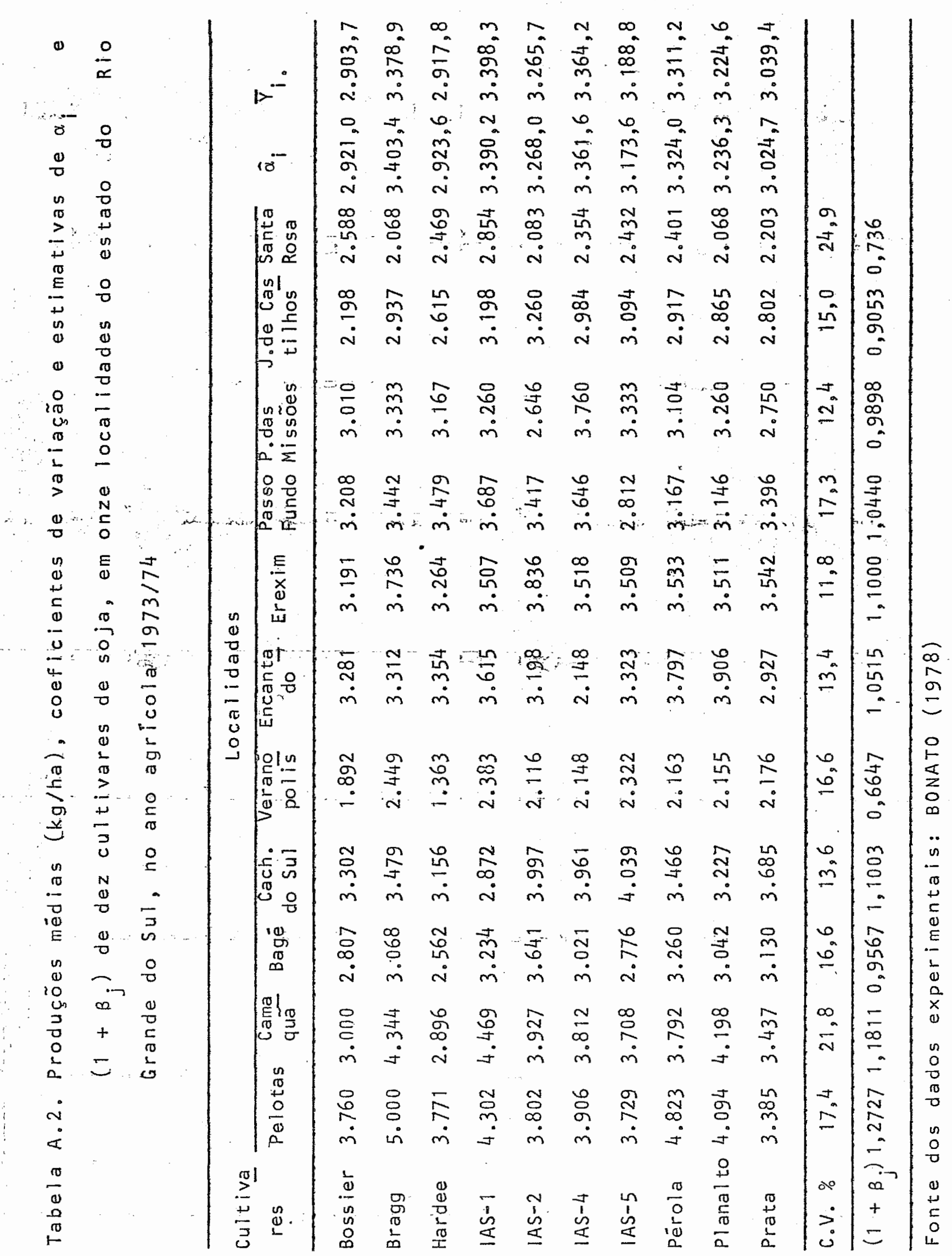




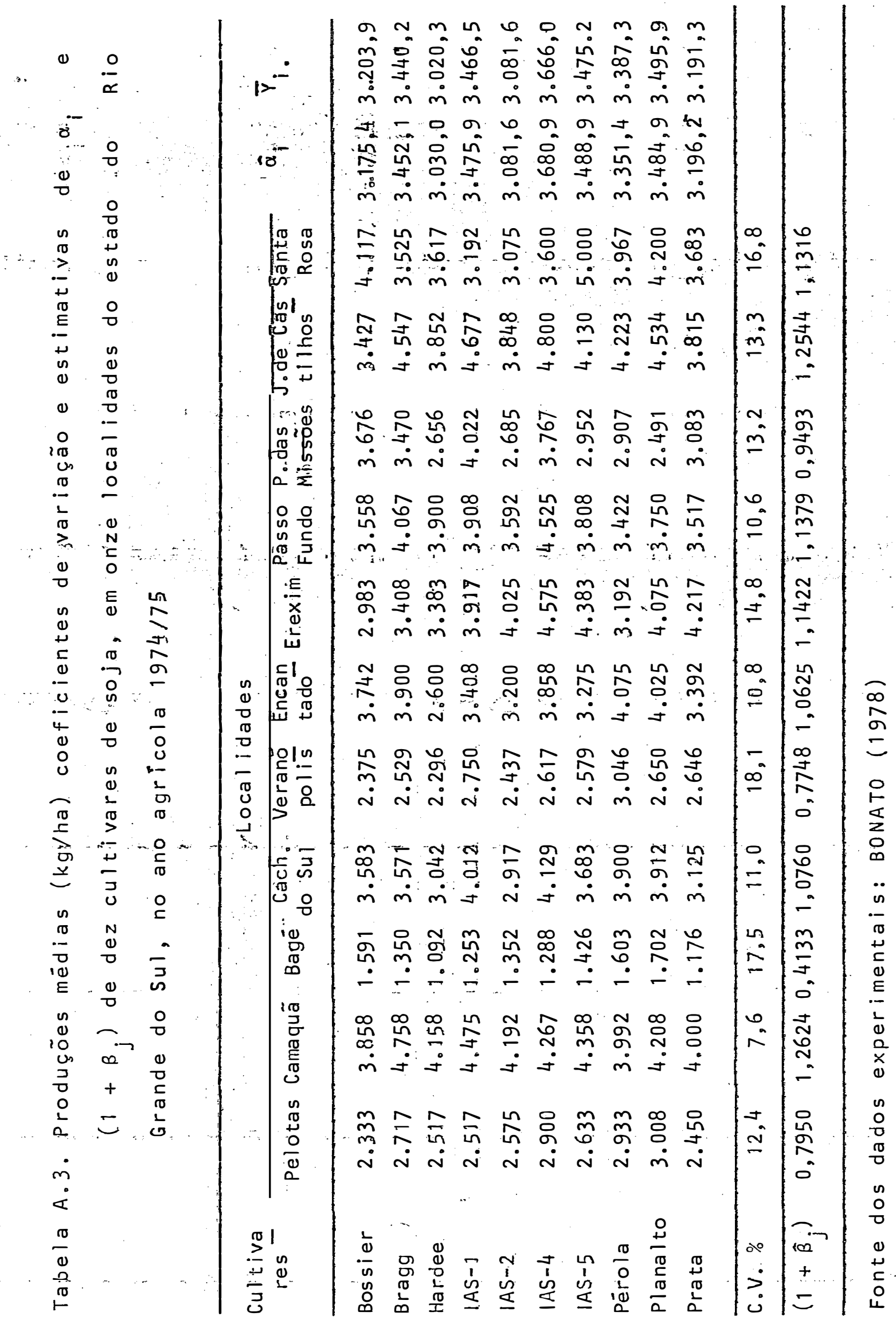


83.

TABELA A.4. Produçōes médias de grãos ( $\mathrm{kg} / \mathrm{ha}$ ) e estimativas de $\bar{\alpha}_{i}$ e $\left(1+\beta_{j}\right)$ do Ensaio Regional Paulista de Varieda des de Trigo, no ano de 1969.

\begin{tabular}{|c|c|c|c|c|c|c|c|c|}
\hline \multirow{2}{*}{$\begin{array}{c}\text { Varieda } \\
\text { des }\end{array}$} & \multicolumn{7}{|c|}{ Localidades } & \multirow{2}{*}{$\hat{\alpha}_{i}$} \\
\hline & Tieté & $\begin{array}{l}\text { C: Bo } \\
\text { nito }\end{array}$ & $\begin{array}{l}\text { Pindo } \\
\text { rama }\end{array}$ & $\begin{array}{c}\text { M.A.de } \\
\text { Sul }\end{array}$ & $\begin{array}{l}\text { Anga } \\
\text { tuba }\end{array}$ & $\begin{array}{l}\text { Parana } \\
\text { panemá }\end{array}$ & $\begin{array}{l}\text { I tape } \\
\text { va }\end{array}$ & \\
\hline
\end{tabular}

\begin{tabular}{|c|c|c|c|c|c|c|c|c|c|}
\hline $\mathrm{BH}-1146$ & 1.924 & 1.066 & 428 & 1.002 & 490 & 743 & 1.472 & $1.020,07$ & $1.017,85$ \\
\hline$v-59$ & 1.688 & 1.428 & 388 & 856 & 224 & 627 & 1.168 & 940,82 & $911 ; 29$ \\
\hline$I A S-20$ & 1.952 & 1.440 & 564 & 688 & 395 & 739 & 518 & 908,09 & 899,43 \\
\hline$s-33$ & 1.608 & 1.736 & 520 & 918 & 479 & 791 & 1.688 & $1.089,86$ & $1.105,71$ \\
\hline F. Brawley & 1.320 & 1.116 & 304 & $804^{3}$ & 20.5 & 783 & 1.268 & 832,99 & 828,57 \\
\hline Cotiporan & 1.584 & 1.426 & 396 & 1.394 & 357 & 733 & 1.260 & $1.021,87$ & $1.021,43$ \\
\hline$S-12$ & 1.916 & 1.526 & 388 & 1.280 & 303 & 471 & 1.642 & $1.117,29$ & $1.075,14$ \\
\hline$L A-1434$ & 1.260 & 1.068 & 518 & 1.258 & 278 & 682 & 960 & 835,27 & 860,57 \\
\hline Sonora-63 & 2.048 & 500 & 324 & 1.316 & 88 & 477 & 1.292 & 923,43 & 863,57 \\
\hline Anhanguera & 1.740 & 1.238 & 372 & 261 & 436 & 1.071 & 1.350 & $1.011,89$ & $1.024,00$ \\
\hline Pioneiro & 2.016 & 1.340 & 436 & 1.203 & 475 & 921 & 588 & 999,40 & 997,00 \\
\hline São Paulo & 1.140 & 1.382 & 358 & 1.354 & 481 & 70.5 & 1.004 & 883,96 & 917,71 \\
\hline Albatroz & 1.360 & 1.692 & 368 & 942 & 528 & 797 & 930 & 922,84 & 945,29 \\
\hline Brasil & 1.552 & $1.380^{\circ}$ & 140 & 1.132 & 310 & 845 & 788 & 900,76 & 878,14 \\
\hline Cacique & 1.604 & 880 & 552 & 1.0 .00 & 637 & 738 & 1.176 & 895,47 & 941,00 \\
\hline Maringā & 1.896 & 1.488 & 374 & 1.590 & 555 & 1.005 & 1.414 & $1.177,36$ & $1.188,86$ \\
\hline C.V. \% & 19,84 & 17,70 & 22,76 & 30,40 & 44,10 & 23,90 & 18,15 & & \\
\hline$\left(1+\vec{\beta}_{j}\right)$ &, 7173 &., 3373 & 4119 & 1,1415 & 0,4039 & 0,7790 & 1,2036 & & \\
\hline
\end{tabular}

Fonte dos dados experimentais: CAMARGo (1972) 
TABELA A.15. Produções mëdias de igrãos ( $\mathrm{kg} / \mathrm{ha}$ ) e estimativas de $\alpha_{i}$ e $\left(1+\beta_{j}\right)$ do Ensaio Reg.ional Paulista de Varieda des de Trigo, no ano agrícola de 1970

\begin{tabular}{|c|c|c|c|c|c|c|c|c|}
\hline \multirow{2}{*}{ Variedades } & \multicolumn{6}{|c|}{ Local idades } & \multirow{2}{*}{$\bar{\alpha}_{i} \cdots$} & \multirow{2}{*}{$\bar{Y}_{i}}$. \\
\hline & Tietê & $\begin{array}{l}\text { Pindo } \\
\text { rama }\end{array}$ & $\begin{array}{c}\text { M. A. do } \\
\text { Sul }\end{array}$ & $\begin{array}{l}\text { C. Bo } \\
\text { nito }\end{array}$ & $\begin{array}{l}\text { Parana } \\
\text { panema }\end{array}$ & $\begin{array}{l}\text { I tape } \\
\text { va }\end{array}$ & & \\
\hline$B H-1146$ & 1.088 & 276 & 1.338 & 828 & 439 & 840 & 707,40 & 801,50 \\
\hline$v-59 \cdots$ & 904 & 344 & 1.665 & 638 & 266 & 512 & 713,85 & 721,50 \\
\hline IAS - 20 & 1.432 & 246 & 1.432 & 291 & 479 & 676 & 724,84 & 759,33 \\
\hline$s-33$ & 872 & 314 & 1.863 & 421 & 339 & 596 & 754,72 & 734,17 \\
\hline F. Brawley & 944 & 190 & 1.670 & 624 & 435 & 528 & 730,93 & 743,50 \\
\hline Cotiporan & 1.020 & 282 & 2.228 & $\therefore 360$ & 273 & 400 & 846,86 & 760,50 \\
\hline$s-12$ & 818 & 164 & 2.245 & 841 & 318 & 764 & 893,83 & 858,33 \\
\hline$L A-1434$ & 632 & $224^{-}$ & $1.929^{\circ}$ & 543 & 310 & 574 & $-739,55$ & 702,00 \\
\hline Sonora-63 & 512 & 342 & 1.736 & 1.000 & 365 & 708 & 728,20 & 777,17 \\
\hline Anhanguera & 1.232 & 178 & 1.236 & 423 & 358 & 532 & 630,38 & 569,83 \\
\hline Pioneiro & 1.280 & 388 & 1.864 & 411 & 440 & 496 & 814,60 & 813,17 \\
\hline São Paulo & 1.012 & 246 & 1.600 & 93 & 342 & 506 & 666,49 & 633,17 \\
\hline Albatroz & 1.108 & 238 & 1.888 & 530 & 485 & 672 & 818,52 & 820,17 \\
\hline Brasil & 1.124 & 124 & 2.000 & 476 & 369 & 616 & 830,59 & 784,83 \\
\hline $1 R N-526-63$ & 868 & 206 & 2.064 & 606 & 266 & 732 & 828,53 & 790,33 \\
\hline Mar ingā & 1.288 & 280 & 1.665 & 808 & 392 & 848 & 822,18 & 880,17 \\
\hline C.V. & 25,50 & 37,30 & 27,14 & 29,70 & 25,60 & 23,29 & & \\
\hline$\left(1+\beta_{j}^{\prime}\right)$ & 1,3053 & 0,3262 & 2,3291 & 0,7318 & 0,4746 & 0,8128 & & \\
\hline
\end{tabular}

Fonte dos dados experimentais: CAMARGO (1972) 


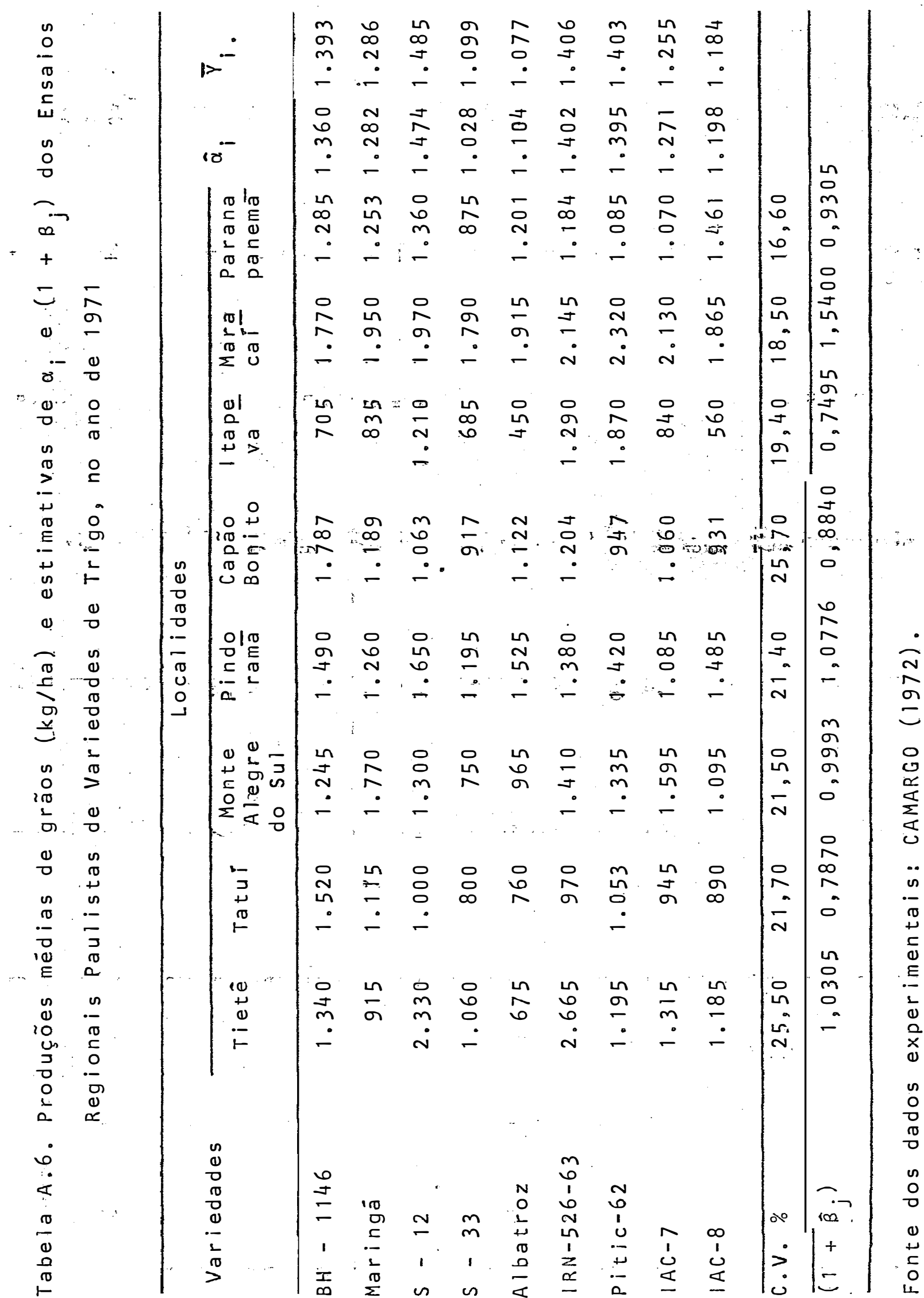




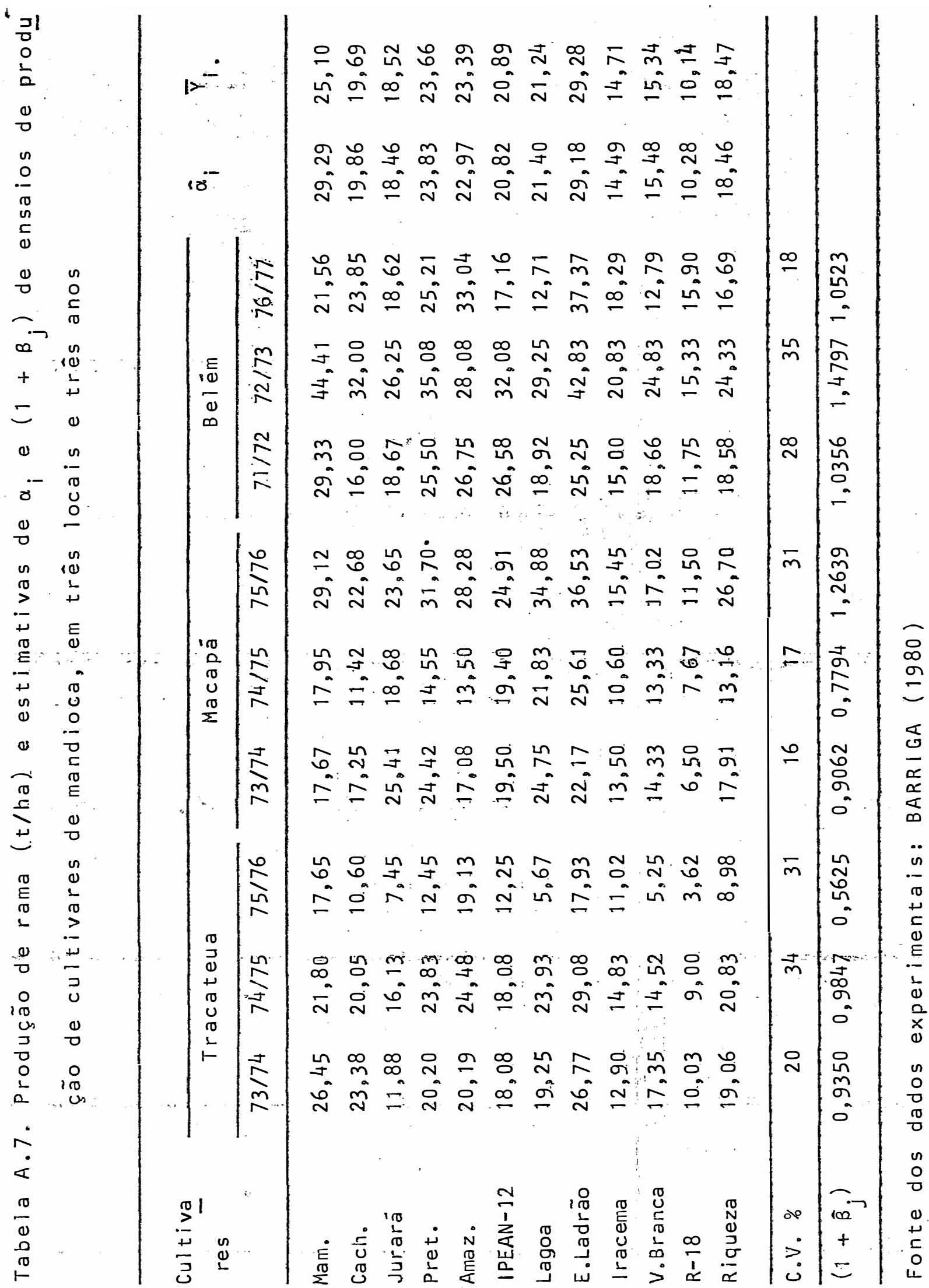




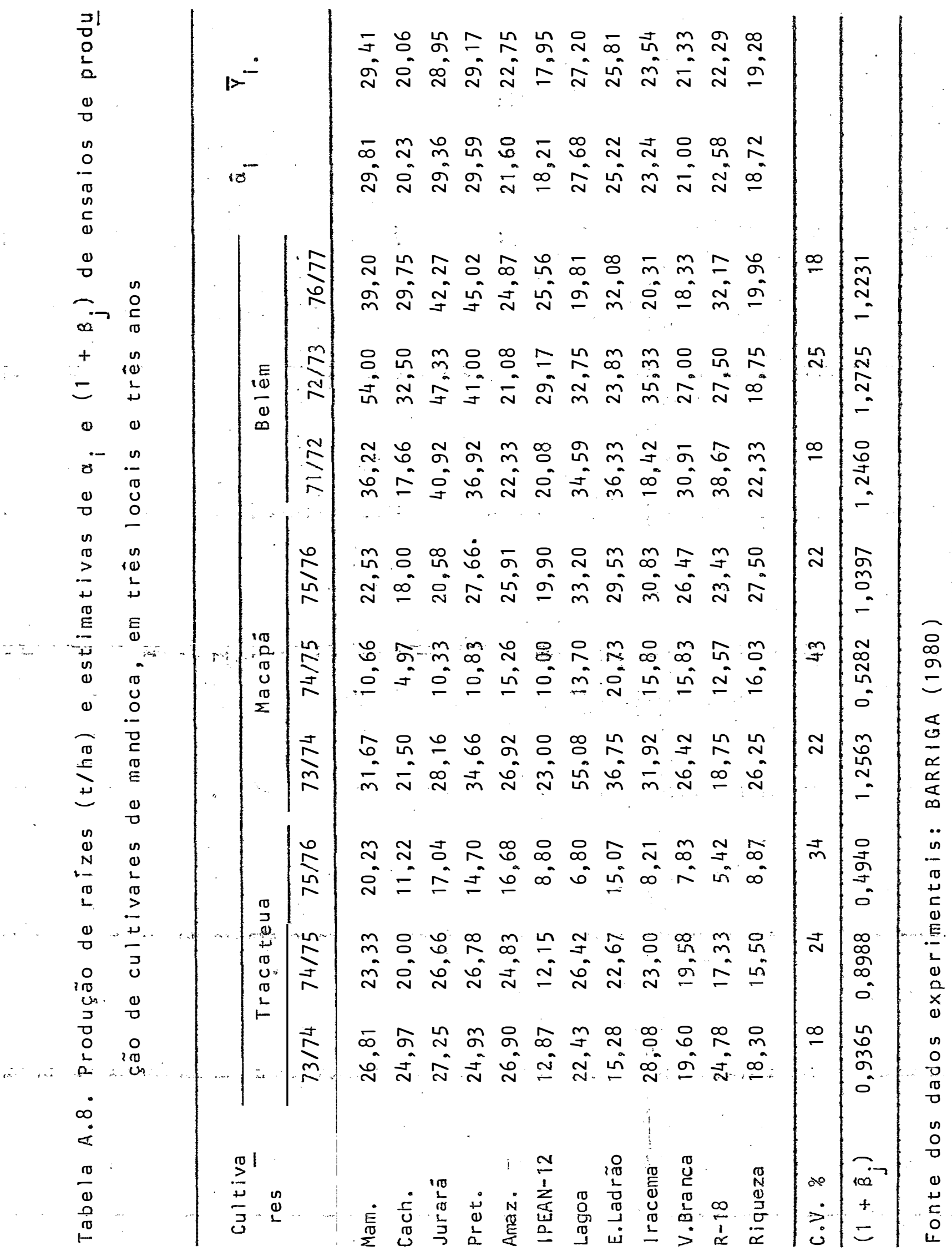


TABELA A.9. Altura da planta (cm) e estimativas de $\alpha_{i}$ e $\left(1+\beta_{j}\right)$ do Ensaio Nacional de Milho Precoce, no ano agríco la $1976 / 77$

\begin{tabular}{|c|c|c|c|c|c|c|}
\hline \multirow{2}{*}{ Cultivares } & \multicolumn{4}{|c|}{ Localidades } & \multirow[b]{2}{*}{$\bar{\alpha}_{i}$} & \multirow[b]{2}{*}{$\bar{Y}_{i}}$. \\
\hline & $\begin{array}{c}\text { Sta Cruz } \\
\text { do Sul } \\
\text { RS }\end{array}$ & $\begin{array}{c}\text { Lond } \mathrm{r} i \\
\text { na } \\
\mathrm{PR}\end{array}$ & $\begin{array}{c}\text { Chape } \\
\text { có } \\
\text { SC }\end{array}$ & $\begin{array}{c}\text { Piracica } \\
\text { ba } \\
\text { SP }\end{array}$ & & \\
\hline Pi ranão & 273 & 234 & 234 & 221 & 240,29 & 240,50 \\
\hline Comp. Planta Ba ixa & 328 & 235 & 241 & 248 & 264,20 & 263,00 \\
\hline AG 62 & 310 & 251 & 249 & 251 & 265,42 & 265,25 \\
\hline AG 64 & .308 & 266 & 251 & 267 & 272,56 & 273,00 \\
\hline AG 65 & 313 & 266 & 262 & 263 & 275,69 & 276,00 \\
\hline $515-R$ & 305 & 243 & 253 & 252 & 263,29 & 263,25 \\
\hline Sintético 10 & 3.23 & 283 & 290 & $\therefore \quad 27.0$ & 290,86 & 291,50 \\
\hline Sintētico 30 & 315 & 250 & 269 & 263 & 276,29 & 276,50 \\
\hline Sintētico 20 & 253 & 20.4 & 228 & 219 & 225,61 & 226,00 \\
\hline CMS XM 603 & 28,3 & 221 & 233 & ; 222 & 240,09 & 239,75 \\
\hline CMS XM $604^{\circ}$ & 340 & 273 & 276 & $\therefore 269$ & 289,80 & 289,50 \\
\hline Piranão - HV & 260 & 234 & 240 & 223 & 238,47 & 239,25 \\
\hline Piranão - V & 275 & 245 & 236 & 202 & 239,53 & 239,50 \\
\hline Cargill 501 & 303 & 243 & 242 & 223 & 253,37 & 252,75 \\
\hline Cargill 507 & 323 & 256 & 260 & 260 & 275,03 & 274,75 \\
\hline$\left(1+\bar{B}_{.}\right)$ & 1,1541 & 0,9494 & 0,9617 & 0,9348 & & \\
\hline
\end{tabular}

Fonte dos dados experimentais: BRASIL (1977a) 


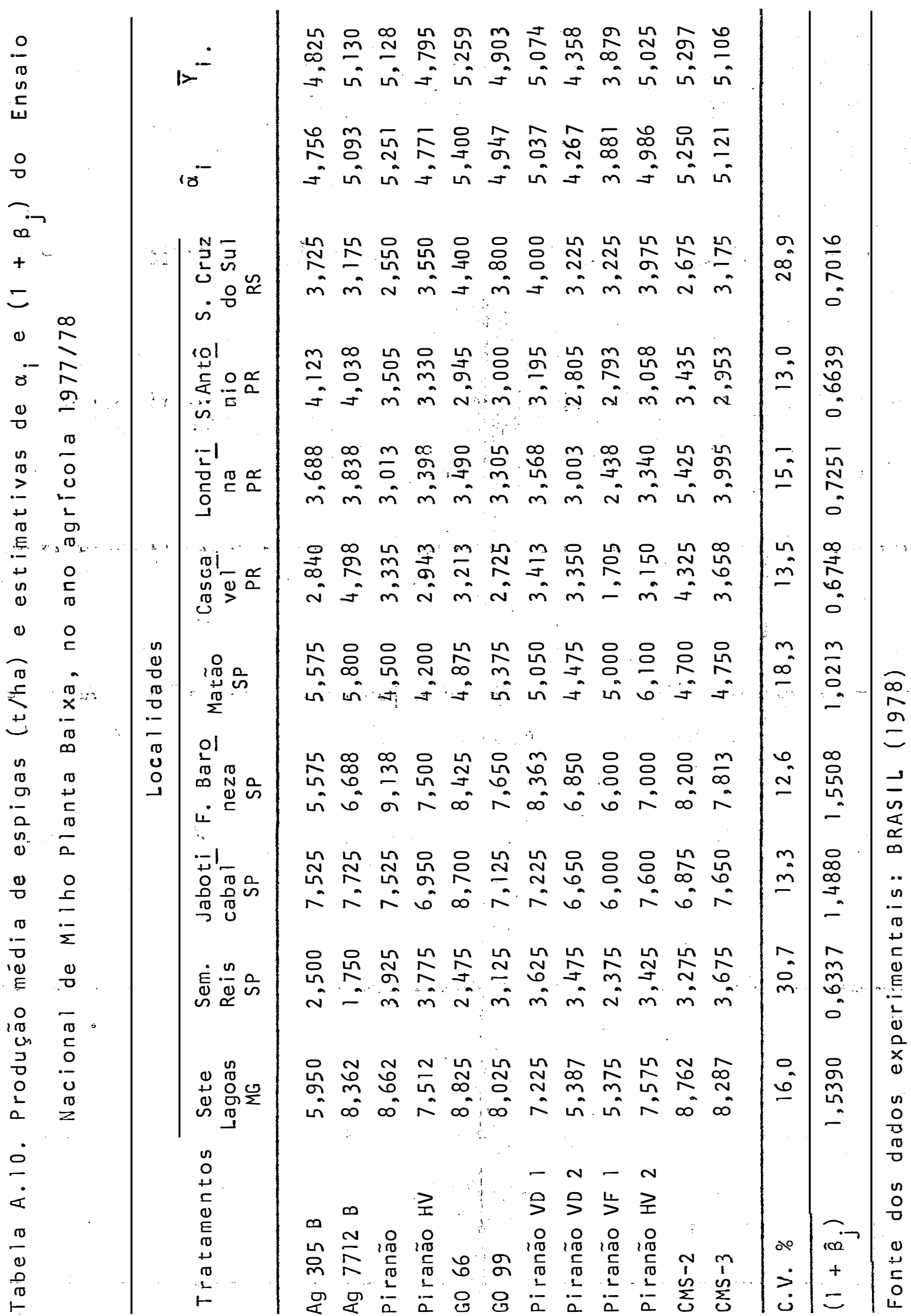




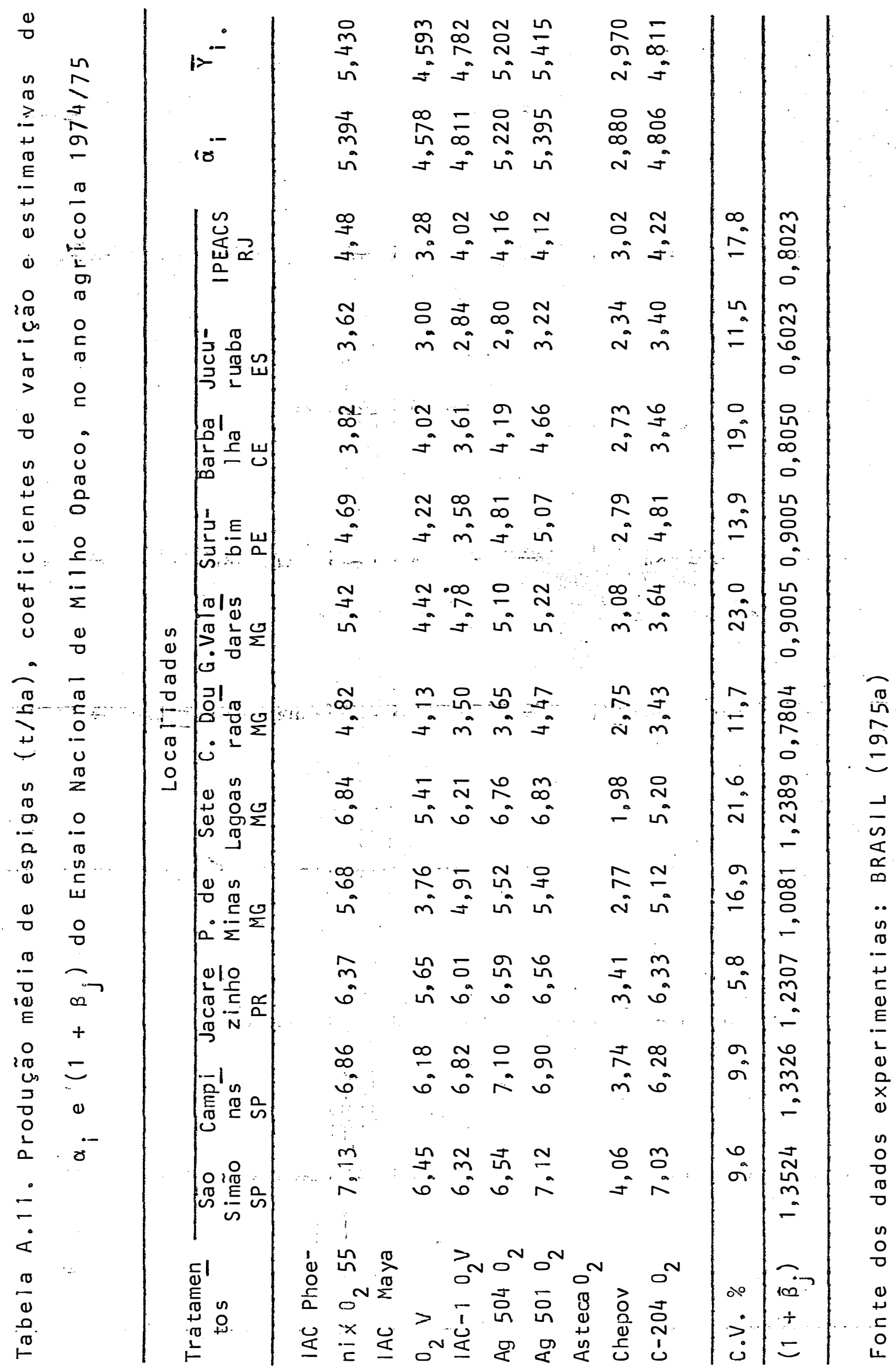




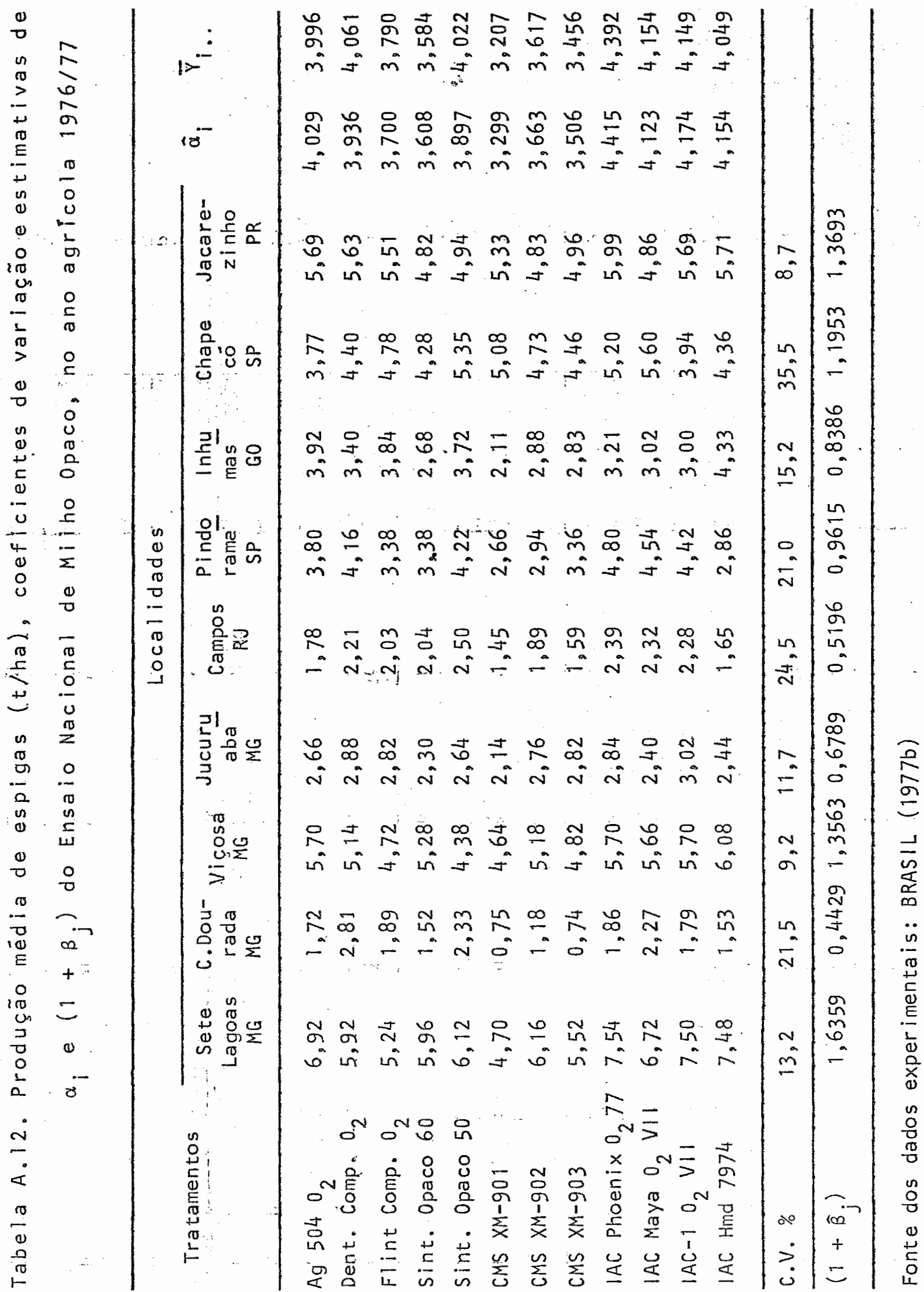




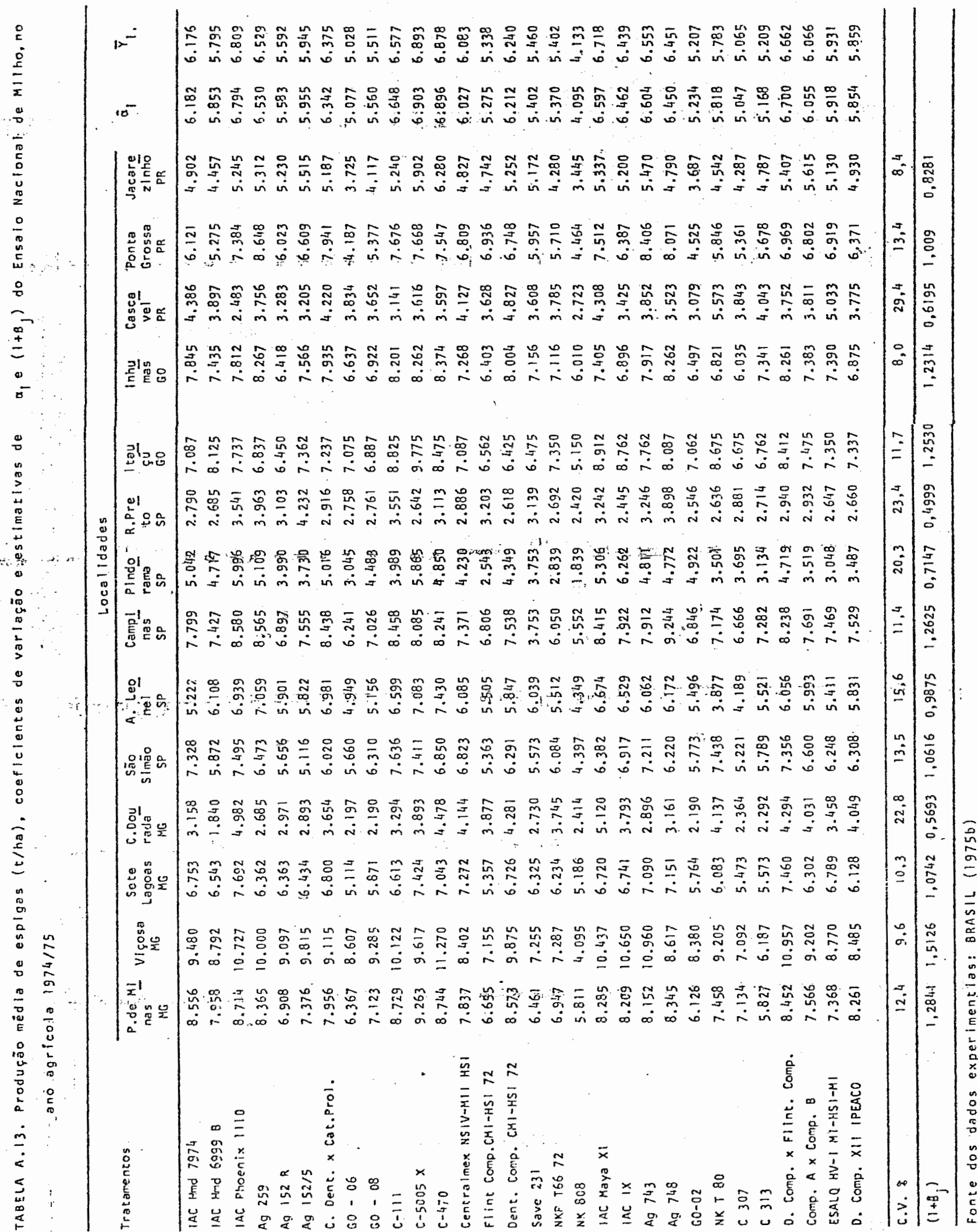


Tabela A.14. Produçāo média de espigas (t/ha), coeficientes de variaçāo e esimati vas de $a_{j}$ e $\left(1+\beta_{j}\right)$ do Ensaio Nacional de Milho, no ano agricola de $1975 / 76$

\begin{tabular}{|c|c|c|c|c|c|c|c|c|c|c|c|}
\hline \multirow{2}{*}{ Tratamenios } & \multicolumn{9}{|c|}{ Localidades } & \multirow[b]{2}{*}{$\bar{\alpha}_{i}$} & \multirow{2}{*}{$\bar{Y}_{i}$. } \\
\hline & $\begin{array}{l}\text { Inhu } \\
\text { mas } \\
60\end{array}$ & $\begin{array}{l}\text { Sete } \\
\text { Lagoas } \\
\text { MGi }\end{array}$ & $\begin{array}{l}\text { C. Dou } \\
\text { rada } \\
\text { MG }\end{array}$ & $\begin{array}{c}\text { Jacare } \\
\text { zinho } \\
\text { PR }\end{array}$ & $\begin{array}{l}\text { P.Para } \\
\text { naiba } \\
\text { MG }\end{array}$ & $\begin{array}{l}V i c ̧ o \\
\text { sa } \\
M G\end{array}$ & $\begin{array}{l}\text { Campi } \\
\text { nas } \\
\text { SP }\end{array}$ & $\begin{array}{l}\text { Andi } \\
\text { rá } \\
\text { PR }\end{array}$ & $\begin{array}{c}\text { Jardinó } \\
\text { pol is } \\
\text { SP }\end{array}$ & & \\
\hline IAC Hmd 7974 & 5,685 & 4,684 & 2,946 & 6,366 & 2,900 & 7,517 & 6,100 & 4,360 & 4,392 & 4,943 & 4,994 \\
\hline IAC Hmd 6999 B & 4,789 & 4,593 & 2,529 & 6,267 & 2,050 & 7,764 & 5,412 & 3,311 & 3,734 & 4,569 & 4,494 \\
\hline IAC Phoenix 1211 & 5,640 & 5,398 & 4,071 & 7,275 & 3,500 & 8,475 & 6,387 & 4,037 & 4,200 & 5,380 & 5,443 \\
\hline IAC Maya XII & 3,746 & 4,647 & 3,208 & 6,320 & 2,350 & 8,232 & 5,662 & 3,586 & 3,449 & 4,629 & 4,578 \\
\hline $\mathrm{Ag} 152 \mathrm{R}$ & 5,055 & 4,784 & 3,024 & 6.527 & 2,700 & 7,647 & 4,962 & 4,486 & 4,373 & 4,801 & 4,840 \\
\hline Ag $162 / 5$ & 5,981 & 4,342 & 4,384 & 7,886 & 1,950 & 8,217 & 5,500 & 4,186 & 4,040 & 5,193 & 6,165 \\
\hline Ag 259 & 5,422 & 5,066 & 3,258 & 7,113 & 2,000 & 7,584 & 5,712 & 4,087 & 4,278 & 4,961 & 4,947 \\
\hline$(-111-x$ & 6,412 & 6,074 & 3,326 & 7,583 & 1,550 & 8,557 & 6,262 & 5,288 & 5,457 & 5,633 & 5,612 \\
\hline$C-5005-M$ & 6,428 & 5,307 & 2,778 & 7,531 & 2,950 & 7,989 & 6,867 & 3,925 & 4,930 & 5,411 & 5,412 \\
\hline 6005 & 5,930 & 4,194 & 2,399 & 6,930 & 2,400 & 8,179 & 5,650 & 4,224 & 3,792 & 4,932 & 4,855 \\
\hline 6006 & 4,899 & 4,843 & 2,021 & 6,358 & 2,800 & 685 & 800 & 4.511 & 54 & 4,785 & 4,775 \\
\hline G0 08 & 2,491 & 3,496 & 1,091 & 3.866 & 2.625 & 6.330 & 4,262 & 3,136 & 2,776 & 3,359 & 3,341 \\
\hline Cent ralmex & 5,070 & 4,713 & 2,661 & 6,237 & 3,000 & $6,901^{\circ}$ & 5,012 & 3,875 & 497 & 4,509 & 4,552 \\
\hline Flint Compos to & 5,001 & 4,234 & 3,365 & 6,310 & 2,600 & 6,270 & 4,900 & 3,062 & 3,520 & 4,307 & 4,362 \\
\hline Dentado Composto & 5,010 & 4,746 & 3.248 & 5,864 & 2,750 & 7,535 & 5,350 & 4,187 & 3,656 & 4,657 & 4,705 \\
\hline Cateto colombia ENPMS & 4,772 & 3,724 & 3,809 & 6,063 & 3,100 & 6.799 & 4,600 & 3,700 & $3 ; 836$ & 4,281 & $4,4,17$ \\
\hline Save 231 & 4,982 & $.4,527$ & 2,016 & 6,058 & $2,525^{\prime}$ & 6,132 & 5,137 & 4.149 & 3,470 & 4,302 & 4,333 \\
\hline$c-408$ & 5,598 & 4,911 & 3,556 & 6.929 & 2,750 & 9,192 & 6,037 & 3,725 & 4,025 & 5,242 & 5,191 \\
\hline HV-Gen 10 & 5,605 & 4,552 & 2,855 & 6,895 & 2,625 & 8,310 & 5,237 & 4,126 & $4,4,76$ & 4,991 & 4,965 \\
\hline 6002 & 5,236 & 4,190 & 2,791 & 6,412 & 3,250 & 8,237 & 5,562 & 3,928 & 4,075 & 4,852 & 4,853 \\
\hline 6010 & 5,949 & $5,455^{\circ}$ & $2 ; 380$ & $7: 068$ & $\cdot 2,950$ & 7,600 & 5,737 & 4,786 & 4,158 & 5,100 & 5,120 \\
\hline Ag $169 \mathrm{R}$ & 5,475 & 5,183 & 2,755 & 7,161 & 2,475 & 8,020 & 4,975 & 3,748 & 4,029 & 4,916 & 4,869 \\
\hline Ag $152 / 5$ & 5,572 & 5,104 & 4,668 & 7.332 & 2,550 & 8,017 & 5,425 & 4,799 & 4,309 & 5,228 & 5,307 \\
\hline ESAL HV I K $\|$ & 5,185 & 4,200 & 3.665 & 6,050 & 2,250 & 6,366 & 5,137 & 3,150 & 3,388 & 4,327 & $4_{i}, 377$ \\
\hline HD Exper. CisPMS & 4,155 & 4,583 & 2,303 & 5,920 & 2,475 & 6,537 & 4,112 & 4,249 & 3,097 & 4,138 & 4,159 \\
\hline$[-111$ & 5,743 & $4 ; 707$ & 2.761 & 7,192 & 2,800 & 8,073 & 5.662 & $.4,625$ & 4,956 & 5,158 & 5,169 \\
\hline$c-315$ & 5,709 & 4,644 & 3.908 & 7,552 & 2.150 & 9,018 & 6,075 & 4,350 & 5,253 & 5,437 & 5,407 \\
\hline$c-5005-x$ & 6,106 & 6,061 & $3.35 i$ & 7.691 & 2.300 & 9,966 & 5,825 & 3,925 & 3,907 & 5,587 & 5,459 \\
\hline$|A C-1 \times|$ & 4,524 & 4,352 & 2.728 & 6,654 & 2,800 & 7,577 & 5,575 & 3,652 & 4,286 & 4,686 & 4,683 \\
\hline Dent. Comp. VIII CNPMS & 5,313 & 4,327 & 2.703 & 6,509 & 2,250 & $7,6,34$ & 5,237 & 3,826 & 3,684 & 4,662 & 4,616 \\
\hline C.v. 2 & 8,5 & 12,3 & 19,4 & 7,1 & 36,1 & 8,4 & 12,1 & 19,0 & 16,4 & & \\
\hline$\left(1+\bar{\beta}_{j}\right)$ & & & 6266 & & & & 1,1311 & & 年 & & \\
\hline
\end{tabular}

Cónte dos dados cxperimentals: BRASIL (1976) 


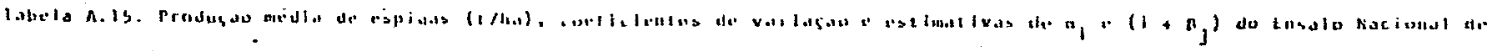
Mllive no anu aciliculs $1976 / 71$

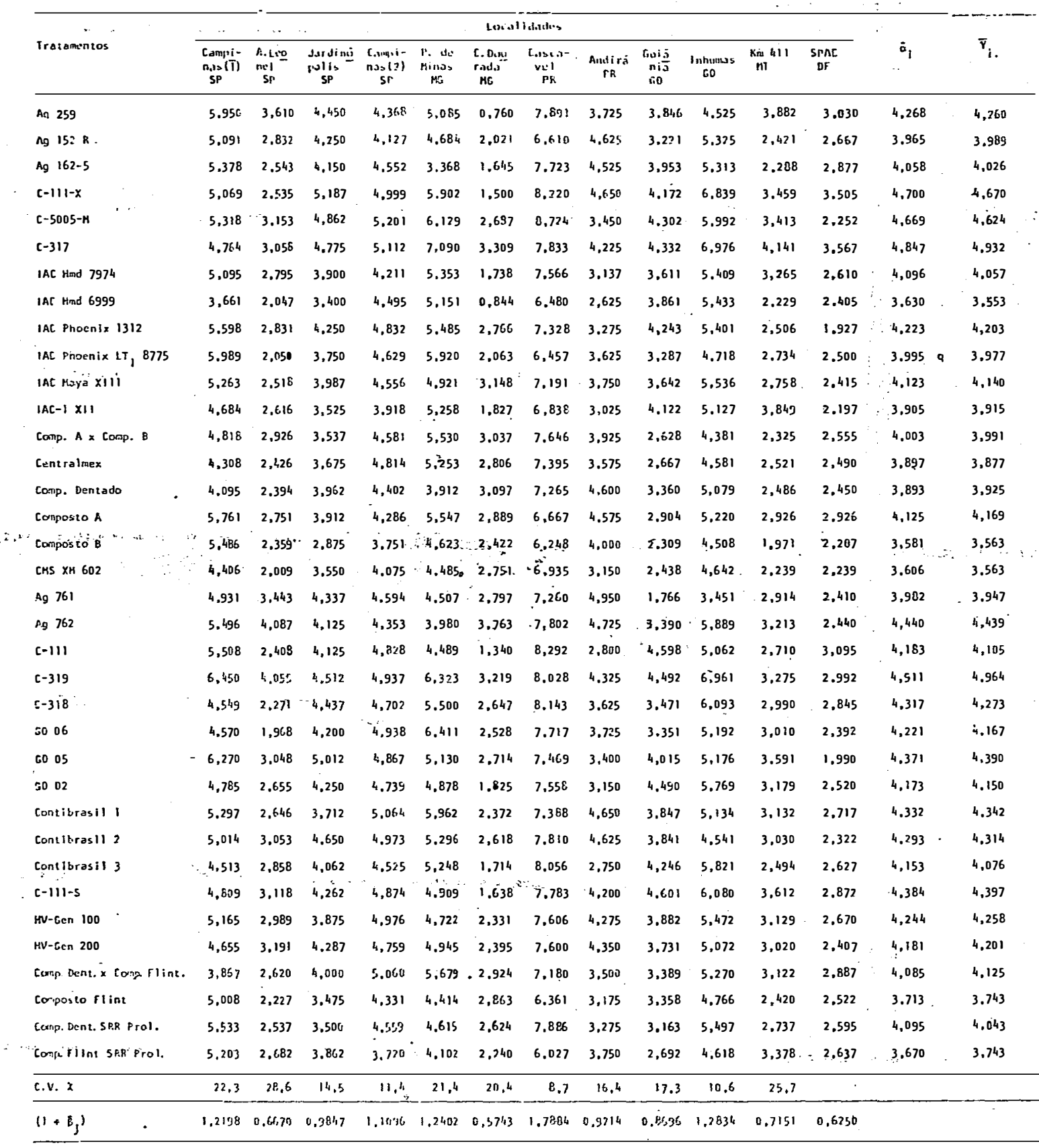

Fonte sos dodos experinicniabs: BHastl $(19776)$ 


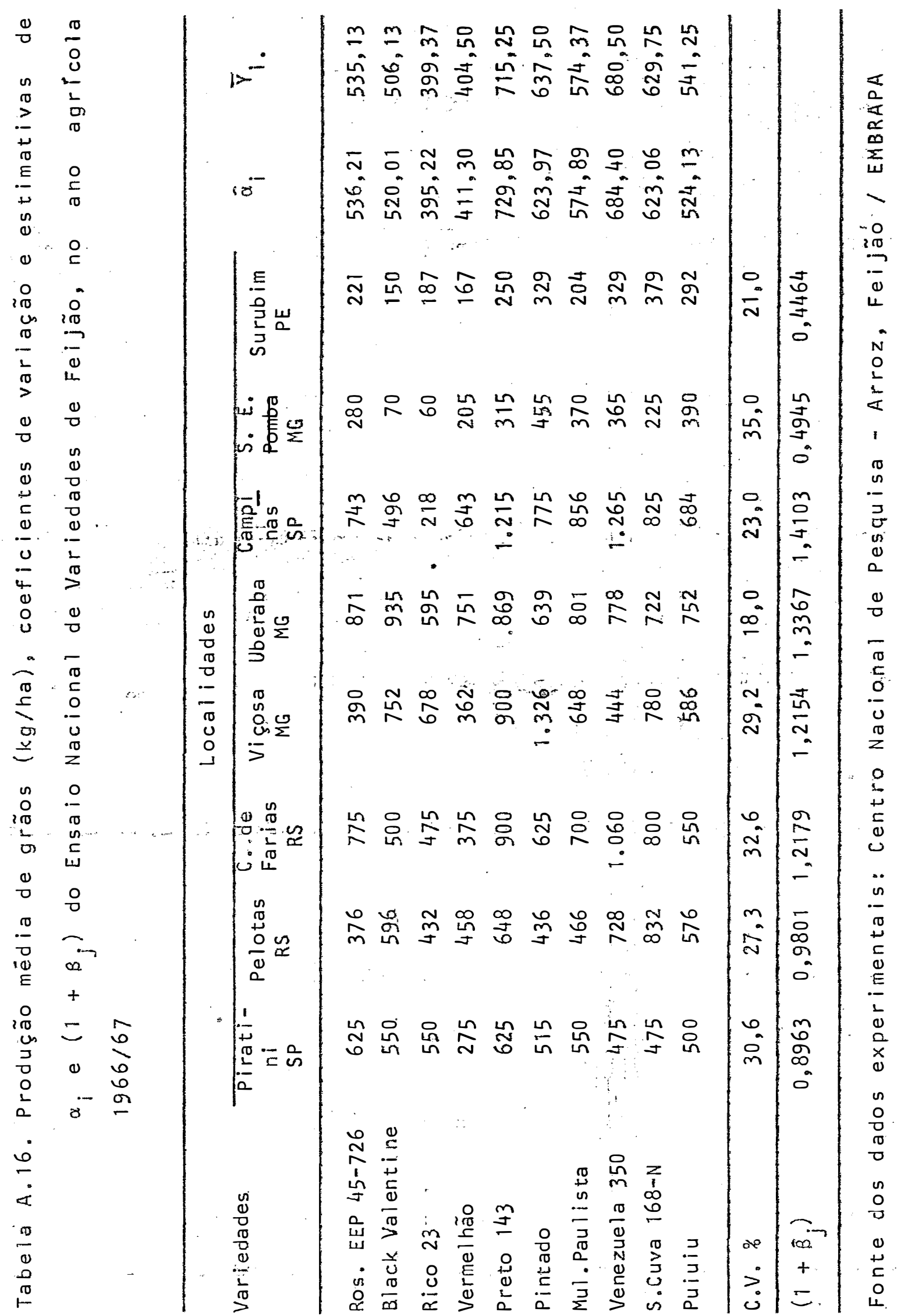




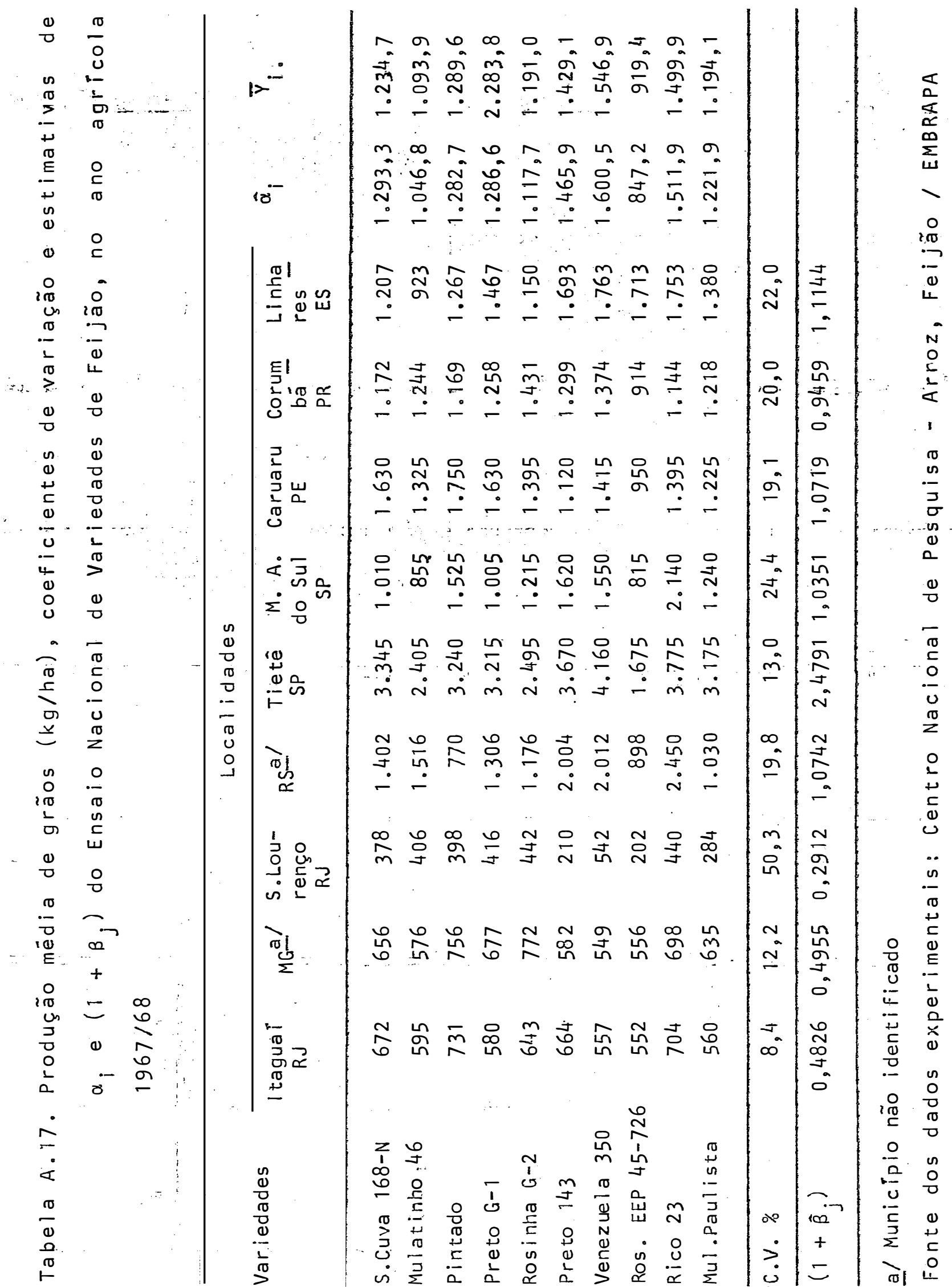




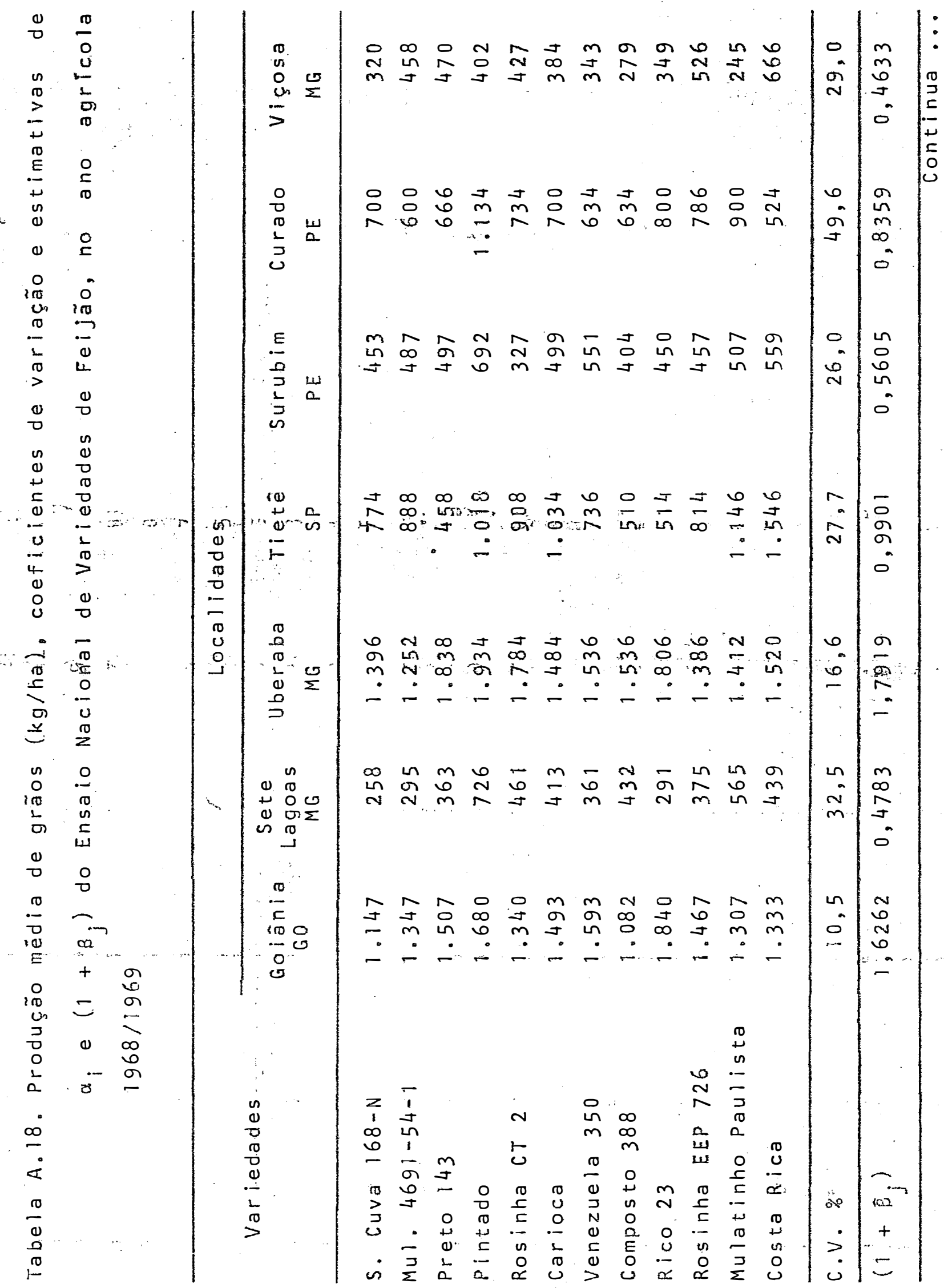




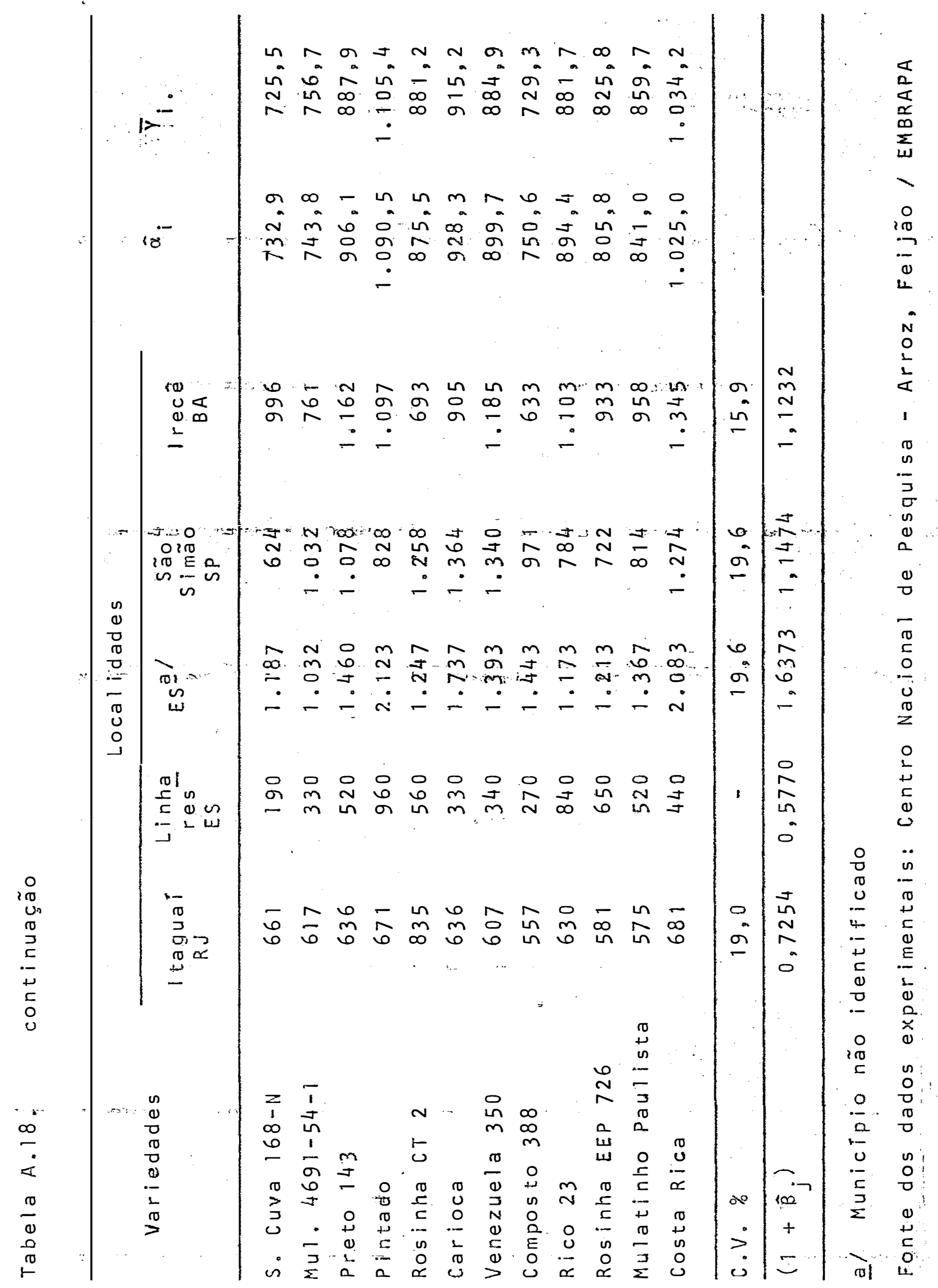




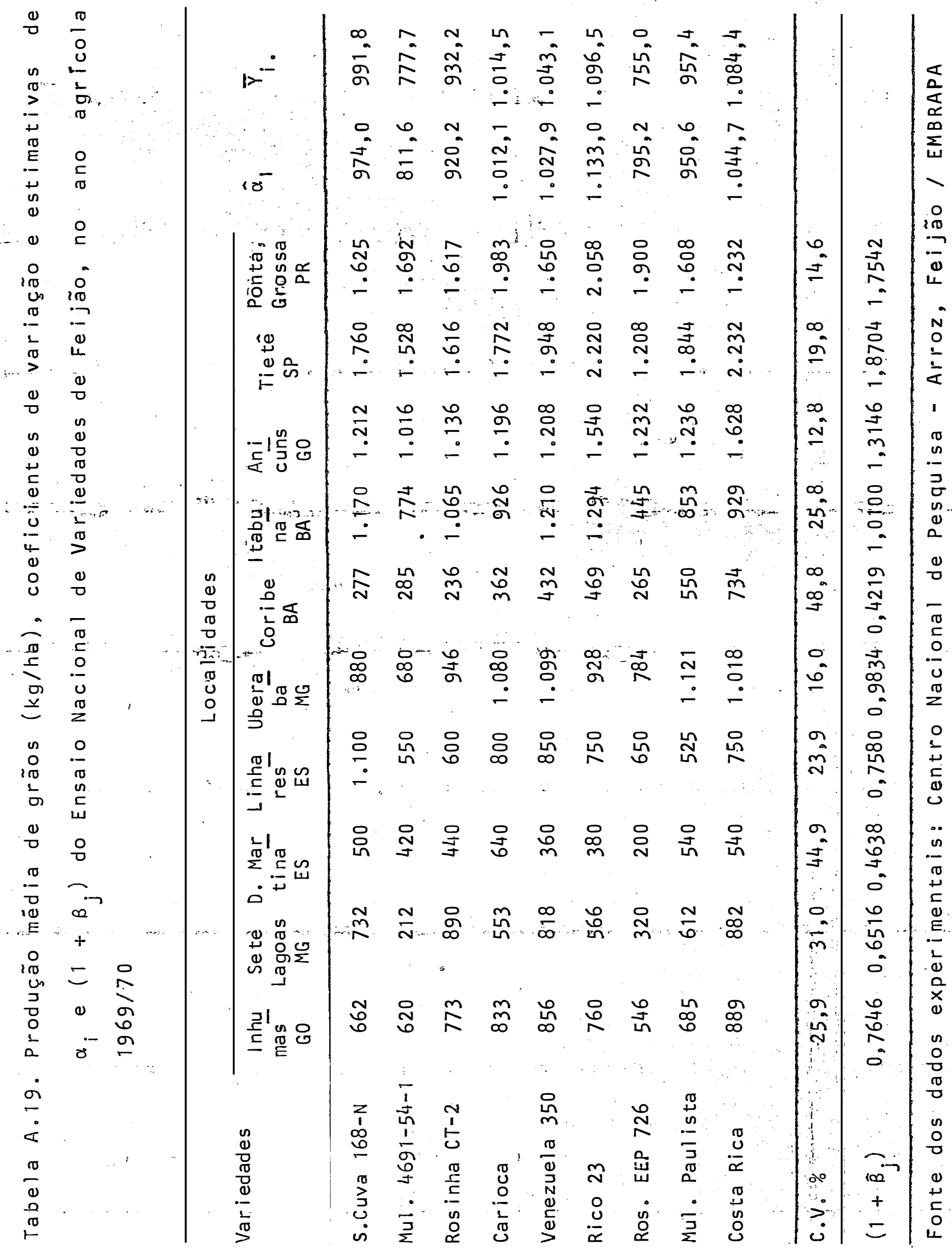




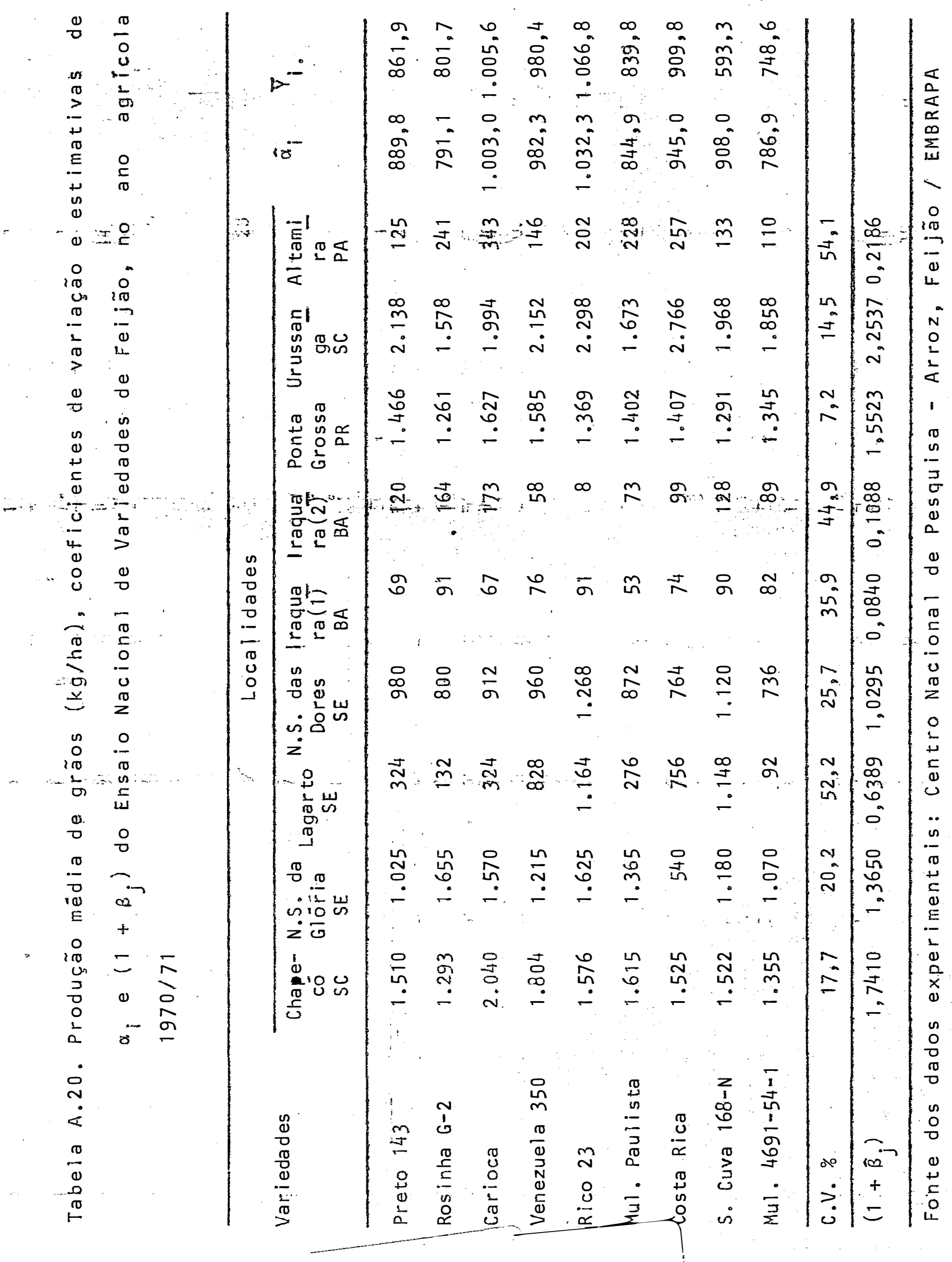




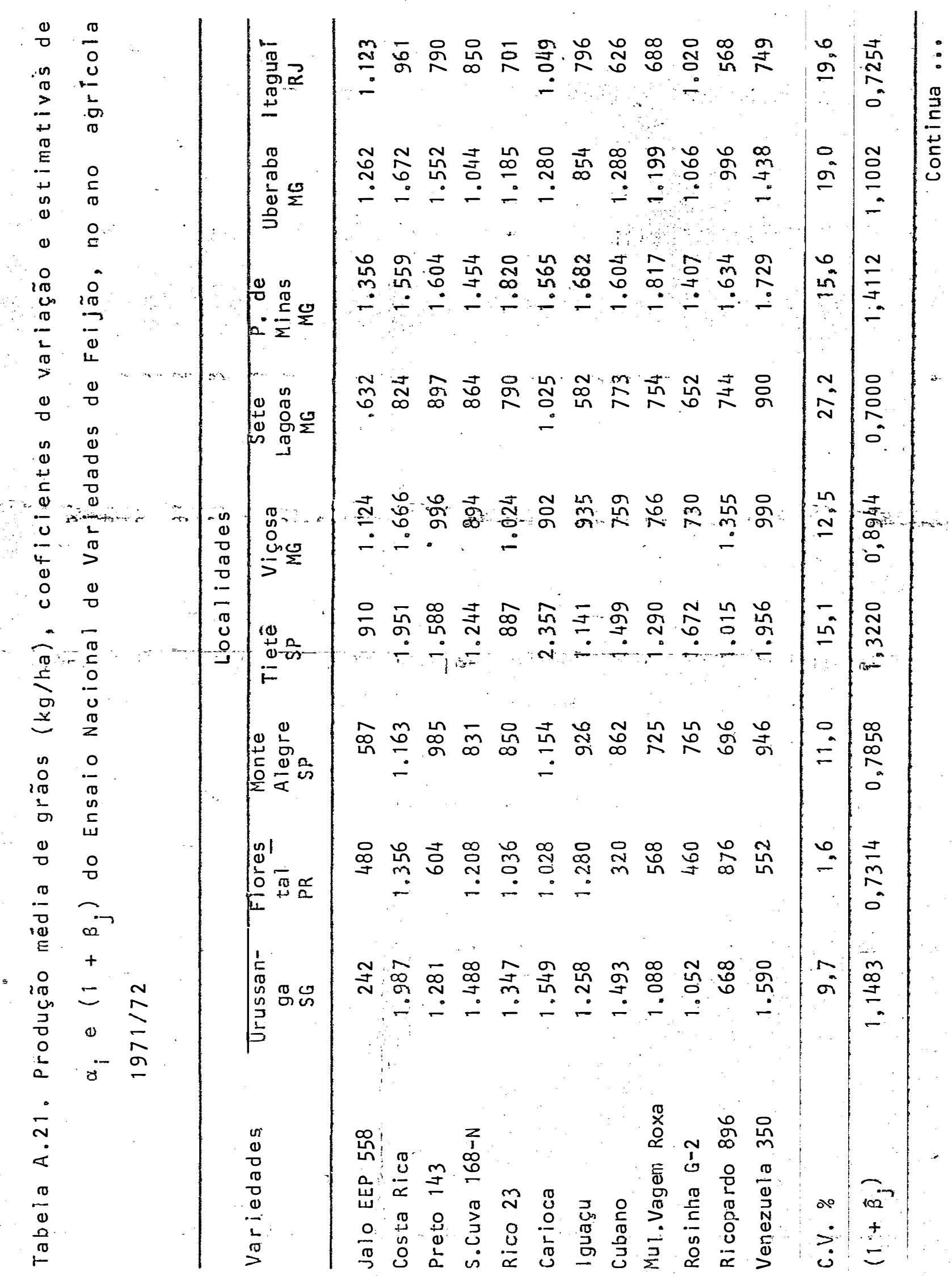




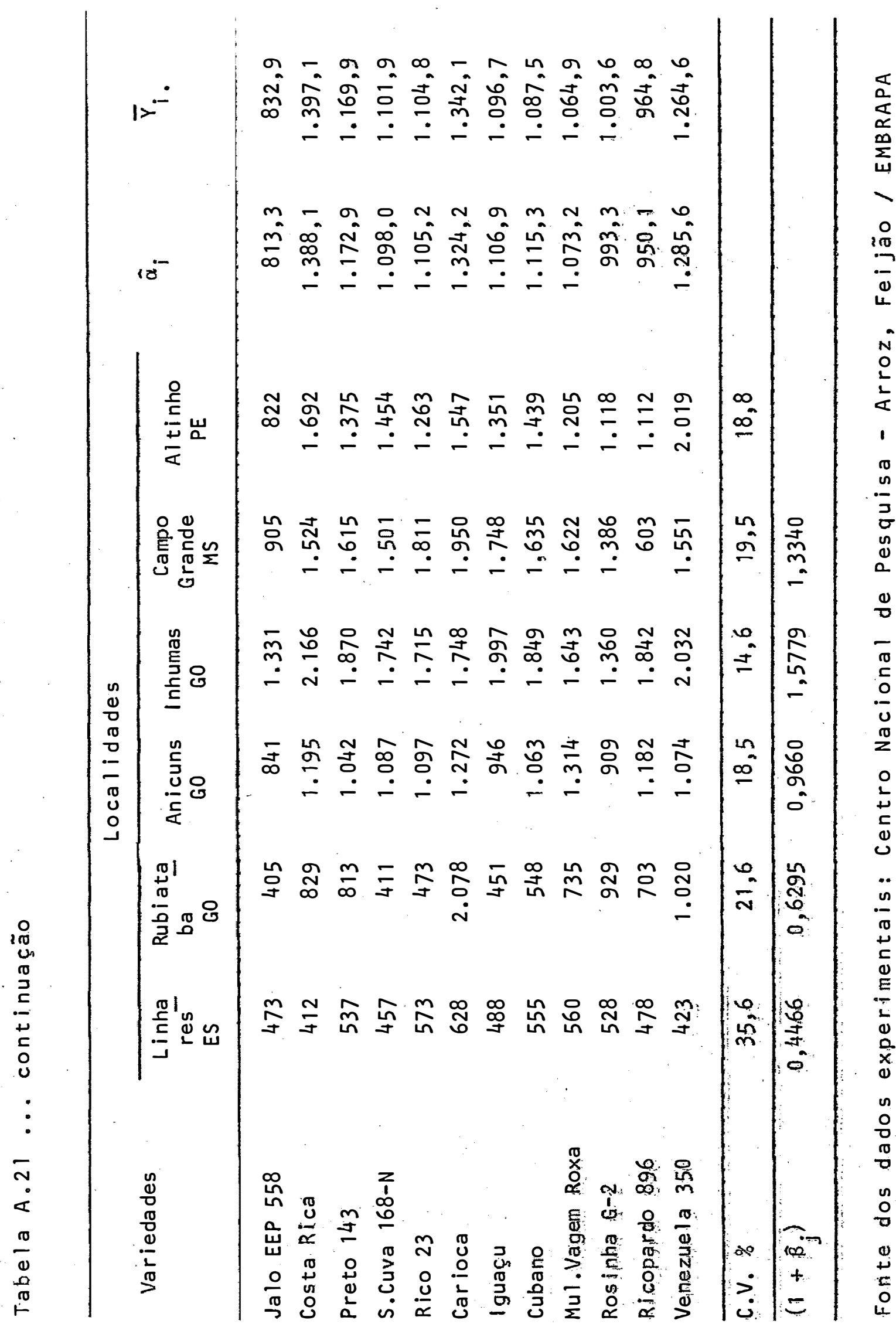

